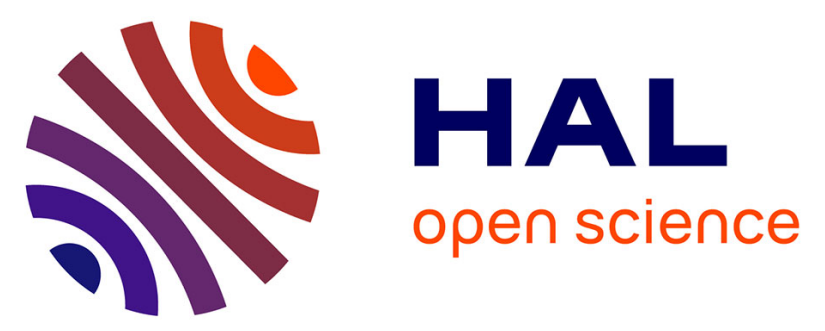

\title{
Head to tail cyclisation of cell-penetrating peptides: impact on GAG-dependent internalisation and direct translocation
}

Mehdi Amoura, Françoise Illien, Alain Joliot, Karine Guitot, John Offer, Sandrine Sagan, Fabienne Burlina

\section{To cite this version:}

Mehdi Amoura, Françoise Illien, Alain Joliot, Karine Guitot, John Offer, et al.. Head to tail cyclisation of cell-penetrating peptides: impact on GAG-dependent internalisation and direct translocation. Chemical Communications, 2019, 55 (31), pp.4566-4569. 10.1039/C9CC01265F . hal-02188663

\section{HAL Id: hal-02188663 \\ https://hal.sorbonne-universite.fr/hal-02188663}

Submitted on 18 Jul 2019

HAL is a multi-disciplinary open access archive for the deposit and dissemination of scientific research documents, whether they are published or not. The documents may come from teaching and research institutions in France or abroad, or from public or private research centers.
L'archive ouverte pluridisciplinaire HAL, est destinée au dépôt et à la diffusion de documents scientifiques de niveau recherche, publiés ou non, émanant des établissements d'enseignement et de recherche français ou étrangers, des laboratoires publics ou privés. 


\title{
Head to tail cyclisation of cell-penetrating peptides: impact on GAG-dependent internalisation and direct translocation
}

\author{
Mehdi Amoura, ${ }^{a}$ Françoise Illien, ${ }^{a}$ Alain Joliot, ${ }^{b}$ Karine Guitot, ${ }^{a}$ John Offer, ${ }^{c}$ Sandrine Sagan ${ }^{a}$ and \\ Fabienne Burlina*
}

\begin{abstract}
A series of cyclic lipidated oligo-Arg cell penetrating peptides were synthesised with varied macrocycle size and lipid chain anchoring site. The study of their cellular uptake revealed different structural requirements to promote efficient glycosaminoglycan-dependent endocytosis and direct translocation.
\end{abstract}

Cell-penetrating peptides (CPPs) are considered as promising systems for the intracellular delivery of probes and therapeutics, with several CPPs currently under clinical development. ${ }^{1}$ They are generally short purely basic or amphipathic peptides that can enter cells by two different pathways: endocytosis and direct translocation across the plasma membrane. The contribution of endocytosis and translocation varies between CPPs and their respective extent is most probably determined by the CPP capacity to interact with key components of the plasma membrane. ${ }^{2}$ In particular, glycosaminoglycans (GAGs) have been shown to be implicated in the endocytosis of several CPPs. ${ }^{3}$ CPP arginine residues play an essential role in GAG binding, ${ }^{4}$ due to their ability to form bidentate hydrogen bonds with GAG carboxylate and sulfate groups. ${ }^{5}$ Previous studies also highlighted the critical role of Trp residues in GAG clustering, ${ }^{6}$ most probably by forming $\pi$ interactions. Phospholipids are the key partners in the translocation pathway, which involves a transient, nondeleterious, perturbation of the lipid bilayer induced by the CPP. Arg residues, which can form neutral ion-pairs with phospholipids, ${ }^{5}$ and Trp residues, which promote interfacial and reversible interaction of the CPP with the lipid bilayer ${ }^{7}$ play a critical role in translocation as well. Interestingly, GAGs are also involved in the mechanism of translocation of some

\footnotetext{
a. Sorbonne Université, École normale supérieure, PSL University, CNRS, Laboratoire des Biomolécules, LBM, 75005 Paris, France

b. Center for Interdisciplinary Research in Biology (CIRB), Collège de France, CNRS, INSERM, PSL Research University, Paris, France

c. The Francis Crick Institute, 1 Midland road, London, NW1 1AT, UK

*Corresponding author: fabienne.burlina@sorbonne-universite.fr

+ Electronic Supplementary Information (ESI) available: [details of any

supplementary information available should be included here]. See
}

DOI: $10.1039 / x 0 \times x 00000 x$ amphipathic CPPs, ${ }^{8}$ possibly by serving as first site of peptide accumulation on the cell-surface before their transfer to the lipid bilayer. Although for most CPPs direct translocation represents a minor route of entry compared to endocytosis, it is potentially more productive because it gives direct access to the cytosol avoiding trafficking through endosomes and possible entrapment of the CPP and its cargo in these organelles. The design of CPPs that steer translocation of their cargo to the cytosol more efficiently is therefore of particular interest.

Many different chemical modifications have been proposed in the past years to boost CPP properties. ${ }^{9}$ Among backbone modifications, cyclisation has been found to give remarkable results and is increasingly applied to CPPs. ${ }^{10-15}$ In particular, cyclisation of Tat was found to improve cellular uptake by inducing maximal spacing between the CPP guanidinium groups, ${ }^{11}$ in agreement with earlier observations made with peptoid analogues of CPPs. ${ }^{16}$ Lipidation is another interesting modification, which can improve CPP interaction with the cell membrane leading to increased translocation efficiency. ${ }^{17-20}$ It was also found to favour GAG-dependent endocytosis of a small linear oligo-Arg CPP, most probably by increasing the local density of the CPP cationic residues through its self-assembly. ${ }^{19}$ By changing the spatial distribution of the CPP functional groups, chemical modifications can therefore modulate CPP interaction with key membrane partners and alter their mechanism of internalisation. In this study, we have analysed the impact on GAG-dependent entry, endocytosis and translocation of head to tail cyclisation, in some cases combined with lipidation, for a series of CPPs. Cyclisations were easily performed using native chemical ligation (NCL). ${ }^{21}$ Conveniently, the Cys residue involved in NCL, could serve after cyclisation for cargo conjugation by a disulfide bridge. Cyclisation was found to always increase the CPP internalisation efficiency, in most cases by improving their interaction with GAGs and endocytosis, but also when it was combined with lipidation, by favouring direct translocation. 


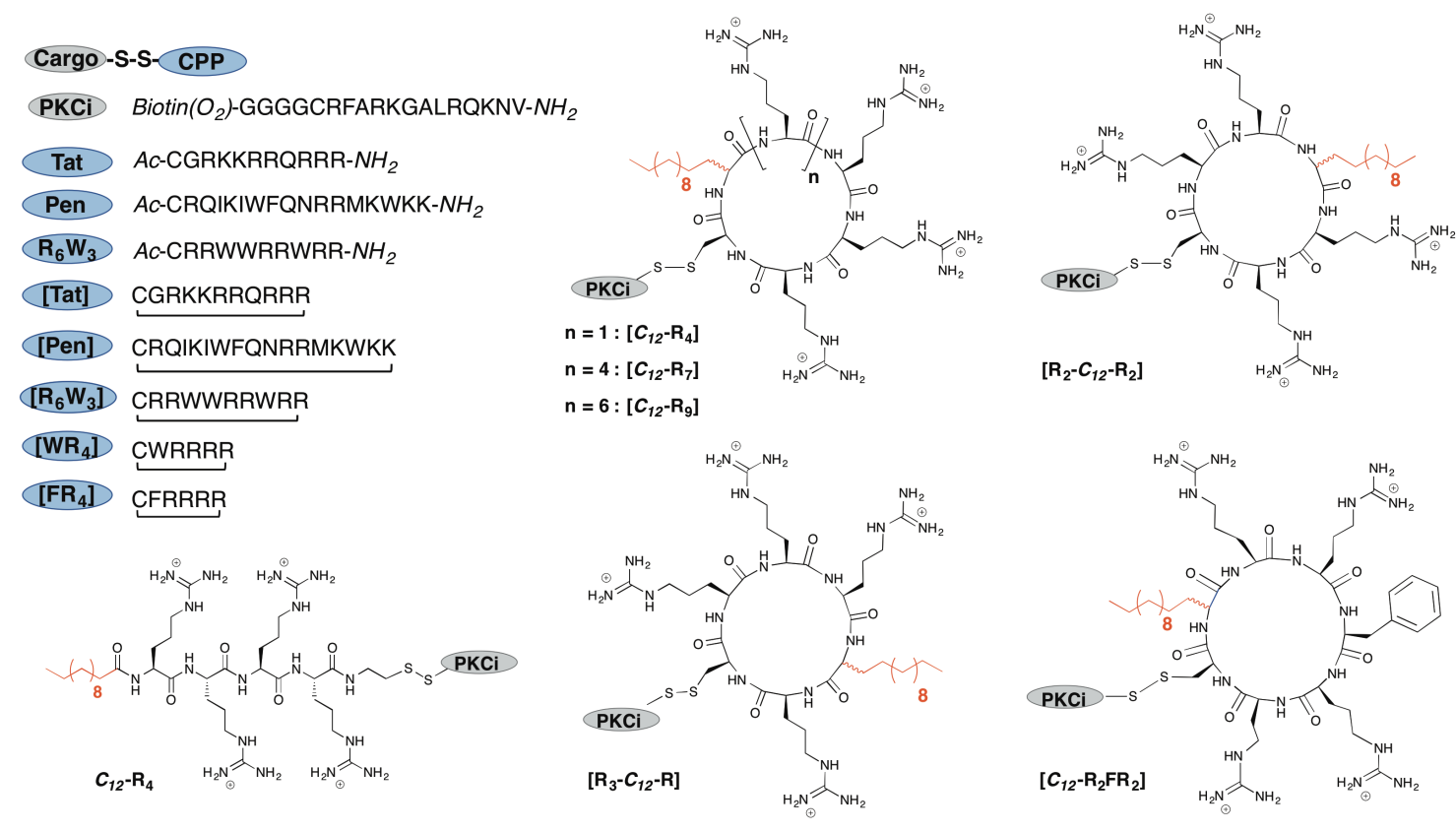

Chart 1 Synthesized CPP-Cargo conjugates. Cyclic CPPs are marked under square brackets, biotin $\left(\mathrm{O}_{2}\right)$ : biotin sulfone, Ac: acetyl.

A small library of CPPs was designed for this study (Chart 1). We first chose to prepare head to tail cyclic derivatives of the classical CPPs Penetratin ${ }^{22}$ (Pen) and $\mathrm{R}_{6} \mathrm{~W}_{3}{ }^{23}$, which had not been evaluated before under their cyclic form, and Tat, ${ }^{24}$ one of the first CPPs cyclized. ${ }^{11}$ It should be noted that our cyclic Tat analogue has a different structure than the previously proposed one. We also examined the impact of cyclisation of the laurylated tetra-arginine CPP $C_{12}-\mathrm{R}_{4}$, which had previously been found to enter cells efficiently by GAG-dependent endocytosis. ${ }^{19}$ For the cyclic derivative, the carbon chain was introduced as the $(R, S)$-2-amino tetradecanoic acid derivative to give CPP $\left[C_{12}-R_{4}\right]$, for which all four Arg residues were kept contiguous. A series of derivatives were also designed to evaluate the impact of the lipid chain anchoring position ( $\left[R_{2}-\right.$ $\left.C_{12}-R_{2}\right]$ and $\left.\left[R_{3}-C_{12}-R\right]\right)$ and macrocycle size. The macrocycle was either enlarged by incorporating 3 or 5 additional Arg residues $\left(\left[C_{12}-R_{7}\right]\right.$ and $\left.\left[C_{12}-R_{9}\right]\right)$ or by introducing a single Phe residue $\left(\left[C_{12}-R_{2} F R_{2}\right]\right)$. Finally, to evaluate the importance of the lipid chain (in the $\left[C_{12}-R_{4}\right] C P P$ ), it was replaced by an aromatic amino acid (Phe or Trp) to give $\left[\mathrm{FR}_{4}\right]$ and $\left[\mathrm{WR}_{4}\right]$.

Cyclic peptides were synthesized by native chemical ligation $(\mathrm{NCL})^{25}$ introducing in the original linear sequence an $\mathrm{N}$-terminal cysteine and a $C$-terminal thioester or a precursor corresponding to an $\alpha$-methylcysteine $(\alpha \mathrm{MeCys})^{26}$ residue (Scheme S1, ESI). The peptides with a preformed thioester function were prepared by Boc solid phase peptide synthesis (SPPS) using a mercaptopropionic acid leucine ( $\mathrm{mpaL}$ ) linker to the resin ${ }^{27,28}$ (Scheme S1, ESI). Cyclisations of the unprotected peptides were performed in standard conditions for $\mathrm{NCL}$ corresponding to phosphate buffer at final $\mathrm{pH} 7$, in the presence of reducing (TCEP) and denaturing (guanidine) agents and of mercaptophenylacetic acid (MPAA) as thiol additive for thioester activation (Scheme S1, ESI). All ligations were found to proceed smoothly with no side reaction and to be complete in less than $18 \mathrm{~h}$ (Figure S3, ESI). Fmoc SPPS was used in our second approach to prepare the linear precursor of Pen with a $C$ terminal $\alpha \mathrm{MeCys}$ residue for in situ generation of the thioester function by $N$ to $S$ acyl transfer (Scheme S1, ESI). To optimise cyclisation conditions, we examined the impact of the buffer composition and $\mathrm{pH}$ on the reaction rate (Table S2, ESI). In all cases, ligations went to completion. Increasing MPAA concentration from 300 to $450 \mathrm{mM}$ or decreasing the $\mathrm{pH}$ from 7 to 5 significantly accelerated the reaction, as previously observed in two-piece ligations ${ }^{26}$ and most likely by shifting the $\alpha \mathrm{MeCys}$ amide to thioester equilibrium towards the thioester. Interestingly, we found here that among all parameters tested, the guanidine concentration had the strongest effect. Reducing it from 6 to $3 \mathrm{M}$, decreased the half-time of the reaction by a factor 2, possibly because of the decreased dielectric constant of the buffer. In the optimised conditions ( $3 \mathrm{M}$ guanidine, 450 mM MPAA, pH 5), cyclisation was almost complete in $7 \mathrm{~h}$. All CPPs, linear and cyclic, were then linked by a disulfide bridge to a non-permeant peptide cargo, which corresponds to a protein kinase $\mathrm{C}$ inhibitor (PKCi) (Chart 1 ). The cargo incorporates on its $\mathrm{N}$-terminus an isotope labelling and affinity tag (Biotin(sulfone)GGGG) to allow its quantification inside cells.

The efficiency of the CPPs was assessed by measuring the amount of intact PKCi delivered inside cells using a protocol based on MALDI-TOF MS established previously. ${ }^{29}$ Absolute quantification of the internalised PKCi peptide was performed after cell lysis in reducing conditions using as internal standard the unconjugated PKCi peptide labelled with a stable isotope (containing 4 bi-deuterated Gly residues in the tag, Table S1 in the ESI). To study the mechanism of entry of the conjugates, we compared their internalisation in CHO-K1 cells (WT cells) at $37^{\circ} \mathrm{C}$ (a temperature at which both endocytosis and translocation can 


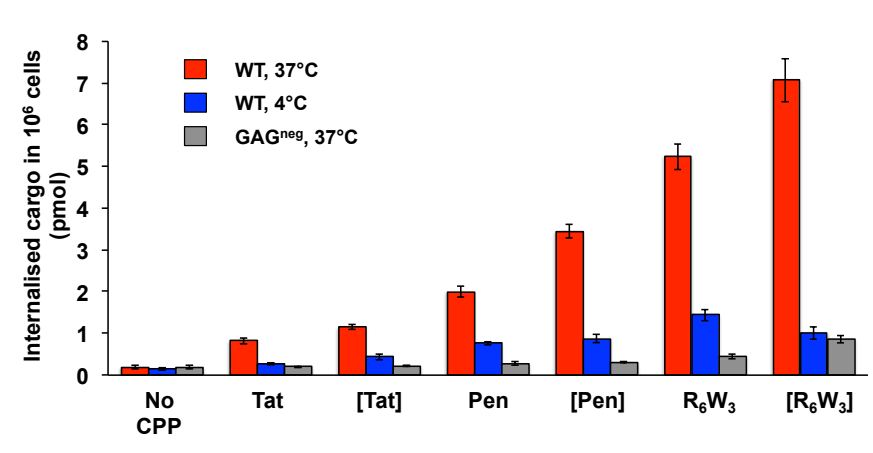

Figure 1 Amount of intact PKCi cargo delivered inside cells by the linear classical CPPs and their cyclic derivatives. The cyclic derivatives are marked under square brackets. Free PKCi (no CPP) and CPP-PKCi conjugates $(7.5 \mu \mathrm{M})$ were incubated with $10^{6} \mathrm{WT}$ or GAG neg cells for $75 \mathrm{~min}$ at $4^{\circ} \mathrm{C}$ or $37^{\circ} \mathrm{C}$.

occur) and at $4^{\circ} \mathrm{C}$ (a temperature at which endocytosis is inhibited and only direct translocation remains effective). The involvement of cell surface GAGs was studied by using $\mathrm{CHO}-745$ cells which are deficient in GAGs (GAGneg cells). It should be noted that none of the conjugates showed toxicity at the concentration used for the internalisation experiments (Fig. S5, ESI).

The linear classical CPPs, Tat, Pen and $\mathrm{R}_{6} \mathrm{~W}_{3}$ (Chart 1 ) and their cyclic derivatives (denoted [Tat], [Pen] and $\left[\mathrm{R}_{6} \mathrm{~W}_{3}\right]$ ) were first studied (Fig. 1, Fig. S7 and Table S4 in the ESI). Interestingly, cyclisation was found to improve cellular uptake of all CPPs in WT cells at $37^{\circ} \mathrm{C}$, even though moderately. $\left[R_{6} W_{3}\right]$ gave the best result by far leading to a total concentration of cargo inside cells of about $7 \mu \mathrm{M}$ (calculated with an estimated volume of $1 \mathrm{pL}$ per $\mathrm{CHO}$ cell), which is close to the conjugate concentration applied outside cells. Our mechanistic studies showed that internalisations of all linear and cyclic CPPs of this series mostly depend on endocytosis, amounts of PKCi delivered in WT cells being notably reduced when the temperature was decreased. However, they were found to also enter cells by translocation. For the conjugate of this series that translocates the best, $\mathrm{R}_{6} \mathrm{~W}_{3}$ $\mathrm{PKCi}$, we measured an intracellular concentration of about 1.4 $\mu \mathrm{M}$ at $4^{\circ} \mathrm{C}$. It is noteworthy that conjugates that enter by translocation first reach the cytosol, from where they can eventually redistribute within the different cell compartments. In addition, conjugate internalisation was found to be principally dependent on GAGs, as cargo amounts measured in GAGneg cells at $37^{\circ} \mathrm{C}$ were much lower than the one obtained in WT cells. In this series of classical CPPs, cyclisation always improved endocytosis, which was found to be mostly dependent on GAGs, but no significant effect could be detected for translocation. Next, we evaluated the series of lipidated oligo-Arg CPPs (Fig. 2, Fig S8 and Table S5 in the ESI). The cyclic derivative $\left[C_{12}-R_{4}\right]$ enters cells more efficiently than the linear analogue $C_{12}-R_{4}$. Remarkably, in this case cyclisation improves both translocation and GAG-dependent entry. Replacement of the lipid chain by a Phe residue ([FR $]$ ) strongly affected endocytosis and direct translocation, showing the benefit of the lipid chain for both routes of entry in the cyclic series, as also observed before in the linear one. ${ }^{19}$ Substitution of the Phe residue by $\operatorname{Trp}\left(\left[\mathrm{WR}_{4}\right]\right)$, which has been found before to favour CPP interaction with membrane components involved in

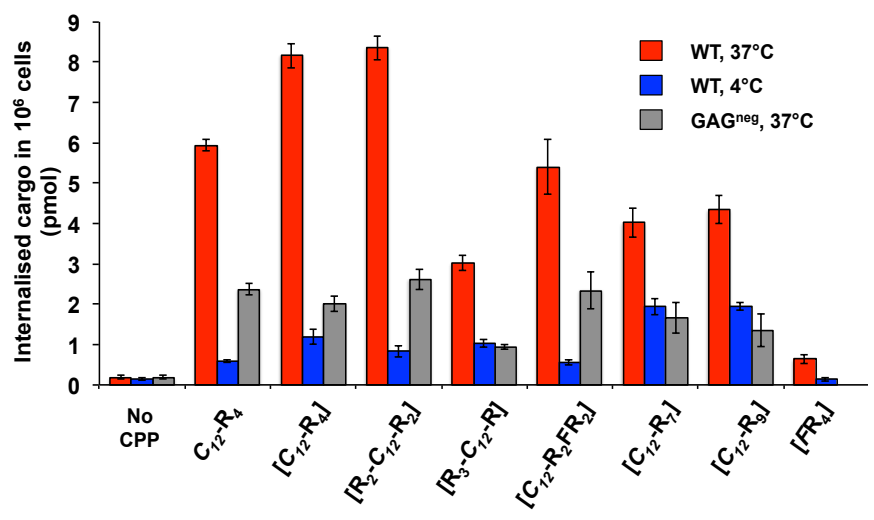

Figure 2 Amount of intact PKCi cargo delivered inside cells by the oligo-Arg derivatives. The cyclic derivatives are marked under square brackets. Free PKCi
(no CPP) and CPP-PKCi conjugates $(7.5 \mu \mathrm{M})$ were incubated with $10^{6}$ WT or GAG ${ }^{\text {eg }}$ cells for $75 \mathrm{~min}$ at $4^{\circ} \mathrm{C}$ or $37^{\circ} \mathrm{C}$.

cellular uptake, ${ }^{6,7}$ had no significant effect here (Fig. S9, ESI), suggesting that a single Trp in the CPP sequence is not sufficient. Changing the lipid chain position within the macrocycle to give compounds $\left[R_{2}-C_{12}-R_{2}\right]$ and $\left[R_{3}-C_{12}-R\right]$ modifies the spatial arrangement of the $4 \mathrm{Arg}$ residues and also the relative positioning of the lipid chain and disulfide linked cargo, which could both affect the uptake efficiency. For example, the cargo and lipid chain are in closer proximity in conjugate $\left[C_{12}-R_{4}\right]$ compared to the 2 other cyclic analogues. Interestingly, $\left[\mathrm{R}_{2}-C_{12^{-}}\right.$ $R_{2}$ ] shows similar uptake efficiency and mechanism as $\left[C_{12}-R_{4}\right]$. In contrast, $\left[R_{3}-C_{12}-R\right]$ enter cells less efficiently in WT cells at $37^{\circ} \mathrm{C}$ due to a decreased ability to use GAG-dependent endocytosis but its translocation capacity is not much affected. These data suggest that the spatial arrangement of the Arg residues plays a crucial role for CPP binding to cell-surface GAGs, interaction being more favourable (in triggering internalisation by endocytosis) when the 4 Arg residues are contiguous or grouped by pairs. Increasing the number of Arg residues to 7 within the macrocycle strongly reduced the global entry inside cells at $37^{\circ} \mathrm{C}$ (by a factor 2 between $\left[C_{12^{-}} \mathrm{R}_{4}\right]$ and $\left[C_{12^{-}}\right.$ $\left.R_{7}\right]$ ) by decreasing GAG-dependent entry. Further increasing the number of $A r g$ residues with $\left[C_{12}-R_{9}\right]$ had no effect. Interestingly, the same phenomenon, although less pronounced, was observed when the macrocycle was enlarged by the addition of a single Phe residue (Compound $\left[C_{12}-R_{2} F R_{2}\right]$ ). The more compact structure resulting in higher local density in basic residues of $\left[C_{12}-R_{4}\right]$ compared to $\left[C_{12}-R_{7 / 9}\right]$ or $\left[C_{12}-R_{2}-R_{2}\right]$ might account for its improved capacity to interact with the sulfated GAGs. On the other hand, $\left[C_{12}-R_{7}\right]$ and $\left[C_{12}-R_{9}\right]$ show remarkable translocation efficiency, leading both to a cargo concentration of about $2 \mu \mathrm{M}$ at $4^{\circ} \mathrm{C}$. Translocation of these vectors was improved compared to $\left[C_{12}-\mathrm{R}_{4}\right]$, showing that this route of entry is favoured by increasing the number of basic residues, as previously observed with linear CPPs. ${ }^{30}$ It should be mentioned that evaluating the efficiency of entry at $4^{\circ} \mathrm{C}$ gives a baseline for cytosolic concentration. Species entering by direct translocation are measured but not species that could, after endocytosis, escape from endosomes to reach the cytosol.

For the most efficient derivatives identified from both nonlipidated and lipidated series (derivatives of $\mathrm{R}_{6} \mathrm{~W}_{3}$ and $C_{12}-\mathrm{R}_{4}$ ), 

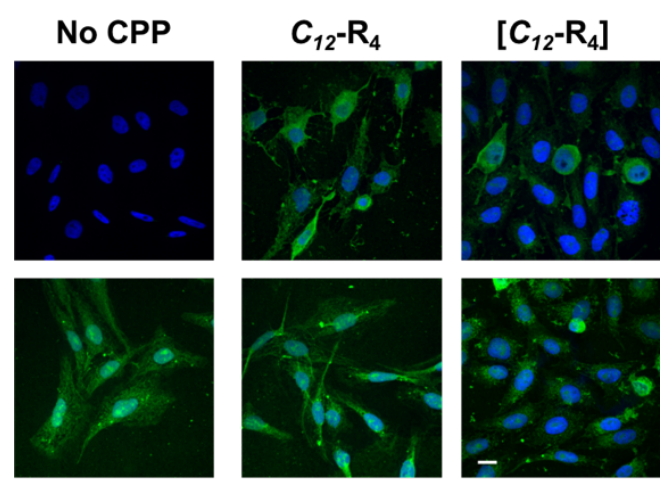

$\mathbf{R}_{6} \mathbf{W}_{3}$

$\left[\mathbf{R}_{6} \mathbf{W}_{3}\right]$

$\left[C_{12}-R_{9}\right]$

Figure 3 Intracellular distribution of the $\mathrm{PKCi}$ cargo at $37^{\circ} \mathrm{C}$. Free $\mathrm{PKC}$ (no CPP) and CPP-PKCi conjugates $(7.5 \mu \mathrm{M})$ were incubated with $10^{5}$ WT cells for $75 \mathrm{~min}$ at $37^{\circ} \mathrm{C}$. The internalised biotinylated PKCi was revealed with streptavidin-Alexa 488 (green) after saturation of the membrane-bound species with unlabelled avidin. Nuclei were stained with DAPI (blue). Scale bar represents $15 \mu \mathrm{m}$.

we also analysed the cargo intracellular distribution in WT cells at 37 and $4^{\circ} \mathrm{C}$ (Fig. 3 and Fig S10 in the ESI). The $\left[C_{12}-R_{9}\right]$ conjugate was also chosen as example of cyclic derivative with efficient translocation properties. The 5 conjugates led at $37^{\circ} \mathrm{C}$ to predominant vesicular signal but diffuse cytosolic signal was also detected, in agreement with the mechanistic data. Interestingly, the $\mathrm{R}_{6} \mathrm{~W}_{3}$ derivatives gave a more homogeneous distribution of the cargo inside cells compared to the lipidated derivatives.

In summary, cyclisation was found to improve uptake efficiency, over the whole range of chemically diverse CPPs designed here, from purely cationic to amphipathic, non lipidated or lipidated peptides. However, our study showed that improved internalisation had different origins depending on the nature of the vector. For $\mathrm{R}_{6} \mathrm{~W}_{3}$ and $C_{12}-\mathrm{R}_{4}$ which had been previously found to favourably interact with cell-surface GAGs, cyclisation further enhanced GAG-dependent internalisation, a result that had not been reported before to our knowledge. This might be attributed to the expected constrained structure of the cyclic vectors compared to linear analogues or to a local increased density of the critical cationic functional groups, leading to better interaction with GAGs. This is supported in the lipidated cyclic CPP series by the fact that extending the macrocycle size, introducing a Phe or even several Arg residues, disfavours GAG-dependent entry. Translocation was also improved by cyclisation in the case of $C_{12}-R_{4}$ and further enhanced by increasing the number of basic residues. This led to the identification of vectors $\left[C_{12}-\mathrm{Rn}\right]$ ( $n=7$ or 9) that translocate with their cargo into the cytosol with remarkable efficiency. Among the derivatives studied, $\left[R_{6} W_{3}\right]$ and $\left[C_{12}-R_{4}\right]$ performed the best for total entry at $37^{\circ} \mathrm{C}$ and $\left[C_{12}-R_{7 / 9}\right]$ showed the best translocation efficiency. They appear as promising vectors for the cellular delivery of therapeutics.

This study was supported by the Agence Nationale de la Recherche (ANR-16-CE16-0016-03).

\section{Conflicts of interest}

"There are no conflicts to declare".

\section{References}

1 G. Guidotti, L. Brambilla, D. Rossi, Trends Pharmacol. Sci., 2017, 38, 406.

2 A. Walrant, S. Cardon, F. Burlina, S. Sagan, Acc. Chem. Res., 2017, 50, 2068.

3 M. E. Favretto, R. Wallbrecher, S. Schmidt, R. van de Putte, R. Brock, J. Control. Release, 2014, 180, 81.

4 A. Ziegler, J. Seelig, Biochemistry, 2011, 50, 4650.

5 J. B. Rothbard, T. C. Jessop, R. S. Lewis, B. A. Murray, P. A. Wender, J. Am. Chem. Soc., 2004, 126, 9506.

6 C. Bechara, M. Pallerla, Y. Zaltsman, F. Burlina, I. D. Alves, O. Lequin, S. Sagan, Faseb J., 2013, 27, 738.

7 M.-L. Jobin, M. Blanchet, S. Henry, S. Chaignepain, C. Manigand, S. Castano, S. Lecomte, F. Burlina, S. Sagan, I. D. Alves, Biochim. Biophys. Acta Biomembr., 2015, 1848, 593.

8 J. Pae, L. Liivamägi, D. Lubenets, P. Arukuusk, Ü. Langel, M. Pooga, Biochim. Biophys. Acta BBA - Biomembr., 2016, 1858, 1860.

9 D. Kalafatovic, E. Giralt, Molecules, 2017, 22, 1929.

10 D. Mandal, A. Nasrolahi Shirazi, K. Parang, Angew. Chem. Int. Ed. Engl., 2011, 50, 9633.

11 G. Lättig-Tünnemann, M. Prinz, D. Hoffmann, J. Behlke, C. Palm-Apergi, I. Morano, H. D. Herce, C. Cardoso, Nat. Commun., 2011, 2:453.

12 Z. Qian, A. Martyna, R. L. Hard, J. Wang, G. Appiah-Kubi, C. Coss, M. A. Phelps, J. S. Rossman, D. Pei, Biochemistry, 2016, 55, 2601.

13 H. Traboulsi, H. Larkin, M.-A. Bonin, L. Volkov, C. L. Lavoie, É. Marsault, Bioconjug. Chem., 2015, 26, 405.

14 M. Horn, F. Reichart, S. Natividad-Tietz, D. Diaz, I. Neundorf, Chem. Commun., 2016, 52, 2261.

15 A. F. L. Schneider, A. L. D. Wallabregue, L. Franz, C. P. R. Hackenberger, Bioconjug. Chem., 2019, DOI 10.1021/acs.bioconjchem. 8 b00855.

16 J. B. Rothbard, E. Kreider, C. L. VanDeusen, L. Wright, B. L. Wylie, P. A. Wender, J. Med. Chem., 2002, 45, 3612.

17 T. Lehto, L. Vasconcelos, H. Margus, R. Figueroa, M. Pooga, M. Hällbrink, Ü. Langel, Bioconjug. Chem., 2017, 28, 782.

18 S. Katayama, H. Hirose, K. Takayama, I. Nakase, S. Futaki, J. Control. Release, 2011, 149, 29.

19 S. A. Bode, M. Thevenin, C. Bechara, S. Sagan, S. Bregant, S. Lavielle, G. Chassaing, F. Burlina, Chem. Commun., 2012, 48 7179.

20 J.-M. Swiecicki, M. Di Pisa, F. Lippi, S. Chwetzoff, C. Mansuy, G. Trugnan, G. Chassaing, S. Lavielle, F. Burlina, Chem. Commun., 2015, 51, 14656.

21 L. Zhang, J. P. Tam, J. Am. Chem. Soc., 1997, 119, 2363.

22 D. Derossi, A. H. Joliot, G. Chassaing, A. Prochiantz, J. Biol. Chem., 1994, 269, 10444.

23 D. Delaroche, B. Aussedat, S. Aubry, G. Chassaing, F. Burlina, G. Clodic, G. Bolbach, S. Lavielle, S. Sagan, Anal. Chem., 2007, 79, 1932.

24 E. Vives, P. Brodin, B. Lebleu, J. Biol. Chem., 1997, 272, 16010.

25 P. E. Dawson, T. W. Muir, I. Clark-Lewis, S. B. Kent, Science, 1994, 266, 776.

26 F. Burlina, G. Papageorgiou, C. Morris, P. D. White, J. Offer, Chem. Sci., 2014, 5, 766.

27 H. Hojo, Y. Kwon, Y. Kakuta, S. Tsuda, I. Tanaka, K. Hikichi, S Aimoto, Bull. Chem. Soc. Jpn,. 1993, 66, 2700.

28 T. M. Hackeng, J. H. Griffin, P. E. Dawson, Proc. Natl. Acad. Sci., 1999, 96, 10068.

29 F. Burlina, S. Sagan, G. Bolbach, G. Chassaing, Nat. Protoc., 2006, 1, 200

30 S. Futaki, W. Ohashi, T. Suzuki, M. Niwa, S. Tanaka, K. Ueda, H. Harashima, Y. Sugiura, Bioconjug. Chem., 2001, 12, 1005. 
Head to tail cyclisation of cell-penetrating peptides: impact on GAGdependent internalisation and direct translocation

\author{
M. Amoura, F. Illien, A. Joliot, K. Guitot, J. Offer, S. Sagan and F. Burlina
}

\title{
Electronic Supplementary Information (ESI)
}

Table of contents:

1) Structure of the CPP-cargo conjugates used in the biological experiments S2

2) Abbreviations $\quad$ S2

3) General information $\quad$ S3

4) General procedures for solid phase peptide synthesis

5) Linear CPPs and peptide cargo

6) Cyclic CPPs $\quad$ S5

a. Strategy A : using preformed peptide-mpaL thioesters $\quad$ S5

b. Strategy B : using peptides with a C-terminal a-methylcysteine S9

7) Synthesis and characterisation of the CPP-cargo disulfide conjugates $\quad$ S11

8) Cell culture and cell viability assays $\quad$ S27

9) Quantification of the internalised cargo by MALDI-TOF MS S27

10) Confocal microscopy experiments $\quad$ S31

11) References $\quad$ S32 


\section{Structure of the CPP-cargo conjugates used in the biological experiments}

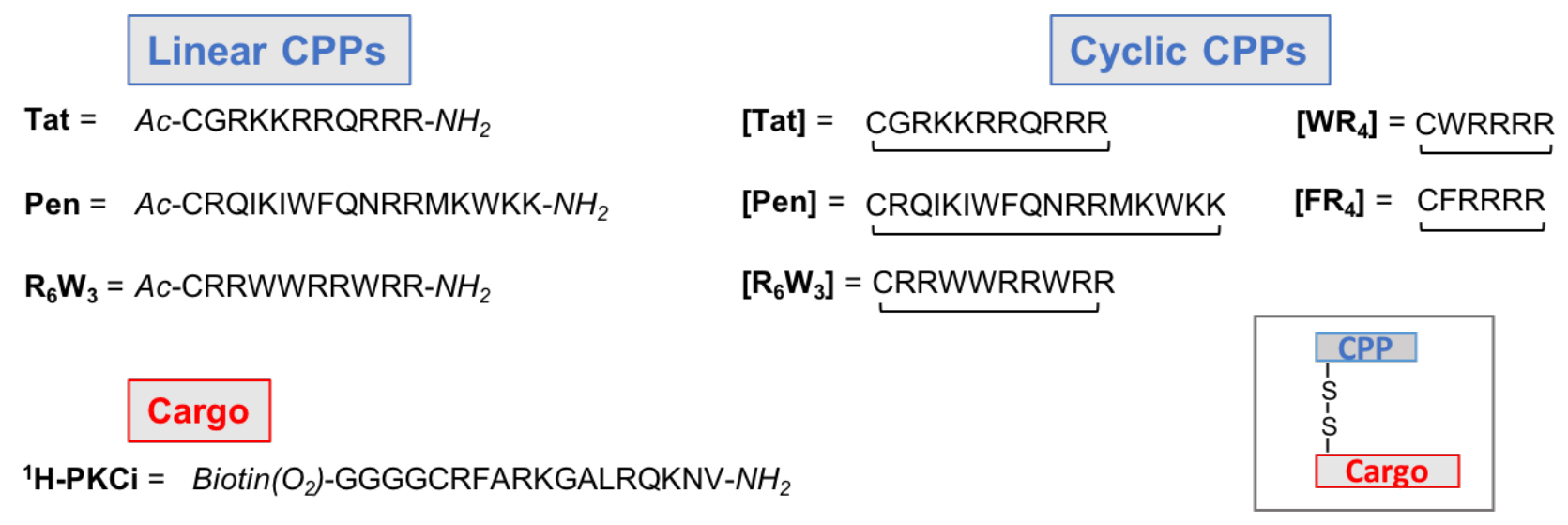

Figure S1. Sequence of the peptide cargo and non lipidated CPPs

$\operatorname{Biotin}\left(\mathrm{O}_{2}\right)=$ biotine sulfone

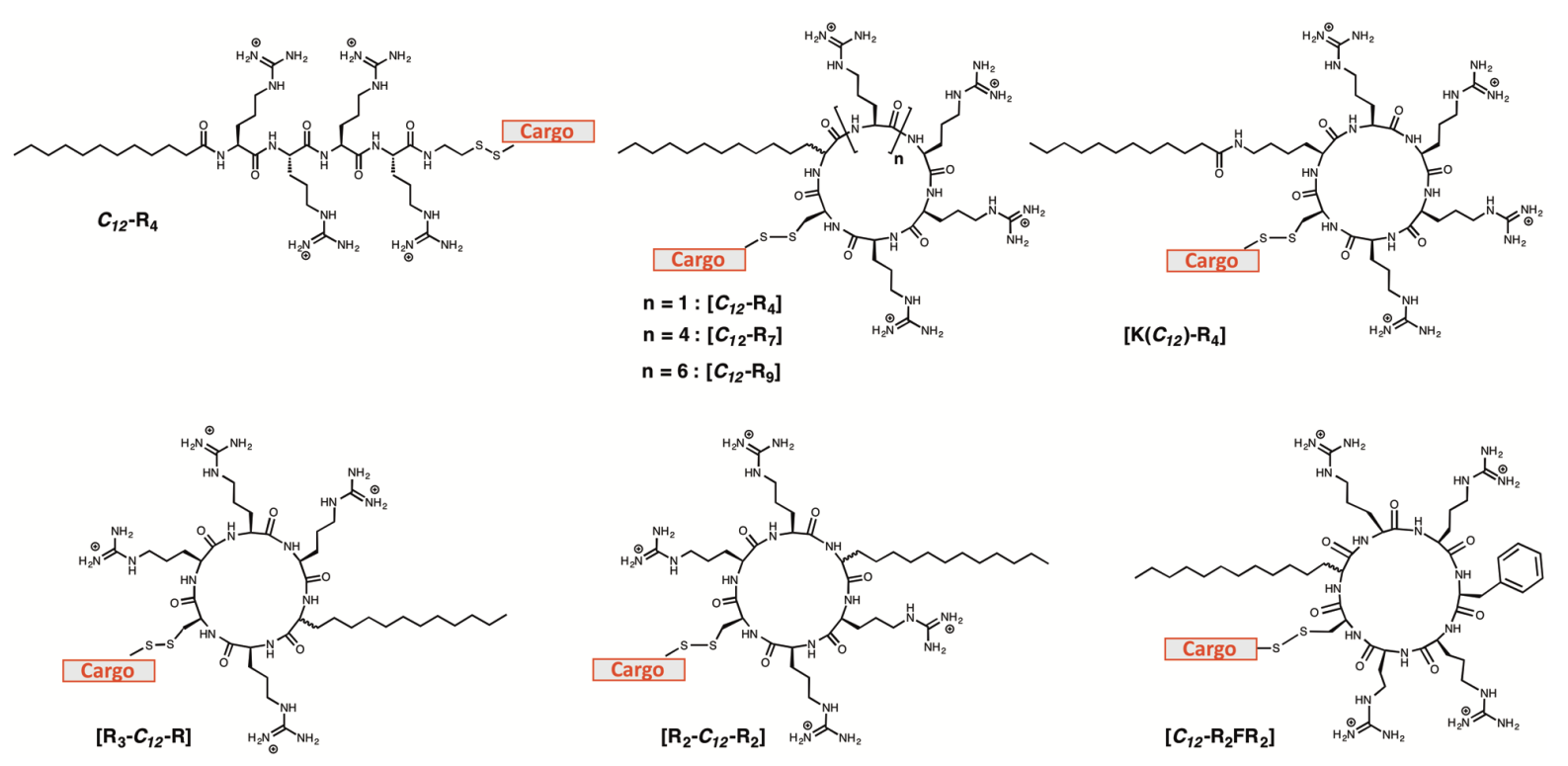

Figure S2. Structure of the lipidated CPP-Cargo conjugates

$\left(\right.$ Cargo $={ }^{1} \mathrm{H}-\mathrm{PKCi}$ shown in Fig. S1)

Note: For the cyclic lipidated cyclic CPPs, the carbon chain was introduced in the peptide sequence as the $(R, S)$-2-amino tetradecanoic acid derivative. A control CPP ([K( $\left.\left.\left(C_{12}\right)-R_{4}\right]\right)$ was also synthesised by coupling lauric acid onto the side chain of a Lys residue, its uptake efficiency compared to $\left[C_{12}-R_{4}\right]$ is shown Fig $S 9$, page $S 31$.

\section{Abbreviations}

Boc, tert-butoxycarbonyl; BSA, bovine serum albumin; $\boldsymbol{C}_{12}$, $(R, S)$ - 2-amino-tetradecanoic acid; $\boldsymbol{C}_{12: 0,}$ lauric acid; calcd, calculated; $\mathbf{C H C A}$, $\alpha$-cyano-4-hydroxycinnamic acid; $\mathbf{C H O}$ cells, Chinese hamster ovary cells; CPP, cell-penetrating peptide; DAPI, 4',6-diamidino-2phenylindole; DCC, dicyclohexylcarbodiimide; DCM, dichloromethane; DIC, N,N'diisopropylcarbodiimide; DMEM, Dulbecco's modified Eagle medium; DIEA, diisopropylethylamine; DMF, N,N-dimethylformamide; DTT, dithiothreitol; FBS, fetal bovine serum; EDT, 1,2-ethandithiol; EDTA, ethylenediamine tetraacetic acid; Fmoc, 9fluorenylmethoxycarbonyl; HBSS, Hanks' Balanced Salt solution, HBTU, 2-(1H- 
benzotriazole-1-yl)-1,1,3,3-tetramethyluronium hexafluorophosphate; HCTU, O-(1H-6chlorobenzotriazole-1-yl)-1,1,3,3-tetramethyluronium hexafluorophosphate, $\mathbf{H O B t}$, 1hydroxybenzotriazole; ${ }^{1} \mathbf{H}-\mathbf{P K C i}$, non deuterated PKCi; ${ }^{2} \mathbf{H}-\mathbf{P K C i}$, deuterated PKCi; $\mathbf{H P L C}$, high performance liquid chromatography; MALDI-TOF MS, matrix-assisted laser desorption/ionization time-of-flight mass spectrometry; MBHA-PS, 4methylbenzhydrylamine polystyrene; MPAA, 4-mercaptophenylacetic acid, mpaL, mercaptopropionic acid leucine; NCL, native chemical ligation, NMP, N-methyl-2pyrrolydone; NpyS, 3-nitro-2-pyridinesulphenyl; PBS, phosphate buffered saline; PKCi, protein kinase C inhibitor; rt, room temperature; SEM, standard error of the mean; SPPS, solid phase peptide synthesis; TCEP, tris(2-carboxyethyl)phosphine; TES, triethylsilane; TFA, trifluoroacetic acid; TIPS, triisopropylsilane.

\section{General information}

Reagents for peptide synthesis and protected amino acids were purchased from Iris Biotech and Merck Chemicals except for $\left(2,2-D_{2}, 98 \%\right)$-Boc glycine, which was obtained from Euriso-top. Solvents (peptide synthesis grade) were obtained from Carlo Erba Reagents. MBHA LL resin was purchased from Bachem. $(R, S)$-Boc-2-amino-tetradecanoic acid (CAS 129850-62-0) was purchased from Polypeptides. Tris- $\mathrm{HCl}$, Triton X-100, trypsin inhibitor and bovine serum albumin were obtained from Sigma-Aldrich. DMEM/F-12 (1:1), FBS, trypsinEDTA (0.05 \% trypsin, $0.02 \%$ EDTA) and HBSS were purchased from Gibco. The cell counting kit (CCK8) was from Dojindo Laboratories. Streptavidin-coated magnetic beads (Dynabeads $₫$ M-280 Streptavidin) were purchased from Invitrogen. The complete mini tablets of protease inhibitors were from Roche. DAPI was from Pierce. Ultrapure water was obtained using a Milli-Q water system from Millipore. All reagents and solvents were used without further purification.

HPLC purifications were carried out on a Waters system (Pump 600, Absorbance detector 2487) using ACE-5 C4 / C8 (300 A, $5 \mu \mathrm{m}, 250 \times 10 \mathrm{~mm}, 5 \mathrm{~mL} / \mathrm{min}$ flow rate) or Kromasil $\mathrm{C} 18(300 \AA, 5 \mu \mathrm{m}, 250 \times 10 \mathrm{~mm}, 5 \mathrm{~mL} / \mathrm{min}$ flow rate) reverse phase columns. Analytical HPLC were performed either on a Waters system (Pump 1525, Absorbance detector 2487), Agilent 1220 Infinity or Dionex Ultimate 3000. Vydac C4 / C18 (5 $\mu \mathrm{m}, 150 \times 4.6 \mathrm{~mm}, 1$ $\mathrm{mL} / \mathrm{min}$ flow rate), Kromasil C18 $(5 \mu \mathrm{m}, 250 \times 4.6 \mathrm{~mm}, 1 \mathrm{~mL} / \mathrm{min}$ flow rate), ACE-5 C4 / C8 $(5 \mu \mathrm{m}, 250 \times 4.6 \mathrm{~mm}, 1 \mathrm{~mL} / \mathrm{min}$ flow rate) or PROTO $200 \mathrm{C} 18(3 \mu \mathrm{m}, 100 \times 4.6 \mathrm{~mm}, 1$ $\mathrm{mL} / \mathrm{min}$ flow rate) columns were used. Linear gradients of solvent $B$ in $A$ were used with $A$ corresponding to $0.1 \%$ TFA in $\mathrm{H}_{2} \mathrm{O}$ and $\mathrm{B}$ to $0.1 \%$ TFA in $\mathrm{CH}_{3} \mathrm{CN}$.

MALDI-TOF MS analyses were performed in the linear or reflector positive ion mode on an ABI Voyager DE-Pro MALDI-TOF mass spectrometer (Applied Biosystems) or 4700 Proteomix MALDI-TOF MS/MS (Applied Biosystems), using as matrix a saturated solution of $\mathrm{CHCA}$ in $\mathrm{CH}_{3} \mathrm{CN} / \mathrm{H}_{2} \mathrm{O} / \mathrm{TFA}$ (50:50:0.1).

\section{General procedures for solid phase peptide synthesis}

Amounts of reagent are given in equivalents (equiv.) with respect to the peptidyl-resin. Peptide syntheses were carried out manually using Fmoc or Boc SPPS and standard protected amino acids unless otherwise mentioned. Syntheses were usually performed at a $0.1 \mathrm{mmol}$ scale.

Fmoc SPPS protocol: Fmoc-protected amino acids $(0.6 \mathrm{mmol}, 6$ equiv.) were activated with HBTU (0.58 mmol, 5.8 equiv., $0.5 \mathrm{M}$ ) and DIEA ( $1.4 \mathrm{mmol}, 14$ equiv.) in NMP ( $3 \mathrm{~min})$ and added to the peptide-resin (coupling for $30 \mathrm{~min}$ ). Capping of eventual unreacted amine 
groups was achieved by treatment with acetic anhydride (10\%) and DIEA (0.5 mmol, 5 equiv.) in DCM for 20 min. Fmoc groups were removed by treatment with $20 \%$ piperidine in NMP ( $3 \times 3 \mathrm{~min}$ ). Final peptide deprotection and cleavage from the resin were performed by treatment with $\mathrm{TFA} / \mathrm{H}_{2} \mathrm{O} / \mathrm{Pr}_{3} \mathrm{SiH}$, 95:2.5:2.5 (3 h) (for peptides containing Met or Cys residues, the cocktail $\mathrm{TFA} / \mathrm{H}_{2} \mathrm{O} / \mathrm{iPr}_{3} \mathrm{SiH} / \mathrm{EDT}$, 94:2.5:1:2.5 was used). TFA was sparged under a stream of $\mathrm{N}_{2}$, peptides were precipitated in ice-cold diethyl ether, recovered by centrifugation and freeze-dried before HPLC purification.

In situ neutralization protocol for Boc SPPS [1]: Boc-protected amino acids (0.6 mmol, 6 equiv.) were activated with HBTU $(0.58 \mathrm{mmol}, 5.8$ equiv., $0.5 \mathrm{M})$ and DIEA (1.4 mmol, 14 equiv.) in NMP (3 minutes) and added to the peptide-resin (coupling for $30 \mathrm{~min}$ ). Boc groups were removed by treatment with TFA $(2 \times 1 \mathrm{~min})$. The resin was carefully washed with NMP. Final peptide deprotection and cleavage from the resin was performed by treatment with anhydrous $\mathrm{HF}\left(2 \mathrm{~h}, 0^{\circ} \mathrm{C}\right)$ in the presence of the following scavengers:

- For $C$-terminal carboxamide peptides with no Cys residues, anisole $(1.5 \mathrm{~mL} / \mathrm{g}$ peptide-resin) and dimethyl sulfide $(0.25 \mathrm{~mL} / \mathrm{g}$ peptide-resin) were used as scavengers.

- For C-terminal carboxamide peptides with a Cys residue protected with $p$ methoxybenzyl, $p$-toluenethiol (300 mg/g peptide-resin) was also added.

- For C-terminal carboxamide peptides with a Cys residue protected with a NpyS, only anisole was used.

- For peptide-mpaL thioesters, the only scavenger added was $p$-cresol $(65 \mathrm{mg} / \mathrm{g}$ peptide-resin).

HF was removed under vacuum and the peptide was precipitated in ice-cold diethyl ether. The precipitate was dissolved in degassed acetic acid $\left(10 \%\right.$ in $\left.\mathrm{H}_{2} \mathrm{O}\right)$, the resin eliminated by filtration and the peptide was freeze-dried before HPLC purification.

\section{Linear CPPs and peptide cargo}

The syntheses of the linear CPPs (Table S1), the PKCi cargo $\left({ }^{1} \mathrm{H}-\mathrm{PKCi}\right)$ and the deuterated internal standard used for MALDI-TOF MS quantification $\left({ }^{2} \mathrm{H}-\mathrm{PKCi}\right)$ have been described previously. ${ }^{[2][3]}$

Table S1. Name and sequences of the peptide cargo and linear CPPs

\begin{tabular}{|c|c|}
\hline Name & Sequence \\
\hline $\begin{array}{l}{ }^{1} \mathrm{H}-\mathrm{PKCi} \\
{ }^{2} \mathrm{H}-\mathrm{PKCi}\end{array}$ & $\begin{array}{l}\text { Biotin(sulfone)GGGGC(NpyS)RFARKGALRQKNV-NH } \\
\text { Biotin(sulfone)GGGGCRFARKGALRQKNV-NH2 }{ }_{2}^{*}\end{array}$ \\
\hline Tat & Ac-CGRKKRRQRRR-NH $\mathrm{H}_{2}$ \\
\hline $\mathrm{R}_{6} \mathrm{~W}_{3}$ & Ac-CRRWWRRWRR-NH $\mathrm{H}_{2}$ \\
\hline Pen & Ac-CRQIKIWFQNRRMKWKK-NH \\
\hline$C_{12}-R_{4}$ & \\
\hline
\end{tabular}

$\mathrm{Ac}=$ acetyl. NpyS, 3-nitro-2-pyridinesulphenyl. ${ }^{*}$ Gly residues shown in red in the sequence are bideuterated. 


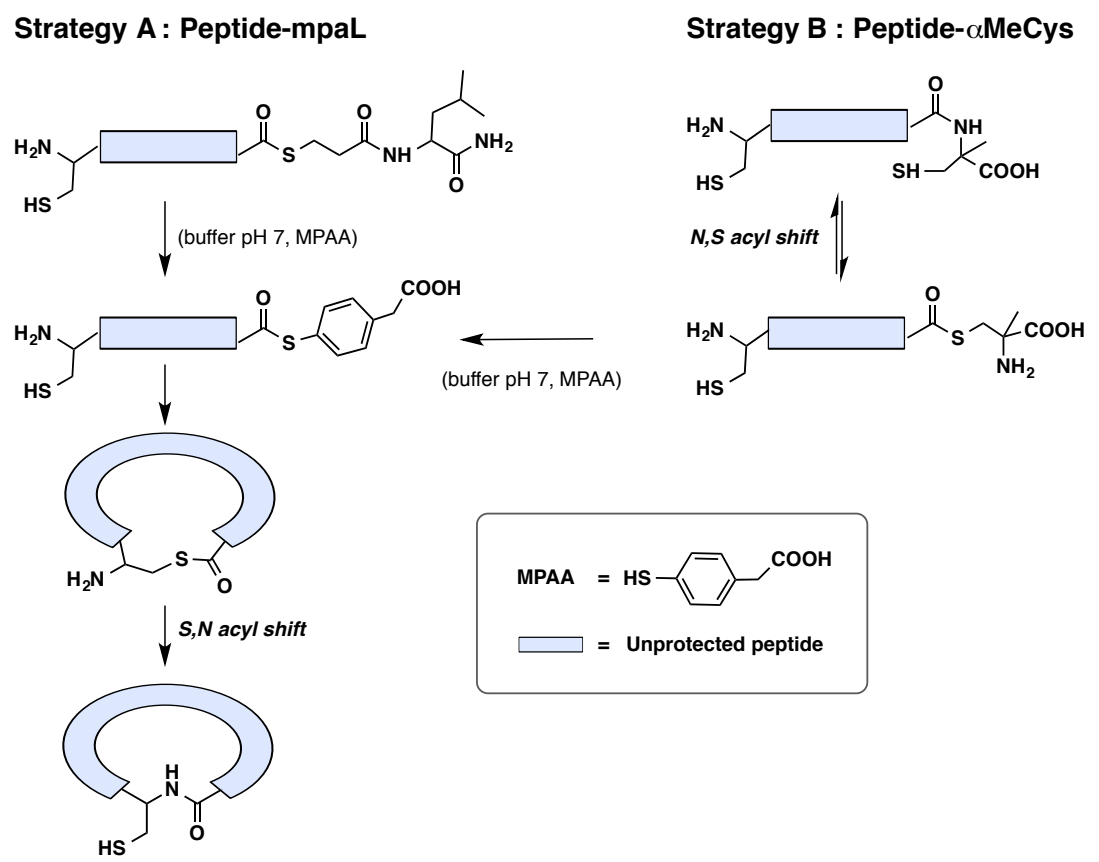

\section{Scheme S1. Strategies used for peptide cyclisation}

a. Strategy A: Synthesis of cyclic CPPs by native chemical ligation (NCL) using peptide-mpaL thioesters

\section{Synthesis of peptide-mpaL thioesters}

The procedure described by Hackeng et al. was applied ${ }^{[4]}$ Briefly, Boc-Leu was first coupled on MBHA-PS resin $(0.54 \mathrm{mmol} / \mathrm{g}, 0.1 \mathrm{mmol}$ ) (see the in situ neutralization protocol for Boc SPPS p. S4). S-trityl-mercaptopropionic acid $(0.2 \mathrm{mmol}, 2$ equiv.) was then coupled using HBTU ( $0.18 \mathrm{mmol}, 1.8$ equiv.) and DIEA ( $0.4 \mathrm{mmol}, 4$ equiv. $)$ in NMP for $1 \mathrm{~h} 30$. The peptideresin was washed with NMP. Removal of the trityl protecting group was performed by 15 min continuous flow with a mixture of TFA/ $\mathrm{H}_{2} \mathrm{O} / \mathrm{TES}, 95: 2.5: 2.5$ followed by washing with NMP. The next Boc-protected amino acid was immediately coupled (HBTU/DIEA activation, 45 min coupling) and the peptides elongated using the in situ neutralization Boc SPPS protocol. Peptides were then deprotected and cleaved from the resin by HF treatment (protocol p. S4) and purified by semi-preparative RP-HPLC. 
Synthesized peptide-mpaL thioesters:

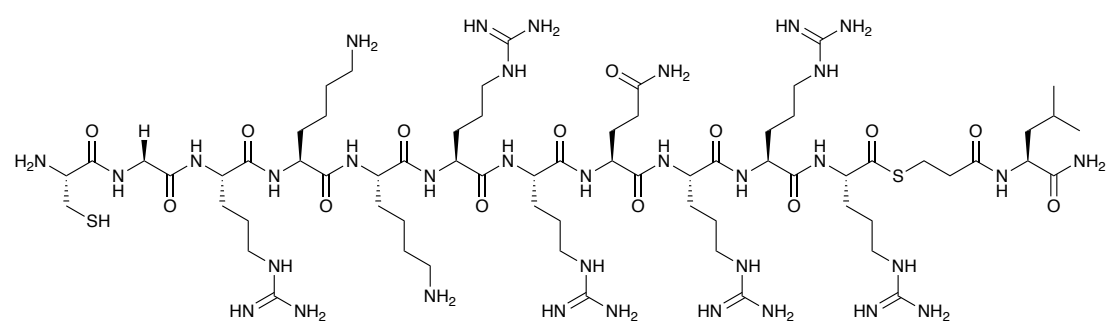

Tat-mpaL (CGRKKRRQRRR-mpaL)

MALDI-TOF $\mathrm{m} / \mathrm{z}[\mathrm{M}+\mathrm{H}]^{+}$calcd.: 1701.1, found: 1701.4

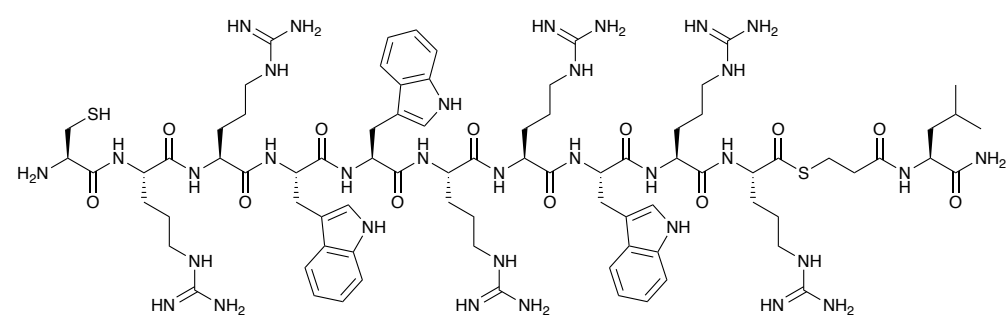

$\mathbf{R}_{6} \mathbf{W}_{\mathbf{3}}-\mathbf{m p a L}$ (CRRWWRRWRR-mpaL)

MALDI-TOF $(\mathrm{m} / \mathrm{z})[\mathrm{M}+\mathrm{H}]^{+}$calcd.: 1817.9, found: 1818.2

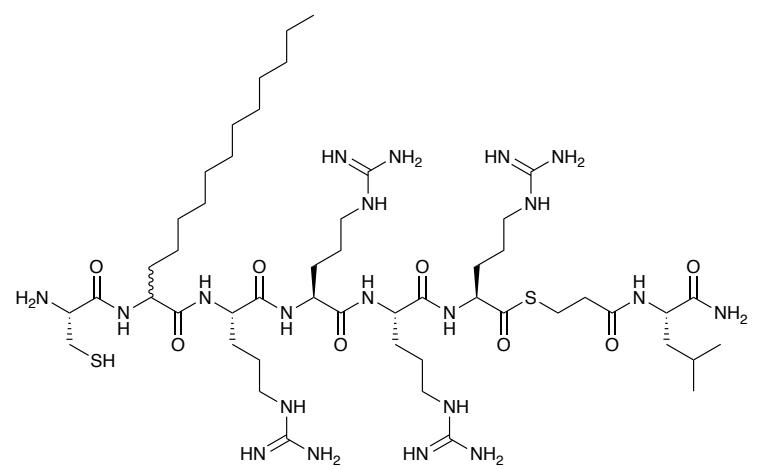

$\boldsymbol{C}_{12}$-R $\mathbf{4}$-mpaL (CC 12 RRRR-mpaL)

MALDI-TOF $(\mathrm{m} / \mathrm{z})[\mathrm{M}+\mathrm{H}]^{+}$calcd.: 1171.7, found: 1771.6

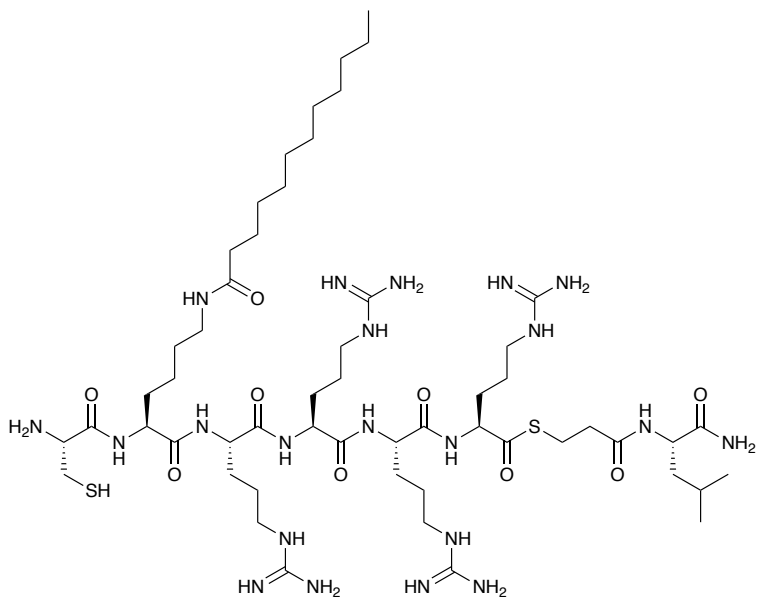

$\mathbf{K}\left(\boldsymbol{C}_{12}\right)-\mathbf{R}_{\mathbf{4}}$-mpaL $\left(\mathrm{CK}\left(\boldsymbol{C}_{12: 0}\right) \mathrm{RRRR}-\mathrm{mpaL}\right)$

MALDI-TOF $(\mathrm{m} / \mathrm{z})[\mathrm{M}+\mathrm{H}]^{+}$calcd.: 1257.8 , found: 1258.9 


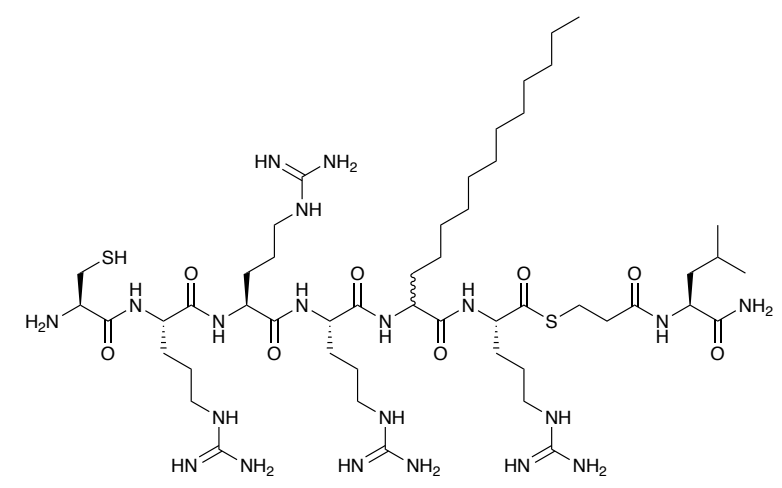

$\mathbf{R}_{\mathbf{3}}-\boldsymbol{C}_{\mathbf{1 2}}$-R-mpaL (CRRRC ${ }_{12}$ R-mpaL)

MALDI-TOF $(\mathrm{m} / \mathrm{z})[\mathrm{M}+\mathrm{H}]^{+}$calcd.: 1171.7, found: 1173.4

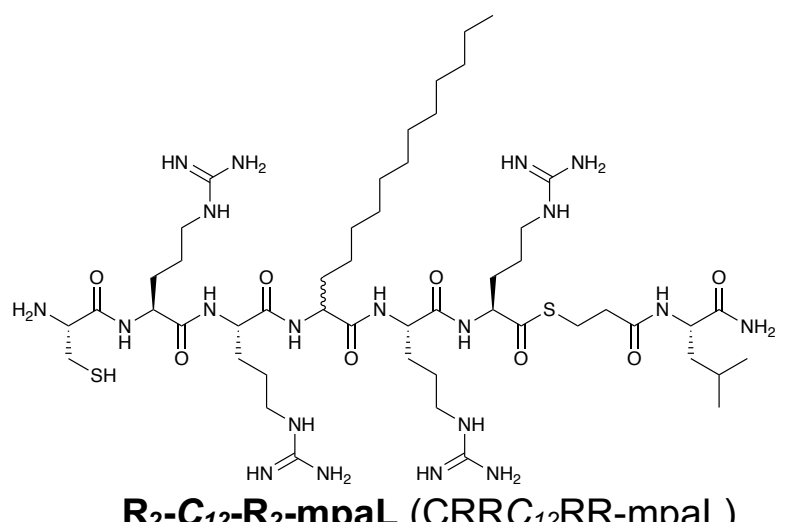

MALDI-TOF $(\mathrm{m} / \mathrm{z})[\mathrm{M}+\mathrm{H}]^{+}$calcd.: 1171.6 , found: 1174.7

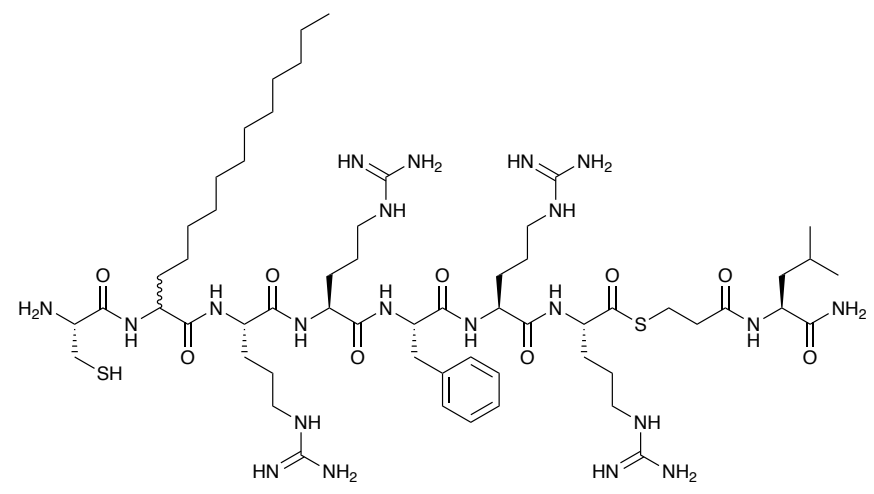

$\boldsymbol{C}_{\mathbf{1 2}}$ - $\mathbf{R}_{\mathbf{2}} \mathrm{FR}_{\mathbf{2}}$-mpaL ( $\mathrm{CC}_{12} \mathrm{RRFRR}$-mpaL)

MALDI-TOF $(\mathrm{m} / \mathrm{z})[\mathrm{M}+\mathrm{H}]^{+}$calcd.: 1318.8 , found: 1320.5

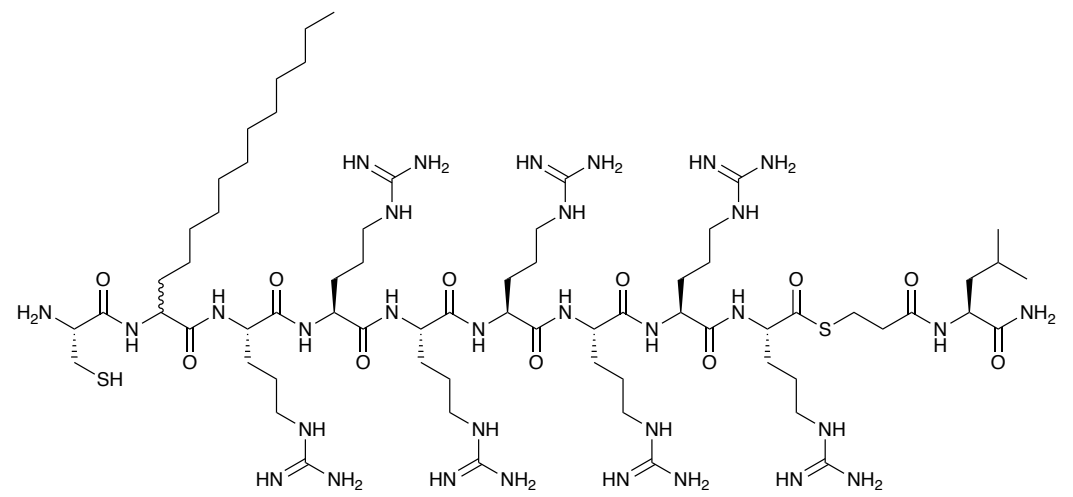

$\boldsymbol{C}_{\mathbf{1 2}}-\mathbf{R}_{\mathbf{7}}-\mathrm{mpaL}\left(\mathrm{CC}_{12} \mathrm{RRRRRRR-mpaL}\right)$

MALDI-TOF $(\mathrm{m} / \mathrm{z})[\mathrm{M}+\mathrm{H}]^{+}$calcd.: 1640.0, found: 1638.2 


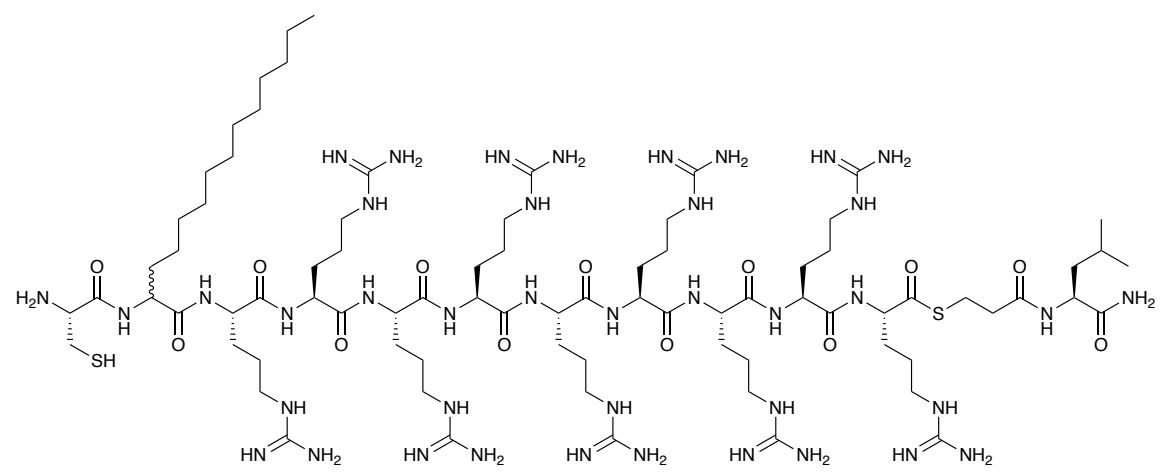

$\mathbf{C}_{12}$-Rg-mpaL (CC ${ }_{12}$ RRRRRRRRR-mpaL)

MALDI-TOF $(\mathrm{m} / \mathrm{z})[\mathrm{M}+\mathrm{H}]^{+}$calcd.: 1952.2, found: 1954.6

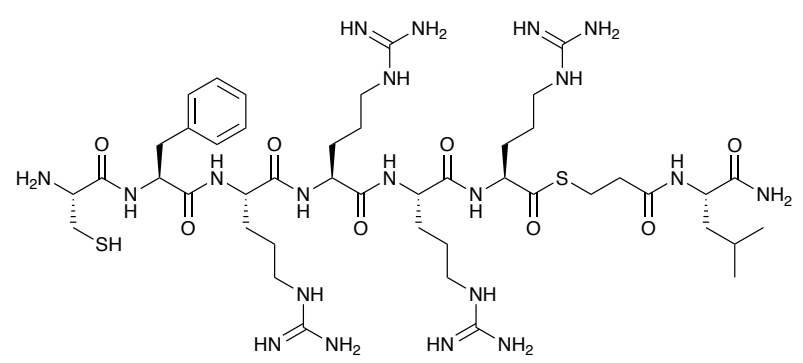

$\mathrm{FR}_{\mathbf{4}}$-mpaL (CFRRRR-mpaL)

MALDI-TOF $(\mathrm{m} / \mathrm{z})[\mathrm{M}+\mathrm{H}]^{+}$calcd.: 1093.6, found: 1093.7

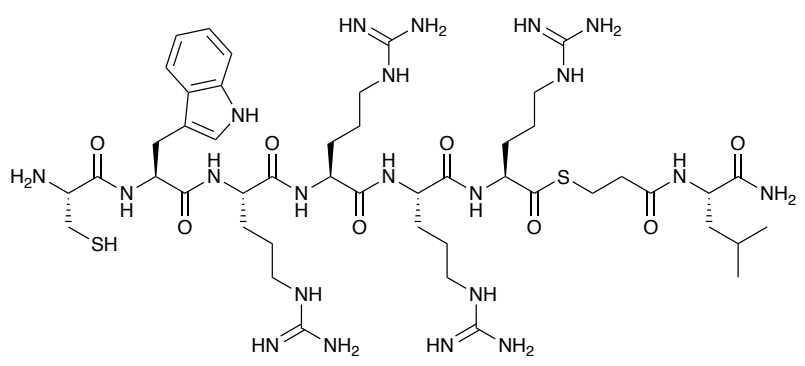

WR $_{4}$-mpaL (CWRRRR-mpaL)

MALDI-TOF $(\mathrm{m} / \mathrm{z})[\mathrm{M}+\mathrm{H}]^{+}$calcd.: 1132.6 , found: 1132.8

\section{Cyclisation of the mpaL thioesters}

A carefully degassed $0.2 \mathrm{M}$ sodium phosphate buffer containing $2 \mathrm{mM}$ EDTA, 3 or $6 \mathrm{M}$ guanidine hydrochloride (see below), $3 \mathrm{mM}$ MPAA and $3.5 \mathrm{mM}$ TCEP was added to the peptide mpaL thioester (concentration $1 \mathrm{mM}$, final pH 6.5 or 7). The ligations were carried out at room temperature and monitored by RP-HPLC (Fig S3). For this purpose $10 \mu \mathrm{L}$ aliquots of the reaction mixture were injected in HPLC. After completion, the reaction mixtures were diluted with $0.1 \%$ TFA in water and purified by RP-HPLC to afford the desired cyclic products (Fig S1 and S2).

$\mathrm{NCL}$ was performed in buffer containing $3 \mathrm{M}$ Guanidine for mpaL derivatives of Tat, $\mathrm{R}_{6} \mathrm{~W}_{3}$, $C_{12}-R_{7}, C_{12}-R_{9}, F R_{4}$ and $W_{4}$, which showed good solubility in these conditions. For the other derivatives, $6 \mathrm{M}$ guanidine was used. 


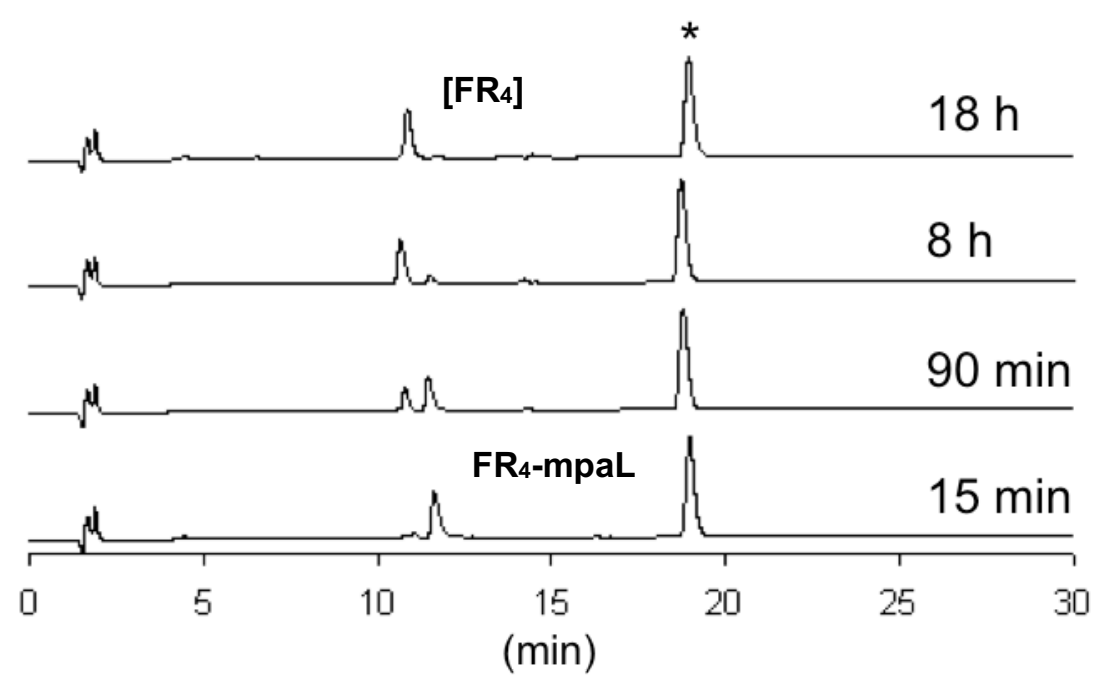

Figure S3. HPLC monitoring of the cyclisation of FR4-mpaL to give [FR

The reaction was performed in $200 \mathrm{mM}$ sodium phosphate buffer containing $2 \mathrm{mM}$ EDTA, 3 $\mathrm{M}$ Guanidine, $3.5 \mathrm{mM}$ TCEP, $3 \mathrm{mM}$ MPAA, final $\mathrm{pH} 6.5$ using $1 \mathrm{mM} \mathrm{FR}_{4}-\mathrm{mpaL}$. HPLC gradient: 0-30 \% B in 30 min; column: Vydac C18; detection wavelength: $214 \mathrm{~nm}$. *MPAA.

\section{b. Strategy B: Synthesis of cyclic CPP by NCL using a peptide with a C-terminal $\alpha$ - methylcysteine ( $\alpha$ MeCys)}

The $C$-terminal $\alpha$-methylcysteine-containing peptide was synthesised by standard Fmoc SPPS on Wang resin functionalised by an a-methylcysteine $(0.20 \mathrm{mmol} / \mathrm{g}, 0.1 \mathrm{mmol})$ as described previously. ${ }^{[5]}$ After completion of elongation, peptide-resin was deprotected and cleaved using the standard cleavage procedure (protocol p S3) and the peptide- $\alpha$ MeCys was purified by RP-HPLC.

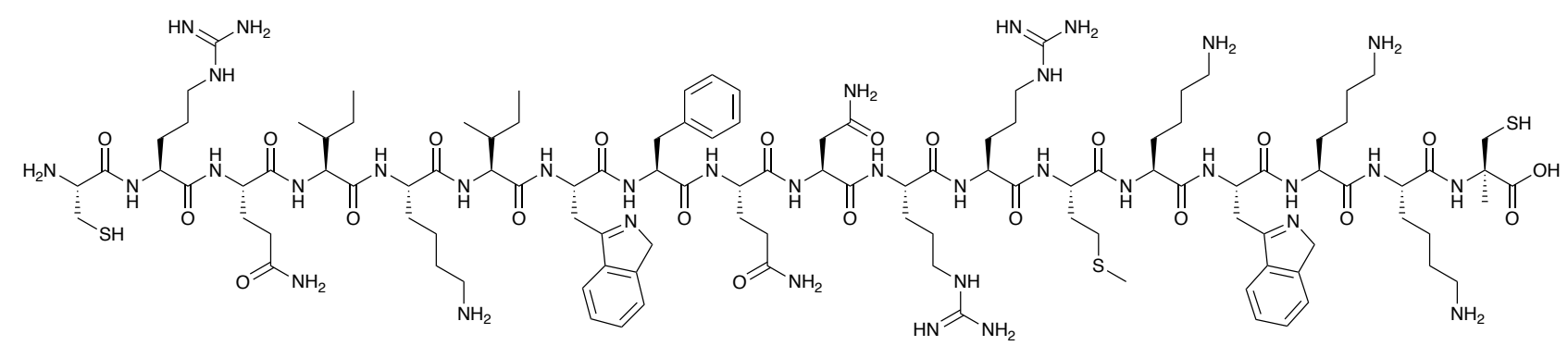

\footnotetext{
Pen- $\alpha$ MeCys (CRQIKIWFQNRRMKWKK- $\alpha$ MeC)

MALDI-TOF $(\mathrm{m} / \mathrm{z})[\mathrm{M}+\mathrm{H}]^{+}$calc.: 2465.3 , found: 2465.7
}

\section{Cyclisation of Pen- $\alpha M e C y s$}

To optimise the conditions of cyclisation, we first evaluated the effect of different parameters $(\mathrm{pH}$, guanidine and MPAA concentration) on the reaction rate. Pen- $\alpha$ MeCys (final concentration $1 \mathrm{mM}$ ) was dissolved in degassed ligation buffer containing $200 \mathrm{mM}$ sodium phosphate, $2 \mathrm{mM}$ EDTA, $50 \mathrm{mM}$ TCEP and the guanidine and MPAA concentrations and $\mathrm{pH}$ indicated Table S2. The reaction was monitored by HPLC injecting aliquots of $10 \mu \mathrm{L}$ of the ligation mixture at different reaction times (Fig S4). The extent of conversion of Pen$\alpha$ MeCys into [Pen] was deduced from the relative areas of both species HPLC peaks, considering that both compounds have the same extinction coefficient at $220 \mathrm{~nm}$. The 
reaction was repeated in larger scale at $\mathrm{pH} 6$ using $3 \mathrm{M}$ Guanidine and $450 \mathrm{mM}$ MPAA and the compound purified by reverse phase HPLC.

Table S2: Effect of $\mathrm{pH}$, guanidine and MPAA concentrations on the half-time of ligation

\begin{tabular}{|llll|}
\hline Guanidine (M) & MPAA $(\mathbf{m M})$ & $\mathbf{p H}$ & $\mathbf{t} \mathbf{1} \mathbf{2}(\mathbf{h})$ \\
\hline 6 & 300 & 6.5 & $>15$ \\
\hline 3 & 300 & 6.5 & 8 \\
\hline 3 & 300 & 5.5 & 6 \\
\hline 3 & 450 & 5.5 & 5 \\
\hline 3 & 450 & 7 & 6 \\
\hline 3 & 450 & 5 & 3.5 \\
\hline
\end{tabular}

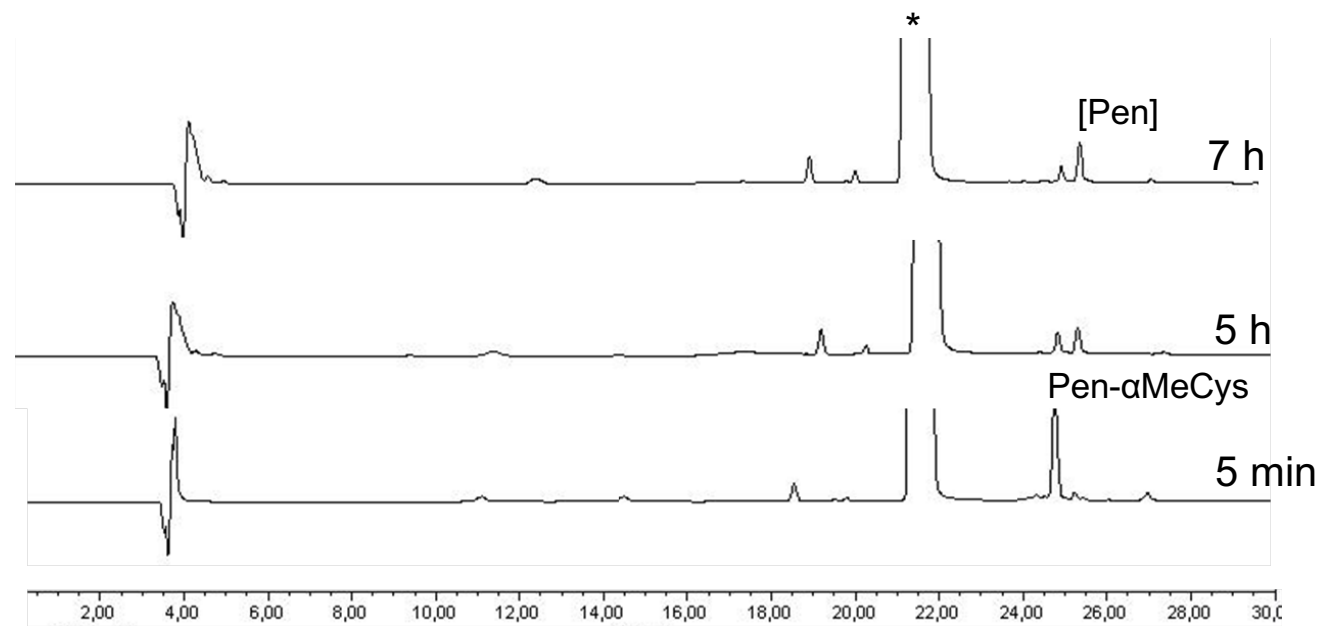

Figure S4. HPLC monitoring of the cyclisation of Pen-aMeCys to give [Pen].

The reaction was performed in $200 \mathrm{mM}$ sodium phosphate buffer containing $2 \mathrm{mM}$ EDTA, 3 M Guanidine, 50 mM TCEP, 450 mM MPAA, pH 6. HPLC gradient: 5-55 \% B in 30 min; column: ACE-5 C8; detection wavelength: 214 nm. *MPAA

Table S3. MALDI-TOF MS characterisation of the cyclic CPPs

\begin{tabular}{|c|c|c|}
\hline Peptide & {$[\mathrm{M}+\mathrm{H}]^{+}$(calc) } & {$[\mathrm{M}+\mathrm{H}]^{+}$(found) } \\
\hline [Tat] & 1481.8 & 1481.6 \\
\hline$\left[\mathrm{R}_{6} \mathrm{~W}_{3}\right]$ & 1598.9 & 1597.6 \\
\hline [Pen] & 2331.1 & 2330.9 \\
\hline$\left[C_{12}-R_{4}\right]$ & 953.2 & 953.4 \\
\hline$\left[\mathrm{K}\left(\mathrm{C}_{12}\right)-\mathrm{R}_{4}\right]$ & 1038.4 & 1039.0 \\
\hline$\left[\mathrm{R}_{3}-\mathrm{C}_{12}-\mathrm{R}\right]$ & 953.2 & 953.4 \\
\hline$\left[\mathrm{R}_{2}-\mathrm{C}_{12}-\mathrm{R}_{2}\right]$ & 953.2 & 953.8 \\
\hline$\left[C_{12}-\mathrm{R}_{2} \mathrm{FR}_{2}\right]$ & 1100.4 & 1100.9 \\
\hline$\left[C_{12}-R_{7}\right]$ & 1420.7 & 1421.7 \\
\hline$\left[C_{12}-R_{9}\right]$ & 1734.2 & 1733.5 \\
\hline$\left[\mathrm{FR}_{4}\right]$ & 875.1 & 875.5 \\
\hline$\left[\mathrm{WR}_{4}\right]$ & 913.8 & 913.7 \\
\hline
\end{tabular}




\section{Synthesis and characterisation of the CPP-PKCi disulfide conjugates used in the biological experiments}

The CPP was dissolved in degassed sodium acetate buffer $(50 \mathrm{mM}, \mathrm{pH} 4.5$ to 5$)$ and mixed with 1.1 eq. of ${ }^{1} \mathrm{H}-\mathrm{PKCi}$ (final peptide concentrations: 1 to $5 \mathrm{mM}$ ). The reaction was monitored by HPLC. At the end of the reaction, conjugates were purified by reverse phase HPLC.

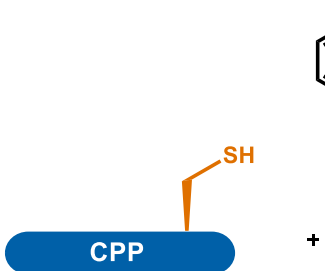<smiles>CSSc1ncccc1[N+](=O)[O-]</smiles>
$50 \mathrm{mM}, \mathrm{pH} 4.5$

\section{Scheme S2. Disulfide bridge formation between the CPP and the cargo}

The conjugates were characterized by MALDI-TOF MS on a Voyager DE-PRO (Applied Biosystems) or on a 4700 Proteomix MALDI-TOF/TOF (Applied Biosystems) in the linear positive ion modes and reflector positive ion mode. The disulfide bond is fragile and a fragmentation is observed at this position during MALDI-TOF MS analysis, the $[\mathrm{M}+\mathrm{H}]^{+}$peak being more difficult to detect in the reflector mode compared to the linear one.

Conjugate $C_{12}-\mathrm{R}_{4}-\mathrm{PKCi}$ has been previously described. ${ }^{[3]}$ 
$\left[\mathrm{C}_{12}-\mathrm{R}_{4}\right]-\mathrm{PKCi}$

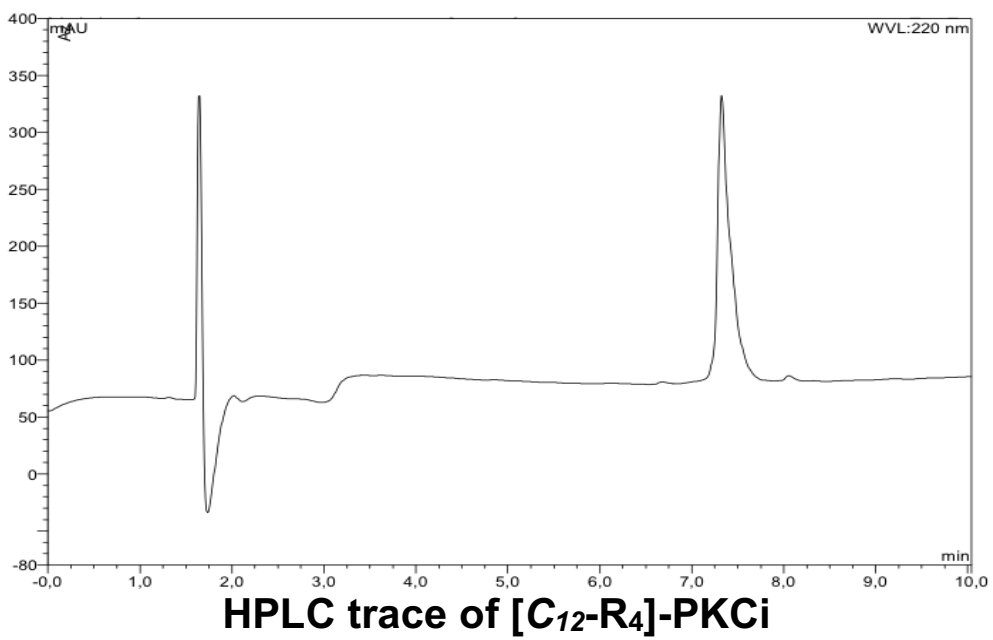

Column: PROTO $200 \mathrm{C} 183 \mu \mathrm{m}, 100 \times 4.6 \mathrm{~mm}$, Higgins Analytical, Inc Gradient: $0-70 \%$ B in $10 \mathrm{~min}, 1 \mathrm{~mL} / \mathrm{min}$ HPLC: Dionex Ultimate 3000

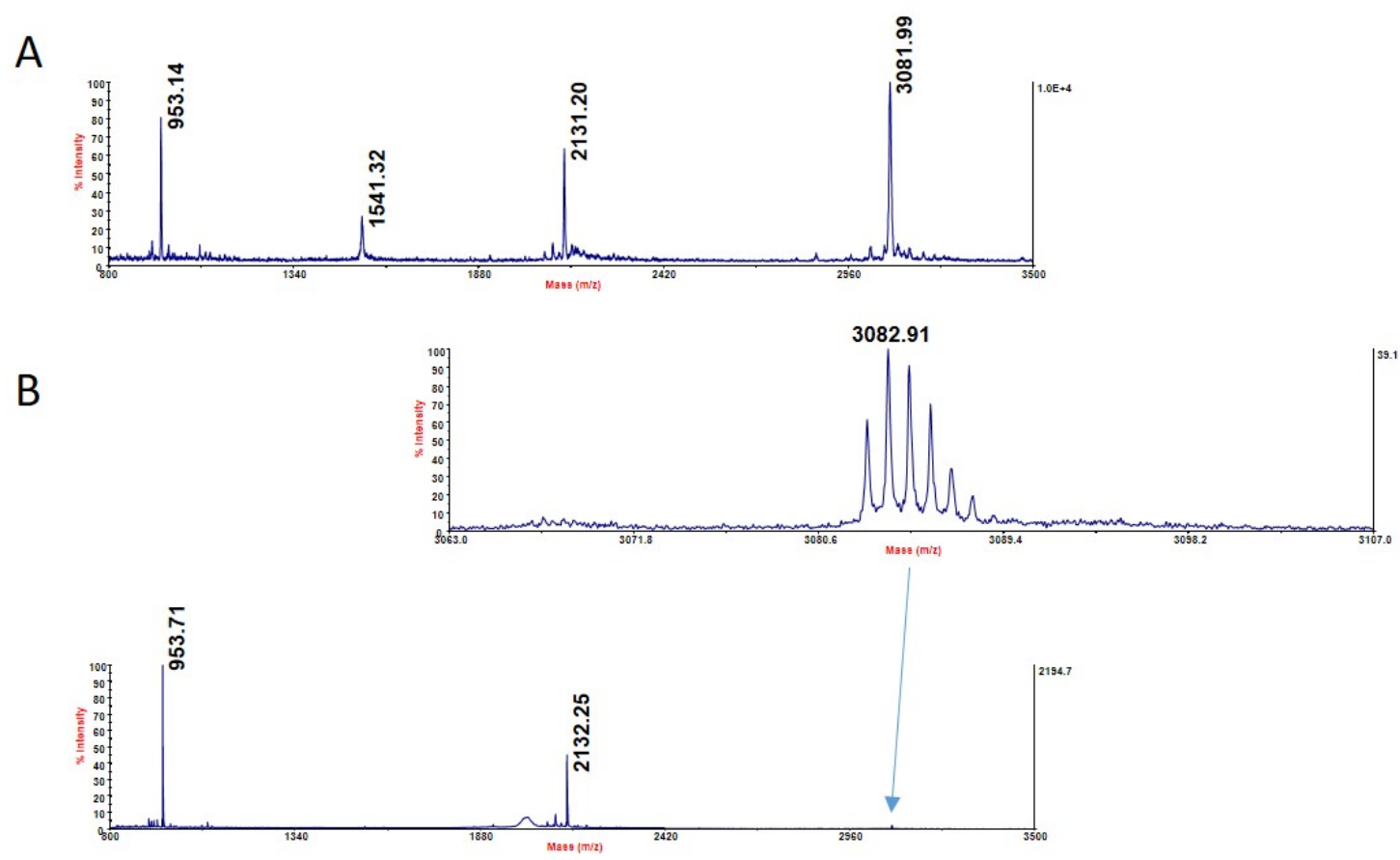

MALDI-TOF MS analysis of the [ $\left.\boldsymbol{C}_{12}-\mathbf{R}_{4}\right]-P K C i$ disulfide conjugate: $\left.A\right)$ in the linear positive ions mode and $\mathbf{B}$ ) in the reflector positive ions mode (top shows a zoom on the $[\mathrm{M}+\mathrm{H}]^{+}$peak).

Reflector mode mass spectrum:

$\mathrm{m} / \mathrm{z} 3082.9$ (monoprotonated ion of $\left[\mathrm{C}_{12}-\mathrm{R}_{4}\right]-\mathrm{PKCi}$, calc. 3083.8)

Fragmentation of the disulfide bond gives two ions at $\mathrm{m} / \mathrm{z} 2132.2(\mathrm{PKCi})$ and $\mathrm{m} / \mathrm{z} 953.7\left(\left[\mathrm{C}_{12^{-}}\right.\right.$ $\left.\mathrm{R}_{4}\right]$ ). 


\section{$\left[\mathrm{K}\left(\mathrm{C}_{12}\right)-\mathrm{R}_{4}\right]-\mathrm{PKCi}$}

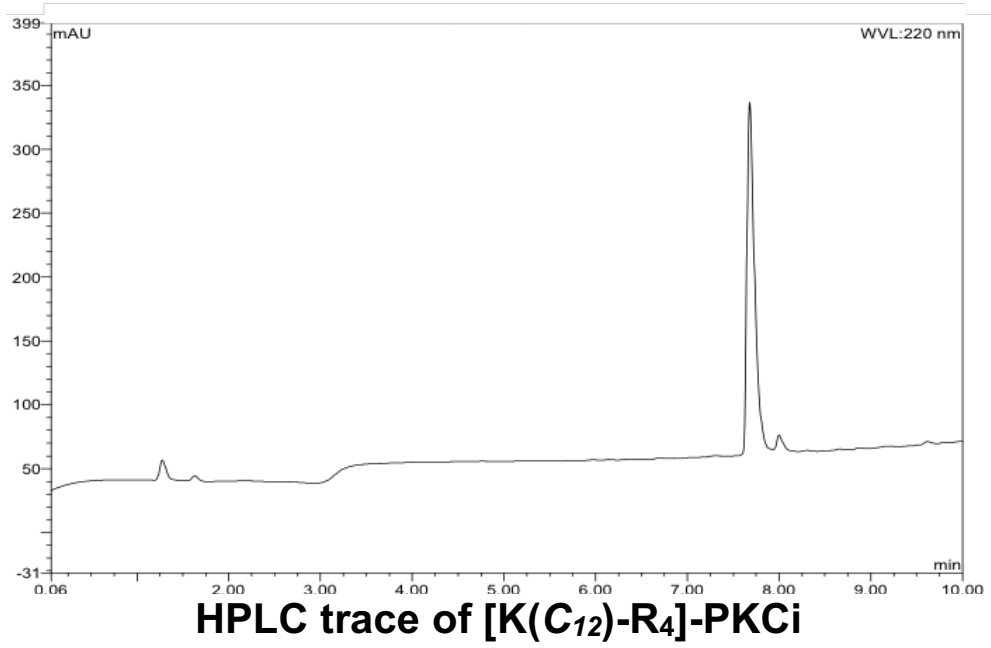

Column: PROTO $200 \mathrm{C} 183 \mu \mathrm{m}, 100$ x 4.6 mm, Higgins Analytical, Inc Gradient: $0-70 \%$ B in $10 \mathrm{~min}, 1 \mathrm{~mL} / \mathrm{min}$

HPLC: Dionex Ultimate 3000

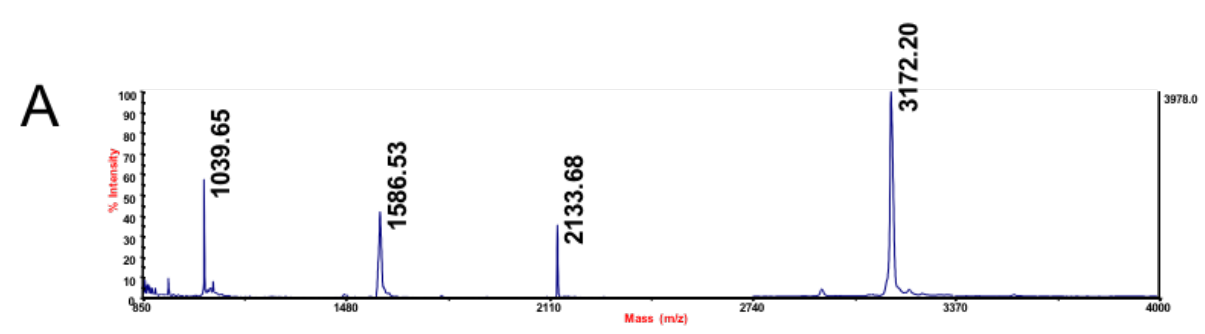

B
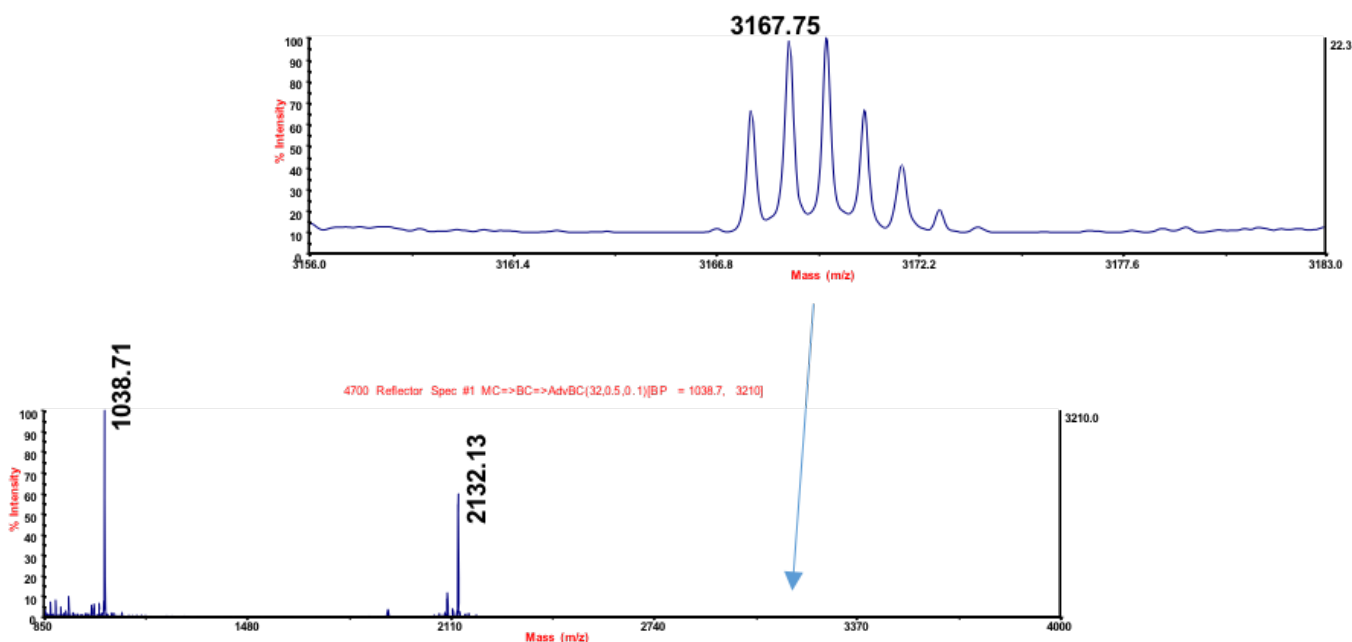

MALDI-TOF MS analysis of the [K( $\left.\left.C_{12}\right)-R_{4}\right]-P K C i$ disulfide conjugate: $\left.A\right)$ in the linear positive ions mode and $\mathbf{B}$ ) in the reflector positive ions mode (top shows a zoom on the $[\mathrm{M}+\mathrm{H}]^{+}$peak).

Reflector mode mass spectrum:

$\mathrm{m} / \mathrm{z} 3167.7$ (monoprotonated ion of $\left[\mathrm{K}\left(C_{12}\right)-\mathrm{R}_{4}\right]-\mathrm{PKCi}$, calc. 3168,9)

Fragmentation of the disulfide bond gives ions at $\mathrm{m} / \mathrm{z} 2132.1(\mathrm{PKCi})$ and $\mathrm{m} / \mathrm{z} 1038.7\left(\left[\mathrm{~K}\left(C_{12}\right)\right.\right.$ $\left.R_{4}\right]$ ). 
$\left[\mathrm{R}_{3}-\mathrm{C}_{12}-\mathrm{R}\right]-\mathrm{PKCi}$

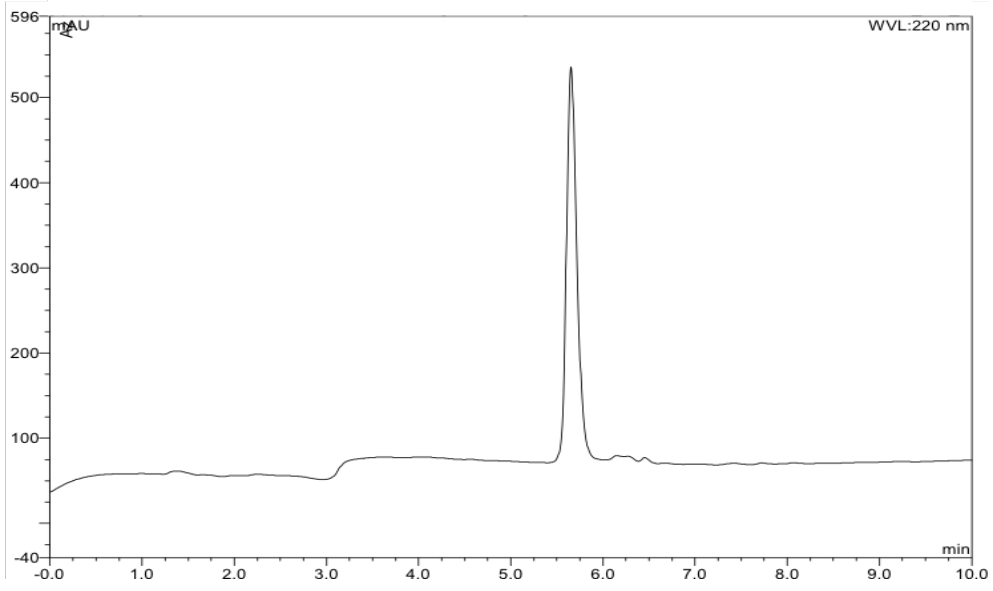

$\mathrm{HPLC}$ trace of $\left[\mathrm{R}_{3}-\mathrm{C}_{12}-\mathrm{R}\right]-\mathrm{PKCi}$

Column: PROTO $200 \mathrm{C} 183 \mu \mathrm{m}, 100 \times 4.6 \mathrm{~mm}$, Higgins Analytical, Inc Gradient: $0-70 \%$ B in $10 \mathrm{~min}, 1 \mathrm{~mL} / \mathrm{min}$

HPLC: Dionex Ultimate 3000

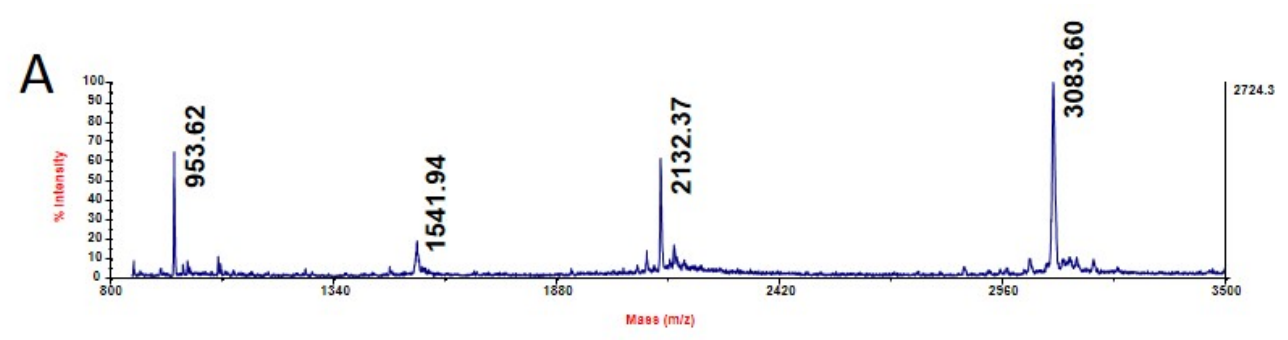

B
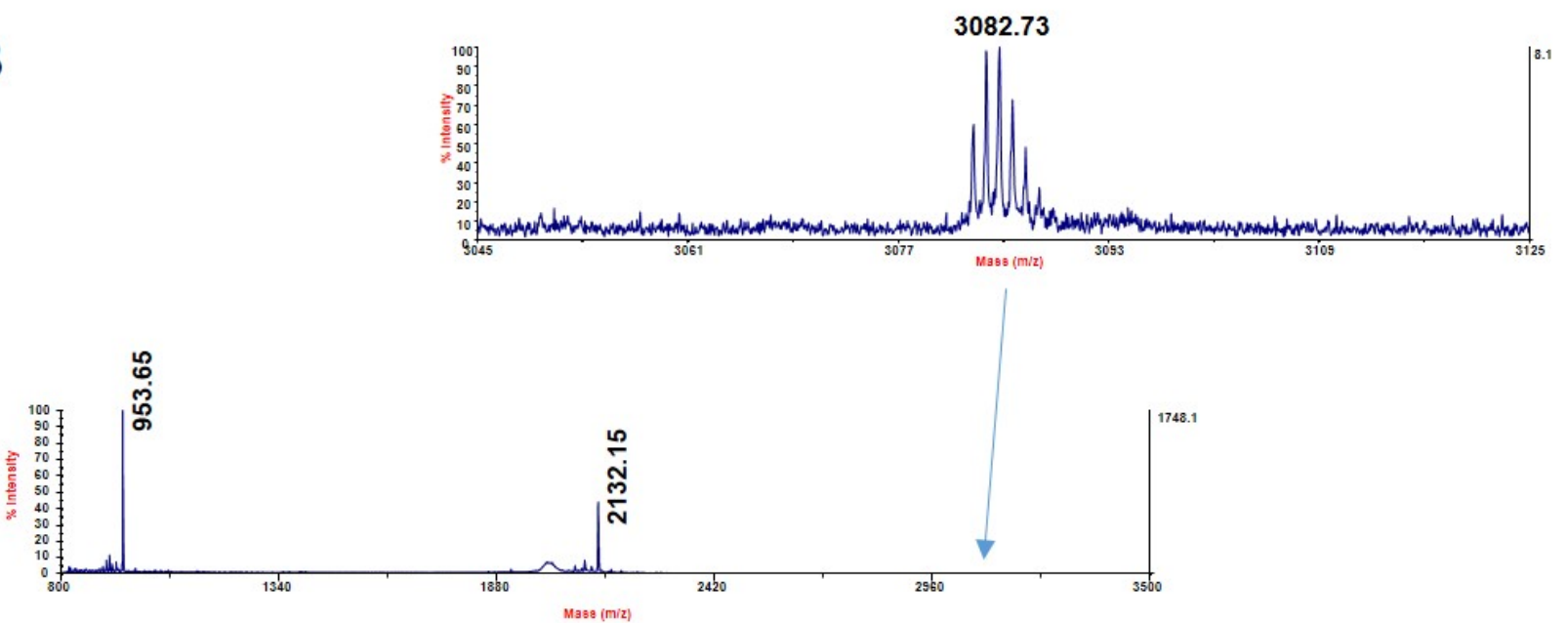

MALDI-TOF MS analysis of the [ $\left.\mathbf{R}_{3}-\boldsymbol{C}_{12}-\mathrm{R}\right]-\mathrm{PKCi}$ disulfide conjugate: $\left.\mathrm{A}\right)$ in the linear positive ions mode and $\mathbf{B}$ ) in the reflector positive ions mode (top shows a zoom on the $[\mathrm{M}+\mathrm{H}]^{+}$peak).

Reflector mode mass spectrum:

$\mathrm{m} / \mathrm{z} 3082.7$ (monoprotonated ion of $\left[\mathrm{R}_{3}-\mathrm{C}_{12}-\mathrm{R}\right]-\mathrm{PKCi}$, calc. 3083.8 )

Fragmentation of the disulfide bond gives ions at $\mathrm{m} / \mathrm{z} 2132.1$ (PKCi) and $\mathrm{m} / \mathrm{z} 953.6\left(\left[\mathrm{R}_{3}-\mathrm{C}_{12^{-}}\right.\right.$ $R]$ ). 


\section{$\left[\mathrm{R}_{2}-\mathrm{C}_{12}-\mathrm{R}_{2}\right]-\mathrm{PKCi}$}

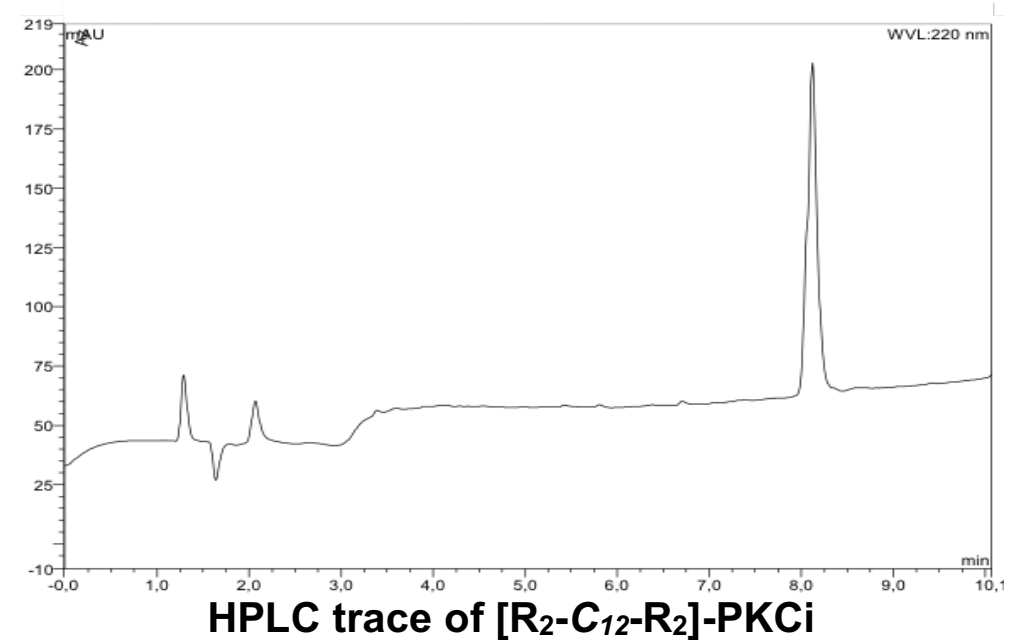

Column: PROTO $200 \mathrm{C} 183 \mu \mathrm{m}, 100 \times 4.6 \mathrm{~mm}$, Higgins Analytical

Gradient: $0-70 \%$ B in $10 \mathrm{~min}, 1 \mathrm{~mL} / \mathrm{min}$

HPLC: Dionex Ultimate 3000

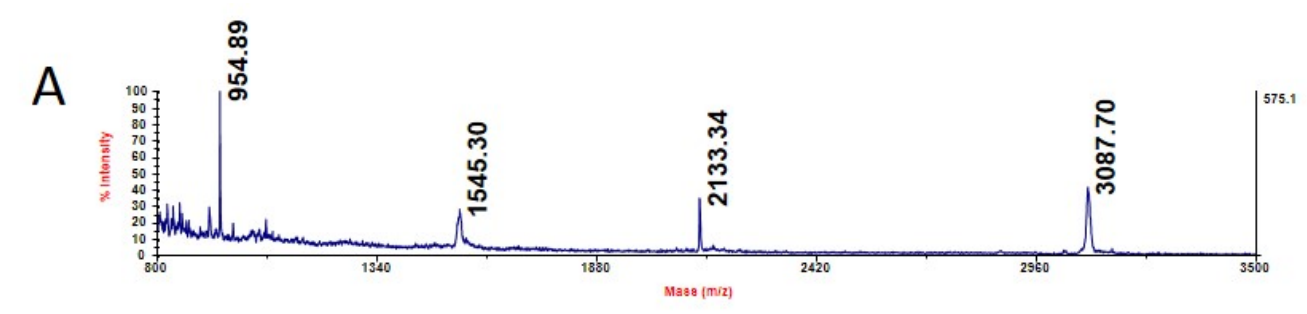

B
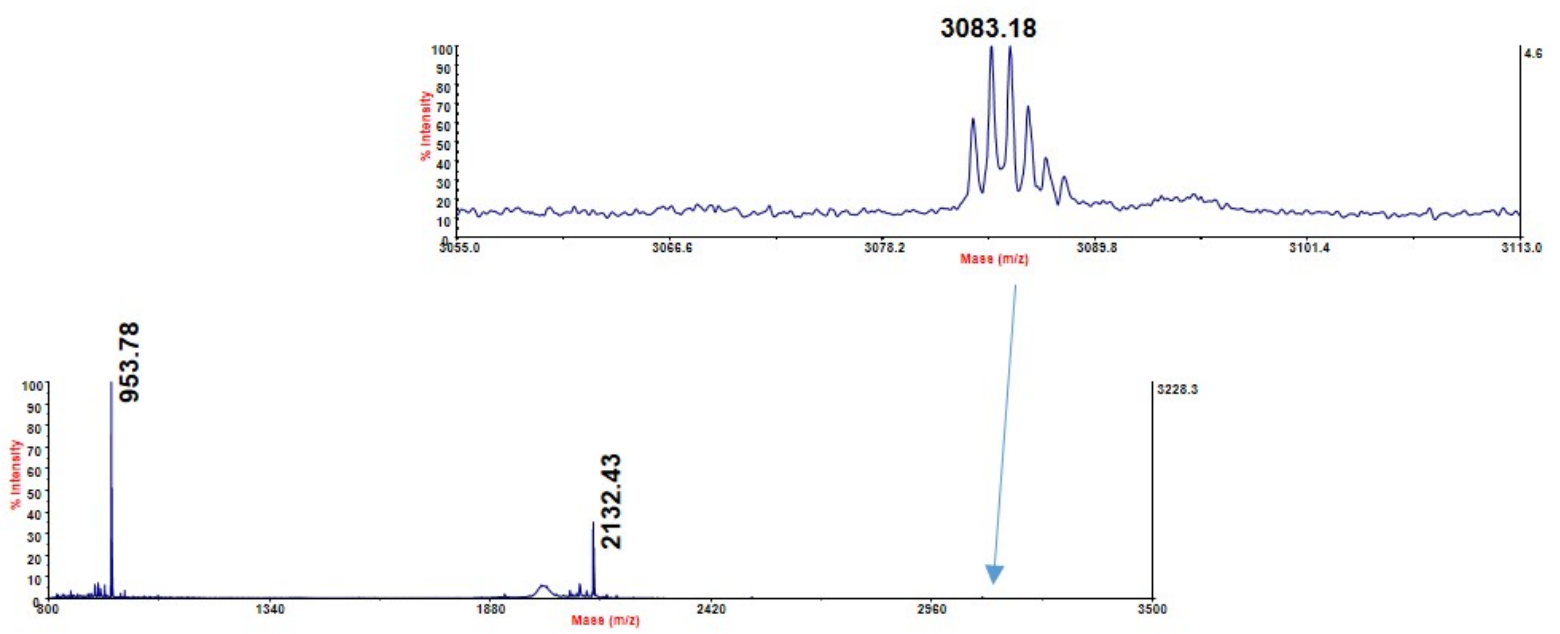

MALDI-TOF MS analysis of the $\left[\mathbf{R}_{2}-\boldsymbol{C}_{12}-\mathbf{R}_{\mathbf{2}}\right]-\mathrm{PKCi}$ disulfide conjugate: $A$ ) in the linear positive ions mode and $\mathbf{B}$ ) in the reflector positive ions mode (top shows a zoom on the $[\mathrm{M}+\mathrm{H}]^{+}$peak).

Reflector mode mass spectrum:

$\mathrm{m} / \mathrm{z} 3083.2$ (monoprotonated ion of $\left[\mathrm{R}_{2}-\mathrm{C}_{12}-\mathrm{R}_{2}\right]-\mathrm{PKCi}$, calc. 3083.8)

Fragmentation of the disulfide bond gives ions at $\mathrm{m} / \mathrm{z} 2132.4$ (PKCi) and $\mathrm{m} / \mathrm{z} 953.8\left[\mathrm{R}_{2}-\mathrm{C}_{12^{-}}\right.$ $\left.R_{2}\right]$ ). 


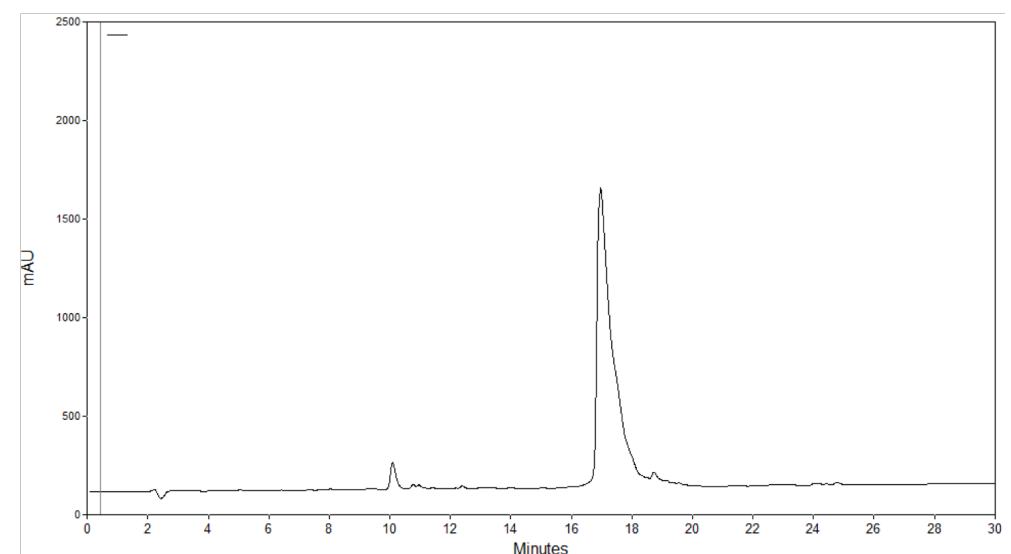

HPLC trace of [ $\left.\mathrm{C}_{12}-\mathrm{R}_{2} \mathrm{FR}_{2}\right]-\mathrm{PKCi}$

Column: Vydac C18 $5 \mu \mathrm{m}, 150 \times 4.6 \mathrm{~mm}$

Gradient: $5-60 \%$ B in $30 \mathrm{~min}, 1 \mathrm{~mL} / \mathrm{min}$

HPLC: Agilent 1220 Infinity

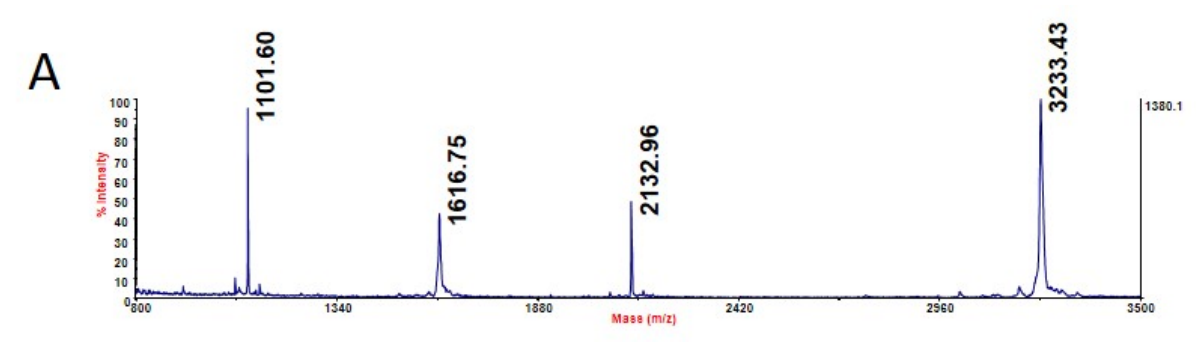

B
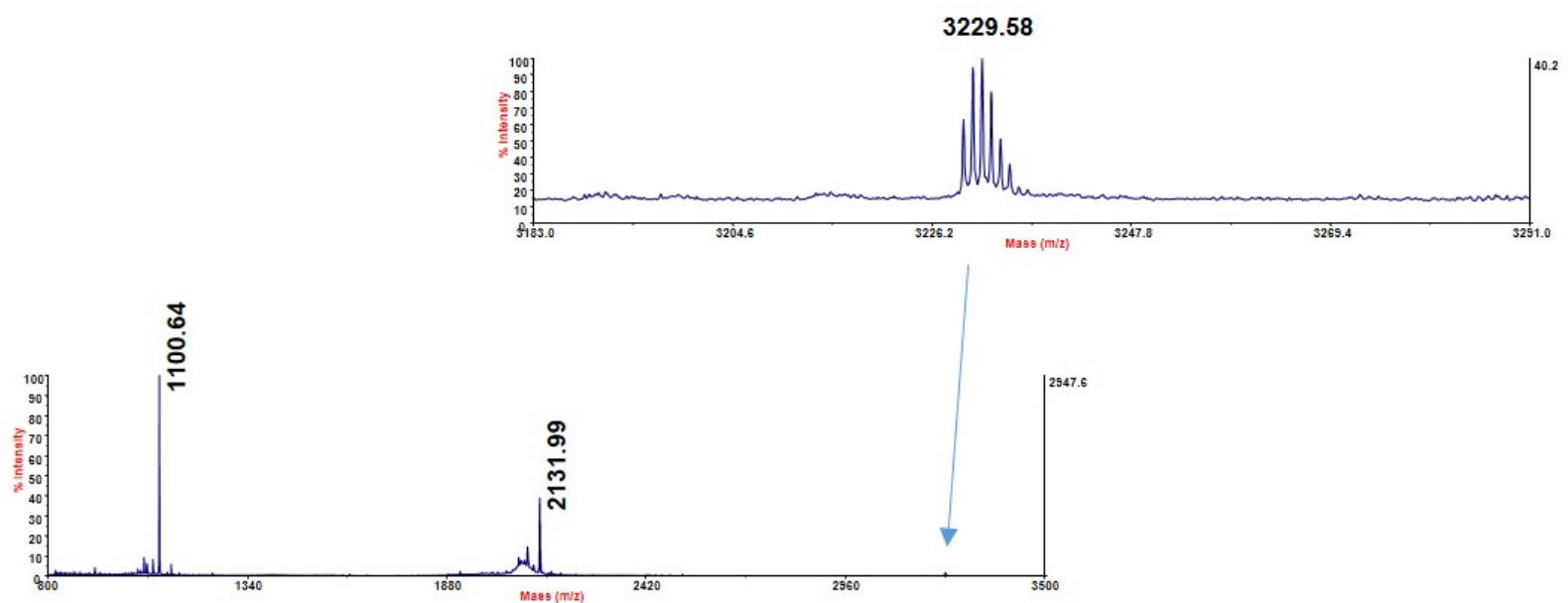

MALDI-TOF MS analysis of the [ $\left.C_{12}-R_{2} F R_{2}\right]-P K C i$ disulfide conjugate: $A$ ) in the linear positive ions mode and $\mathbf{B}$ ) in the reflector positive ions mode (top shows a zoom on the $[\mathrm{M}+\mathrm{H}]^{+}$peak).

Reflector mode mass spectrum:

$\mathrm{m} / \mathrm{z} 3229.6$ (monoprotonated ion of [ $\left.C_{12}-\mathrm{R}_{2} \mathrm{FR}_{2}\right]-\mathrm{PKCi}$, calc. 3230.9)

Fragmentation of the disulfide bond gives ions at $\mathrm{m} / \mathrm{z} 2132(\mathrm{PKCi})$ and $\mathrm{m} / \mathrm{z} 1100.6$ ([C $\mathrm{C}_{12^{-}}$ $\left.\mathrm{R}_{2} \mathrm{FR}_{2}\right]$ ). 


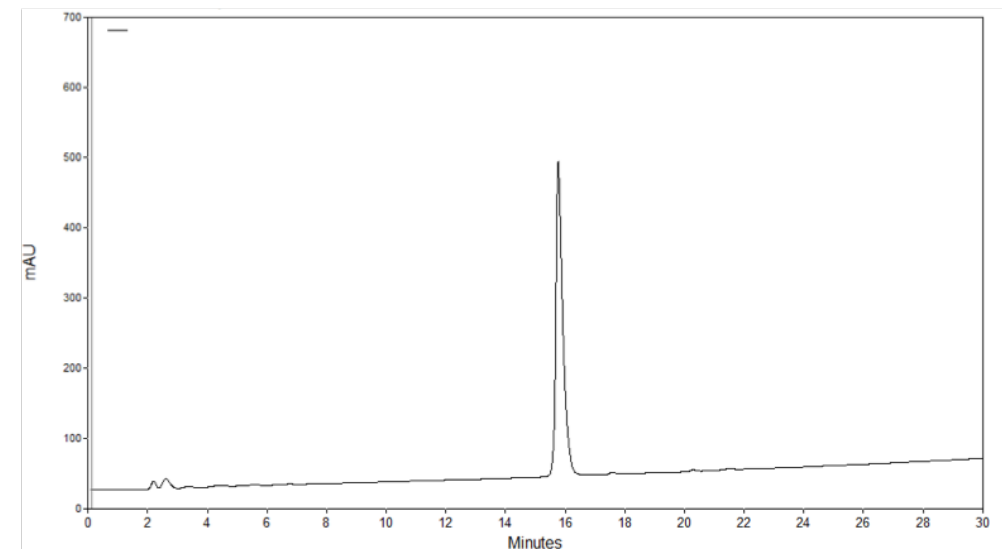

\section{HPLC trace of $\left[\boldsymbol{C}_{12}-\mathrm{R}_{7}\right]-\mathrm{PKCi}$}

Column: Vydac C18 $5 \mu \mathrm{m}, 150 \times 4.6 \mathrm{~mm}$

Gradient: 5-60 \% B in $30 \mathrm{~min}, 1 \mathrm{~mL} / \mathrm{min}$

HPLC: Agilent 1220 Infinity

A

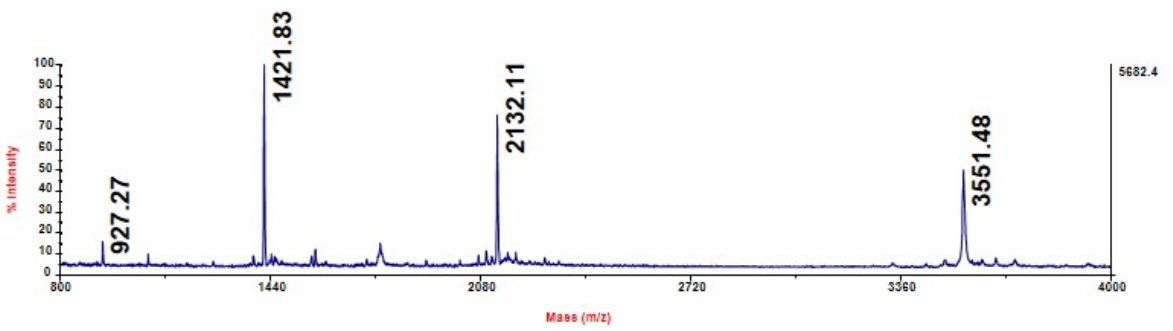

B
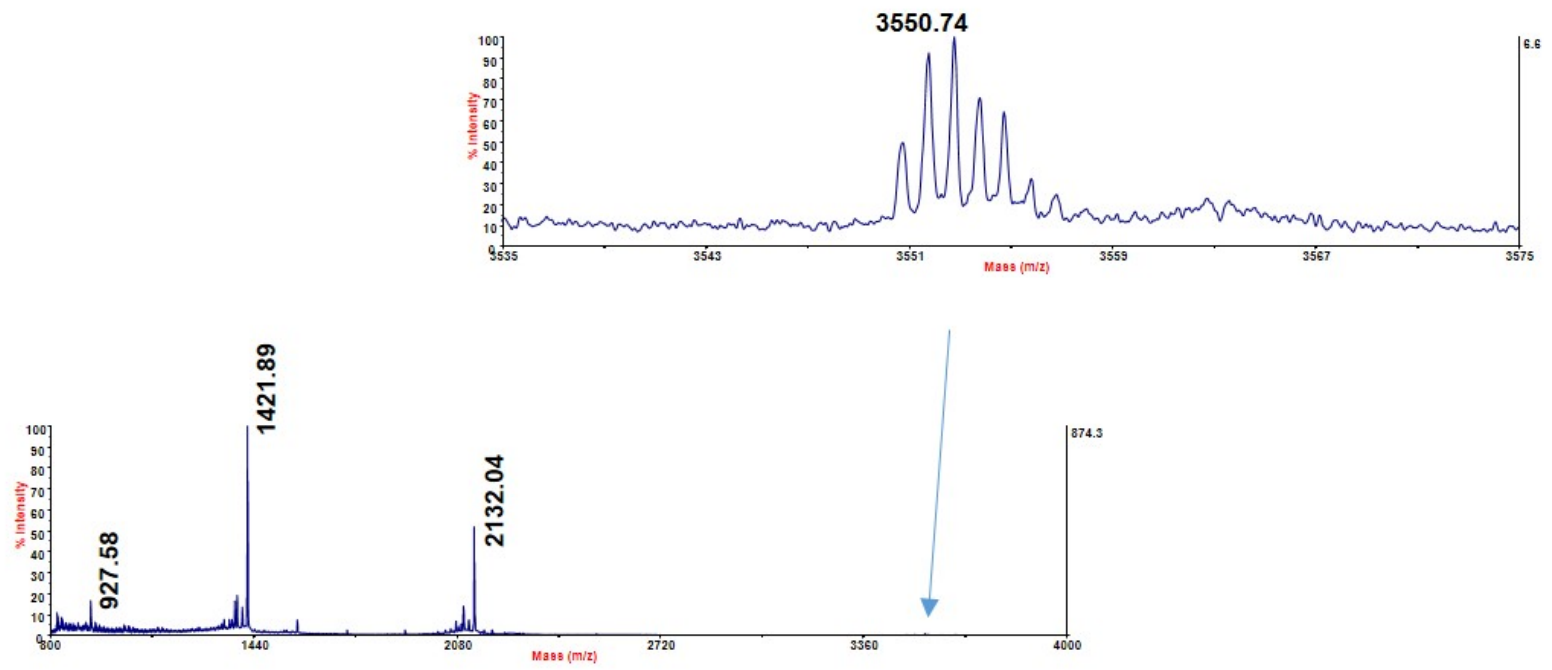

MALDI-TOF MS analysis of the $\left[\boldsymbol{C}_{12}-\mathrm{R}_{7}\right]-\mathrm{PKCi}$ disulfide conjugate: $\left.A\right)$ in the linear positive ions mode and $\mathbf{B}$ ) in the reflector positive ions mode (top shows a zoom on the $[\mathrm{M}+\mathrm{H}]^{+}$peak).

Reflector mode mass spectrum:

$\mathrm{m} / \mathrm{z} 3550.7$ (monoprotonated ion of [ $\left.C_{12}-R_{7}\right]-P K C i$, calc. 3551.2).

Fragmentation of the disulfide bond gives ions at $\mathrm{m} / \mathrm{z} 2132.0(\mathrm{PKCi})$ and $\mathrm{m} / \mathrm{z} 1421.9\left(\left[C_{12^{-}}\right.\right.$ $\left.\mathrm{R}_{7}\right]$ ). 
$\left[C_{12-R 9}\right]-P K C i$

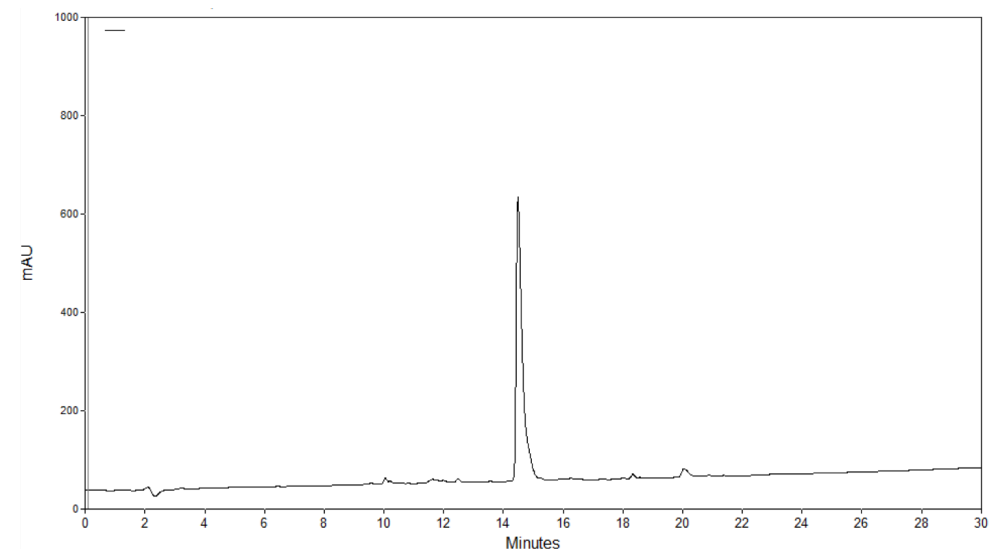

HPLC trace of [ $\left.\boldsymbol{C}_{12}-\mathbf{R}_{9}\right]-P K C i$

Column: Vydac C18 $5 \mu \mathrm{m}, 150 \times 4.6 \mathrm{~mm}$

Gradient: 5-65 \% B in $30 \mathrm{~min}, 1 \mathrm{~mL} / \mathrm{min}$

HPLC: Agilent 1220 Infinity

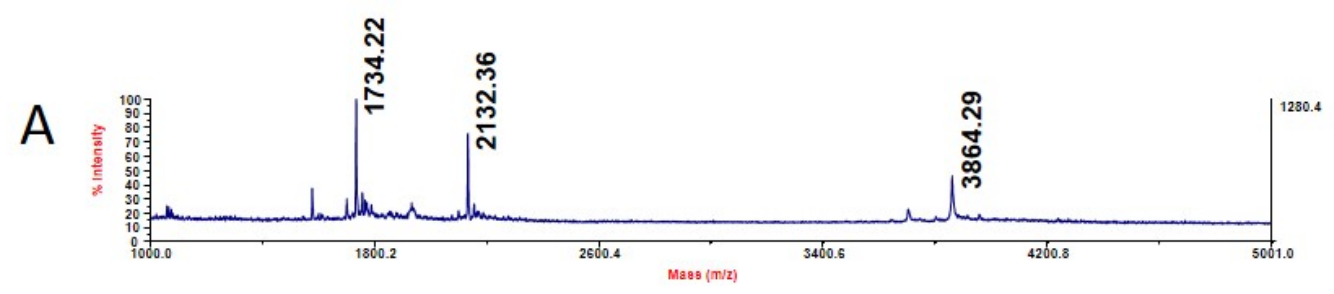

B

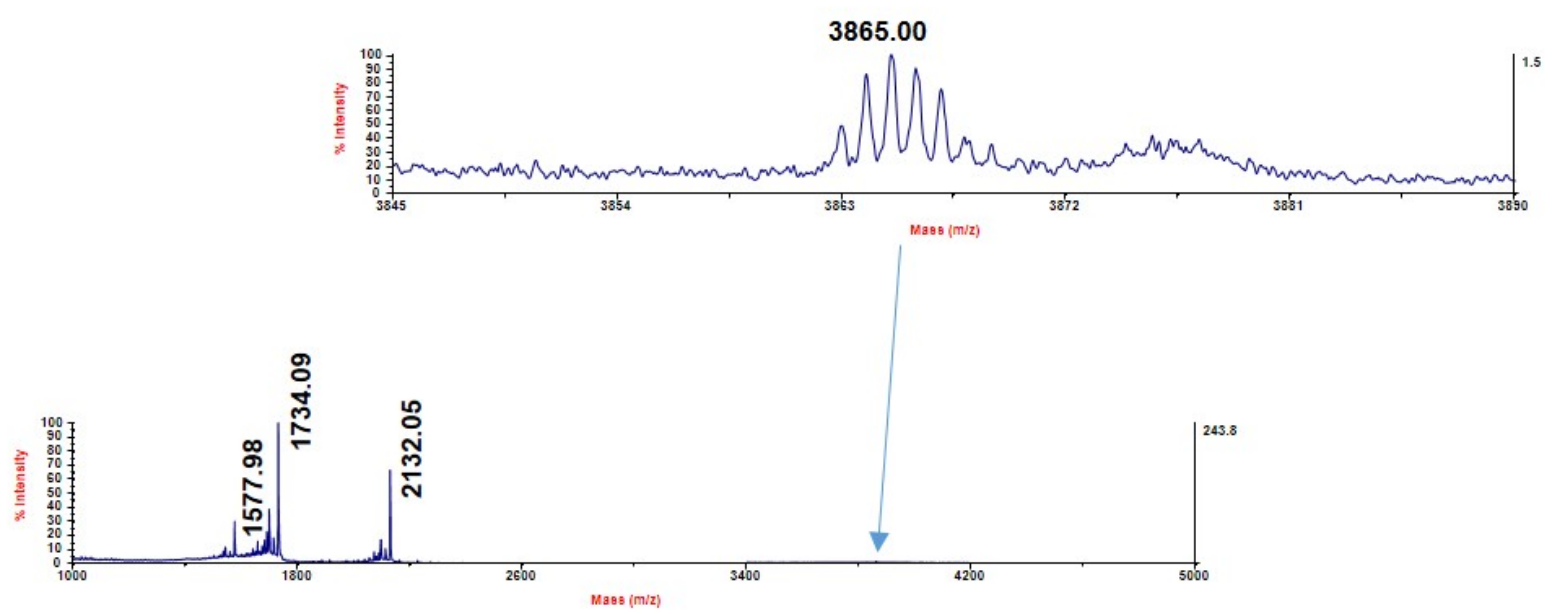

MALDI-TOF MS analysis of the [ $\left.\boldsymbol{C}_{12}-\mathrm{R}_{9}\right]-\mathrm{PKC} \mathrm{i}$ disulfide conjugate: $\left.\mathrm{A}\right)$ in the linear positive ions mode and $\mathbf{B}$ ) in the reflector positive ions mode (top shows a zoom on the $[\mathrm{M}+\mathrm{H}]^{+}$peak).

Reflector mode mass spectrum:

$\mathrm{m} / \mathrm{z} 3865.0$ (monoprotonated ion of $\left[\mathrm{C}_{12}-\mathrm{R}_{9}\right]-\mathrm{PKCi}$, calc. 3864.7)

Fragmentation of the disulfide bond gives ions at $\mathrm{m} / \mathrm{z} 2132.0$ (PKCi) and $\mathrm{m} / \mathrm{z} 1734.1$ ([C $\mathrm{C}_{12^{-}}$ $\left.\mathrm{R}_{9}\right]$ ). 
[FR4]-PKCi

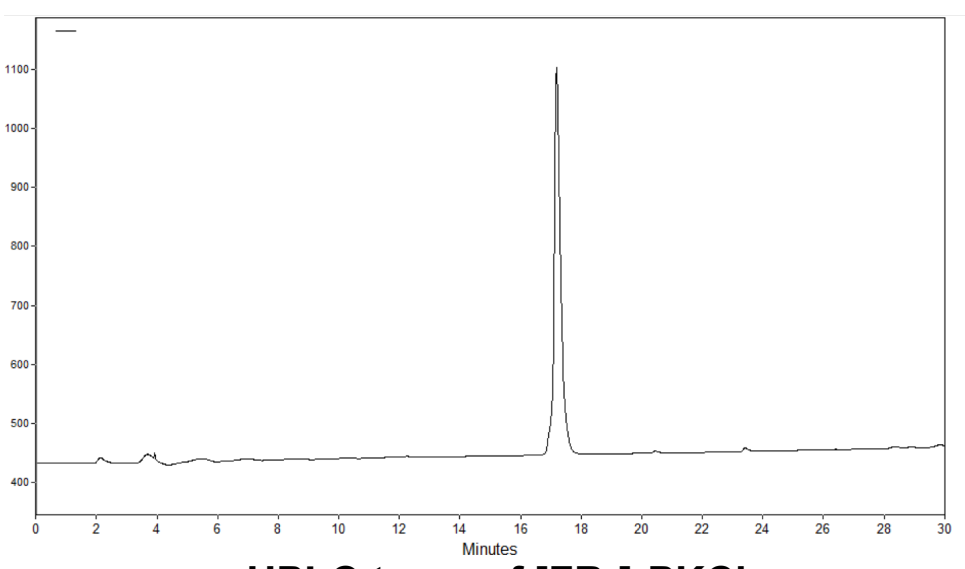

HPLC trace of $\left[\mathrm{FR}_{4}\right]-\mathrm{PKCi}$

Column: Vydac C18 $5 \mu \mathrm{m}, 150 \times 4.6 \mathrm{~mm}$

Gradient: $0-40 \%$ B in $30 \mathrm{~min}, 1 \mathrm{~mL} / \mathrm{min}$

HPLC: Agilent 1220 Infinity

A

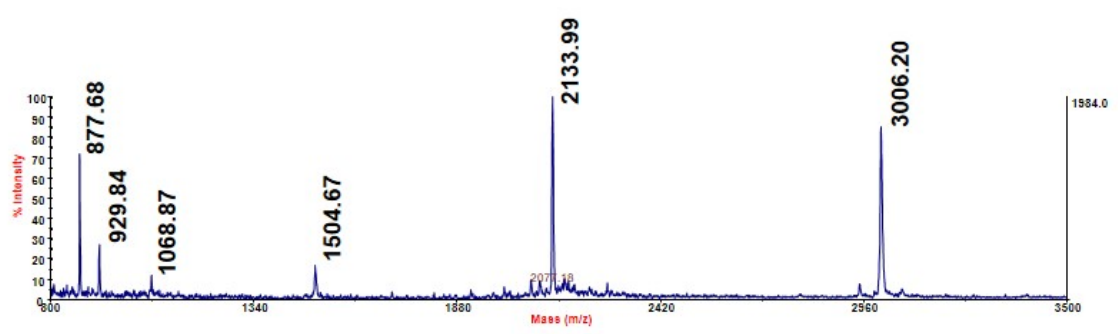

B
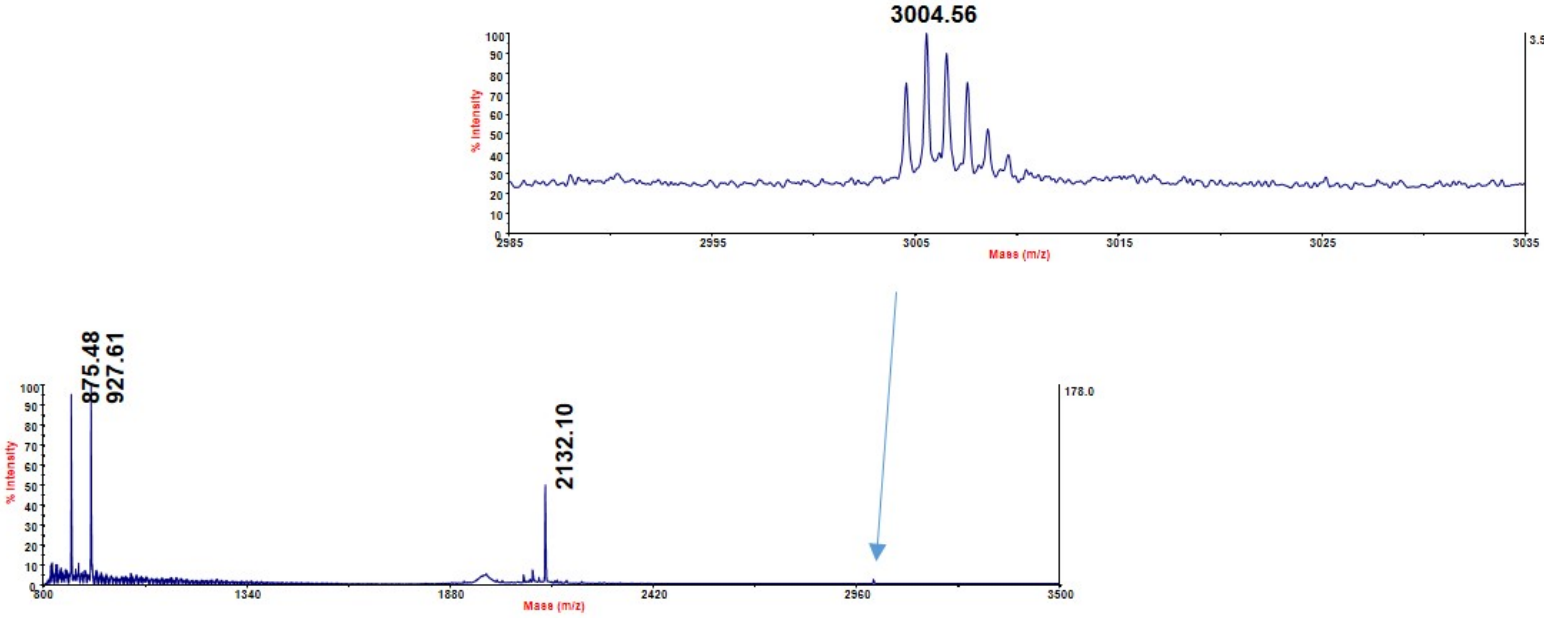

MALDI-TOF MS analysis of the [FR4]-PKCi disulfide conjugate: $A$ ) in the linear positive ions mode and $\mathbf{B}$ ) in the reflector positive ions mode (top shows a zoom on the $[\mathrm{M}+\mathrm{H}]^{+}$ peak).

Reflector mode mass spectrum:

$\mathrm{m} / \mathrm{z} 3004.6$ (monoprotonated ion of [FR4]-PKCi, calc. 3005.6).

Fragmentation of the disulfide bond gives ions at m/z 2132.1 (PKCi) and m/z 875.5 [FR $]$ ]). 
$\left[\mathrm{WR}_{4}\right]-\mathrm{PKCi}$

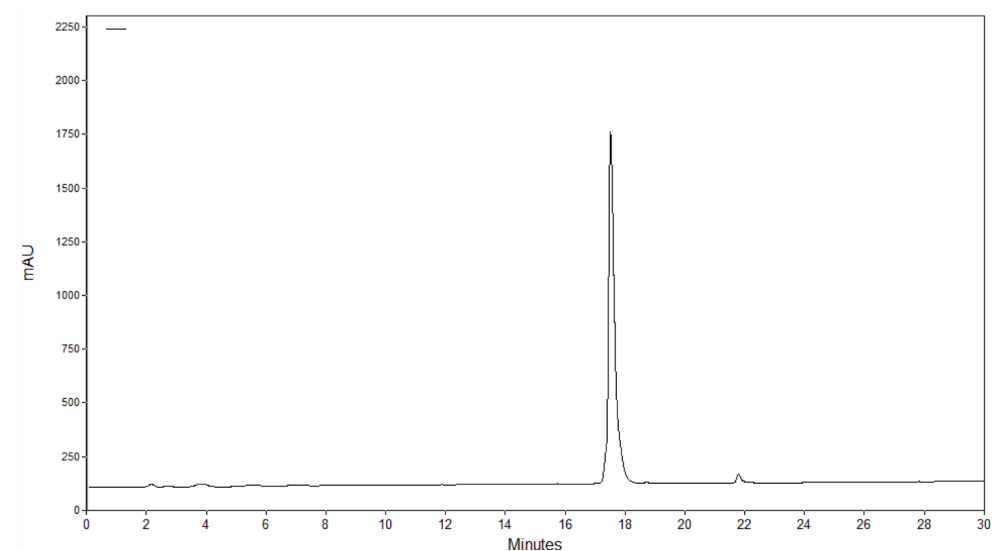

HPLC trace of $\left[W_{4}\right]-P K C i$

Column: Vydac C18 $5 \mu \mathrm{m}, 150 \times 4.6 \mathrm{~mm}$

Gradient: $0-40 \%$ B in $30 \mathrm{~min}, 1 \mathrm{~mL} / \mathrm{min}$

HPLC: Agilent 1220 Infinity

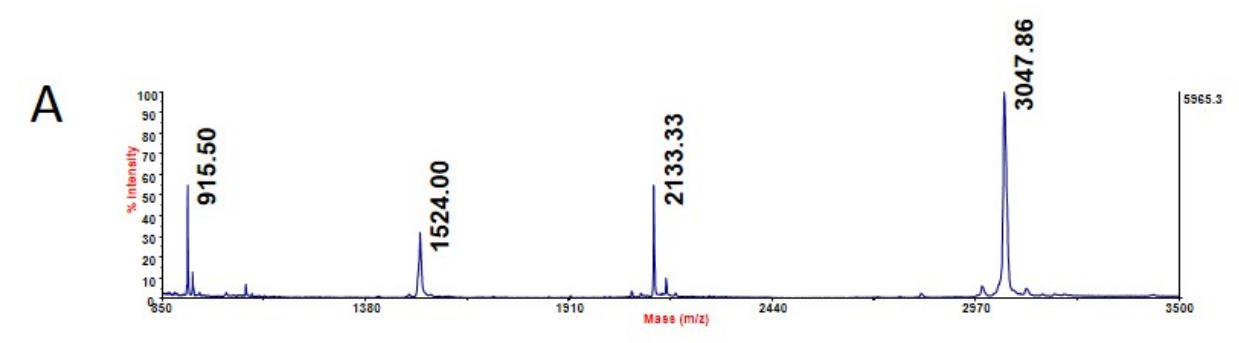

B
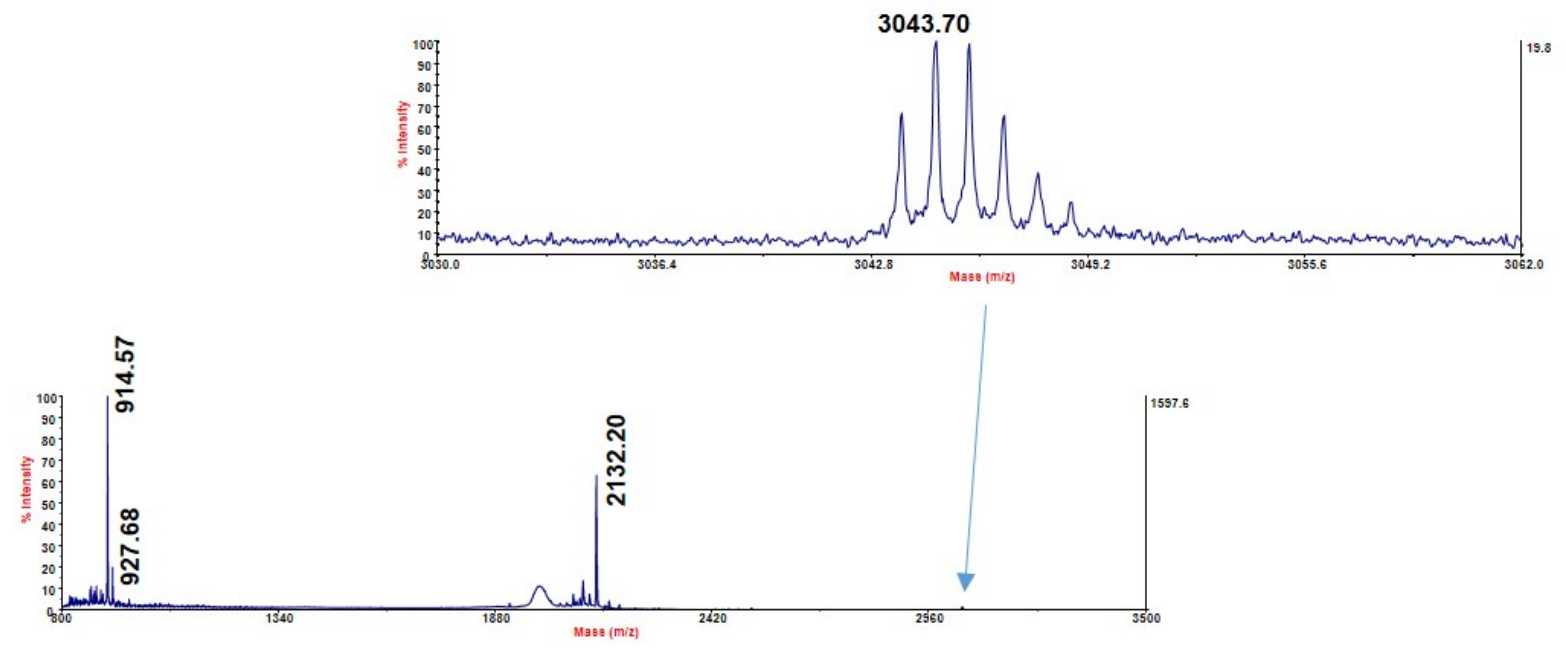

MALDI-TOF MS analysis of the [WR $\mathbf{W R}_{4}-\mathrm{PKCi}$ disulfide conjugate: $\mathrm{A}$ ) in the linear positive ions mode and $\mathbf{B}$ ) in the reflector positive ions mode (top shows a zoom on the $[\mathrm{M}+\mathrm{H}]^{+}$ peak).

Reflector mode mass spectrum:

$\mathrm{m} / \mathrm{z} 3043.7$ (monoprotonated ion of [WR $]$-PKCi, calc. 3044.3).

Fragmentation of the disulfide bond gives ions at m/z 2132.2 (PKCi) and m/z 914.6 [WR 4 ). 
[Tat]-PKCi

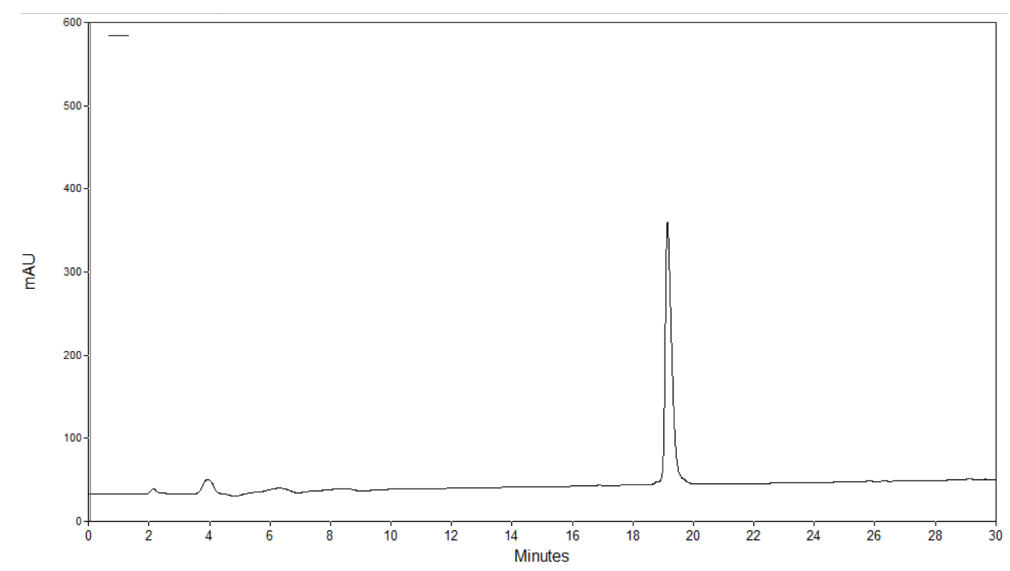

HPLC trace of [Tat]-PKCi

Column: Vydac $\mathrm{C} 185 \mu \mathrm{m}, 150 \times 4.6 \mathrm{~mm}$

Gradient: $0-30 \%$ B in $30 \mathrm{~min}, 1 \mathrm{~mL} / \mathrm{min}$

HPLC: Agilent 1220 Infinity

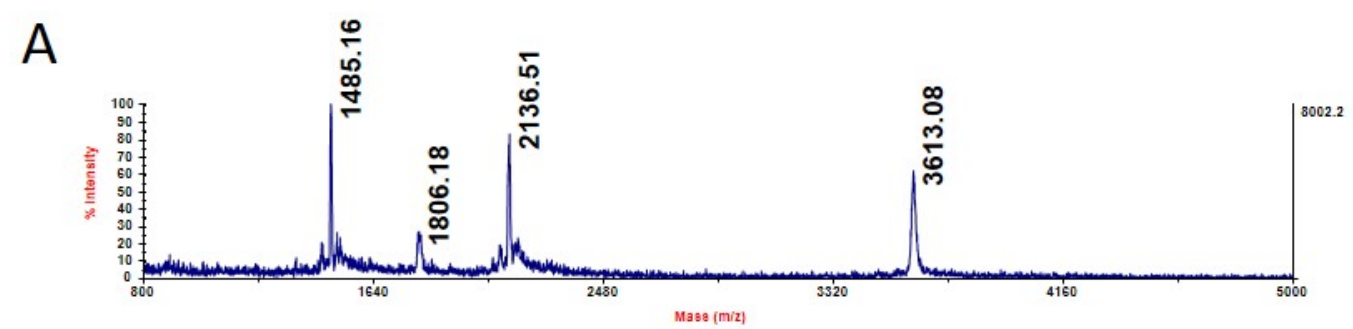

B

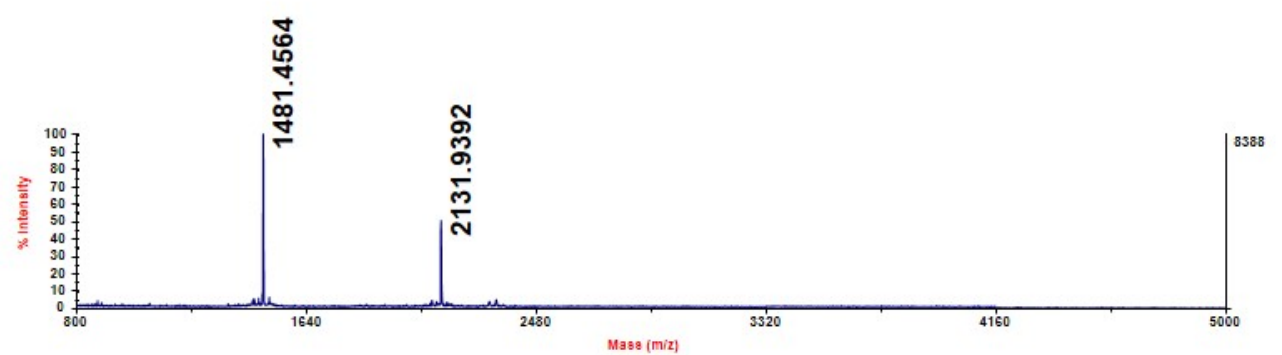

MALDI-TOF MS analysis of the [Tat]-PKCi disulfide: A) in the linear positive ions mode and $\mathbf{B}$ ) in the reflector positive ions mode (the $[\mathrm{M}+\mathrm{H}]^{+}$peak was not detected here). Linear mode mass spectrum:

$\mathrm{m} / \mathrm{z} 3613.1$ (monoprotonated ion of [tat]-PKCi, calc. 3612.3).

Fragmentation of the disulfide bond gives ions at $\mathrm{m} / \mathrm{z} 2136.5$ (PKCi) and $\mathrm{m} / \mathrm{z} 1485.2$ [Tat]). 


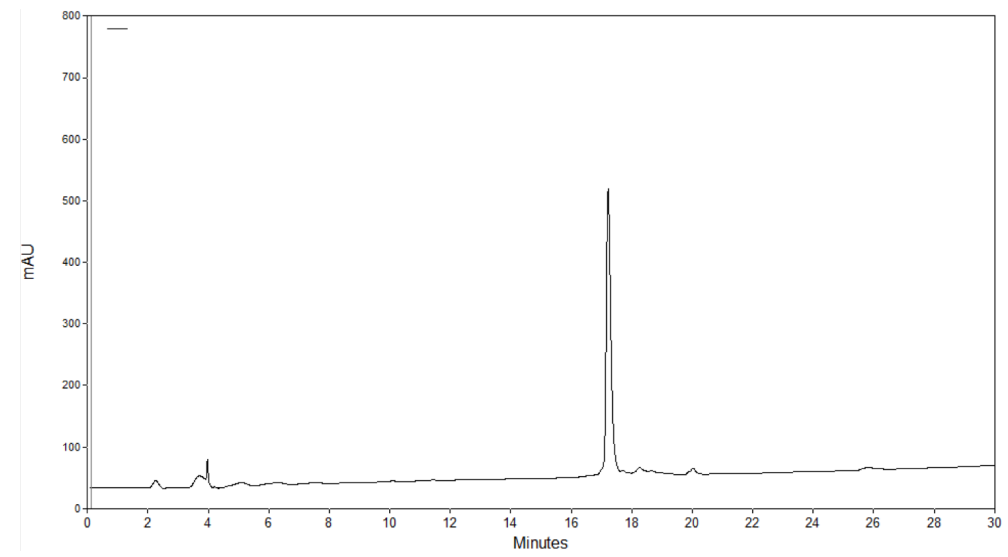

HPLC trace of $\left[\mathbf{R}_{6} \mathbf{W}_{3}\right]-\mathrm{PKC} i$

Column: Vydac C18 $5 \mu \mathrm{m}, 150 \times 4.6 \mathrm{~mm}$

Gradient: 0-50 \% B in $30 \mathrm{~min}, 1 \mathrm{~mL} / \mathrm{min}$

HPLC: Agilent 1220 Infinity

A

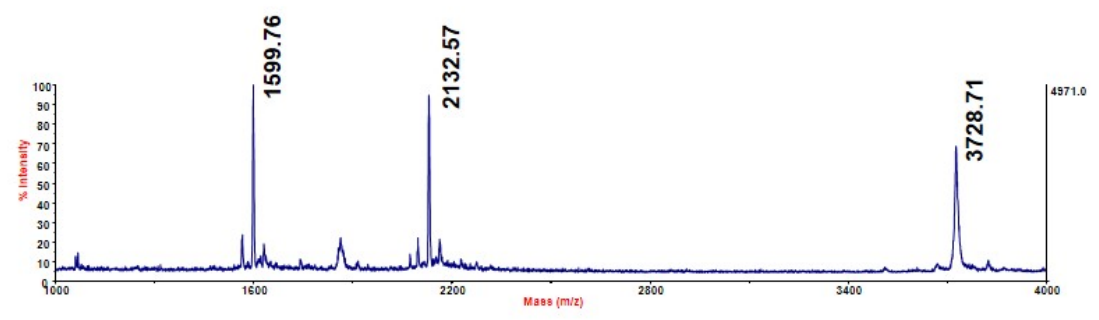

B
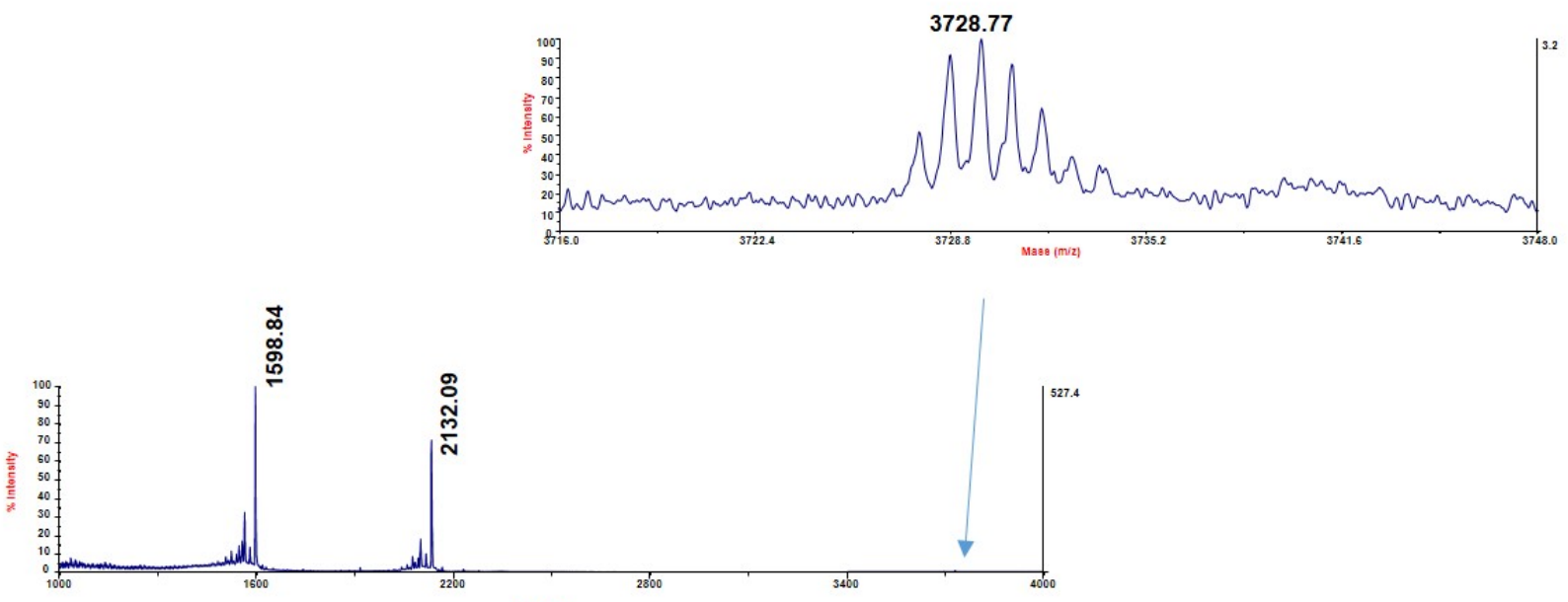

MALDI-TOF MS analysis of the [ $\left.\mathbf{R}_{6} \mathbf{W}_{3}\right]-P K C i$ disulfide conjugate: $\left.A\right)$ in the linear positive ions mode and $\mathbf{B}$ ) in the reflector positive ions mode (top shows a zoom on the $[\mathrm{M}+\mathrm{H}]^{+}$ peak).

Reflector mode mass spectrum:

$\mathrm{m} / \mathrm{z} 3728.8$ (monoprotonated ion of $\left[\mathrm{R}_{6} \mathrm{~W}_{3}\right]-\mathrm{PKCi}$, calc. 3729.4).

Fragmentation of the disulfide bond gives ions at $\mathrm{m} / \mathrm{z} 2132.1$ (PKCi) and $\mathrm{m} / \mathrm{z} 1598.8\left[\mathrm{R}_{6} \mathrm{~W}_{3}\right]$ ). 
[Pen]-PKCi

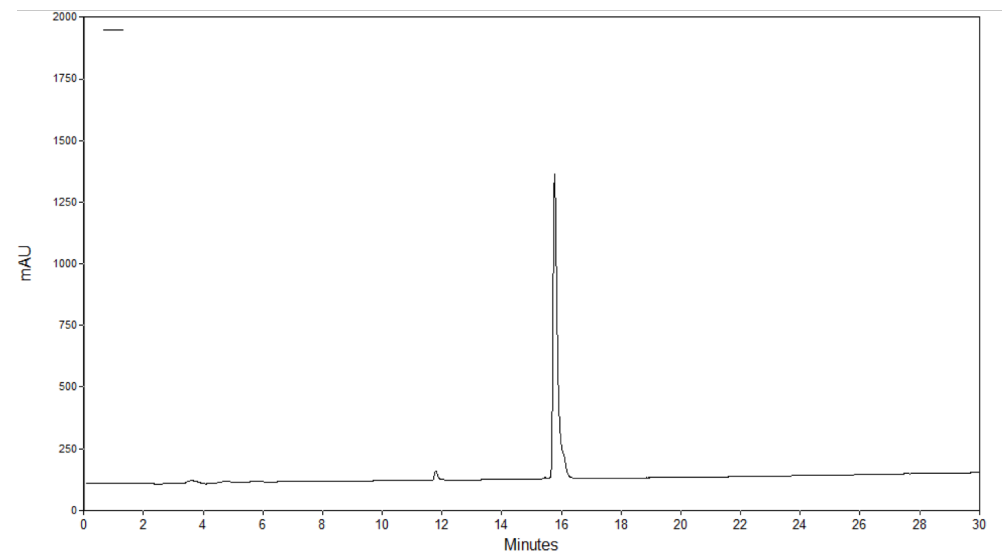

HPLC trace of [Pen]-PKCi

Column: Vydac C18 $5 \mu \mathrm{m}, 150 \times 4.6 \mathrm{~mm}$

Gradient: 0-60 \% B in $30 \mathrm{~min}, 1 \mathrm{~mL} / \mathrm{min}$

HPLC: Agilent 1220 Infinity

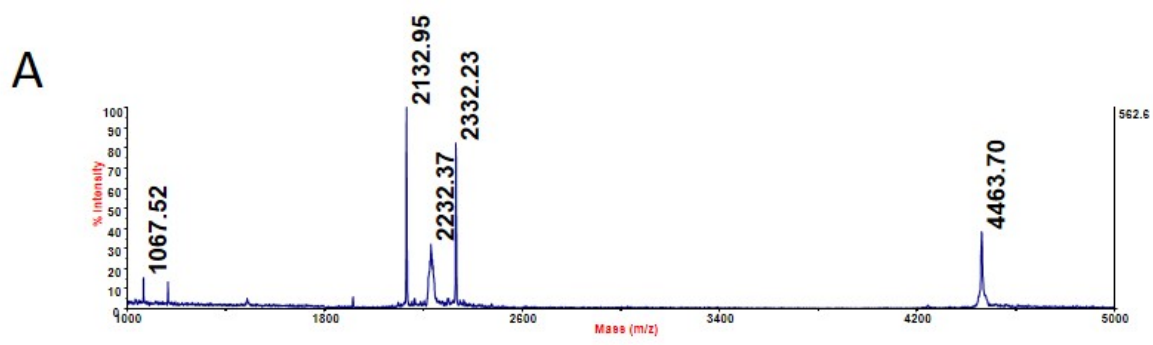

B
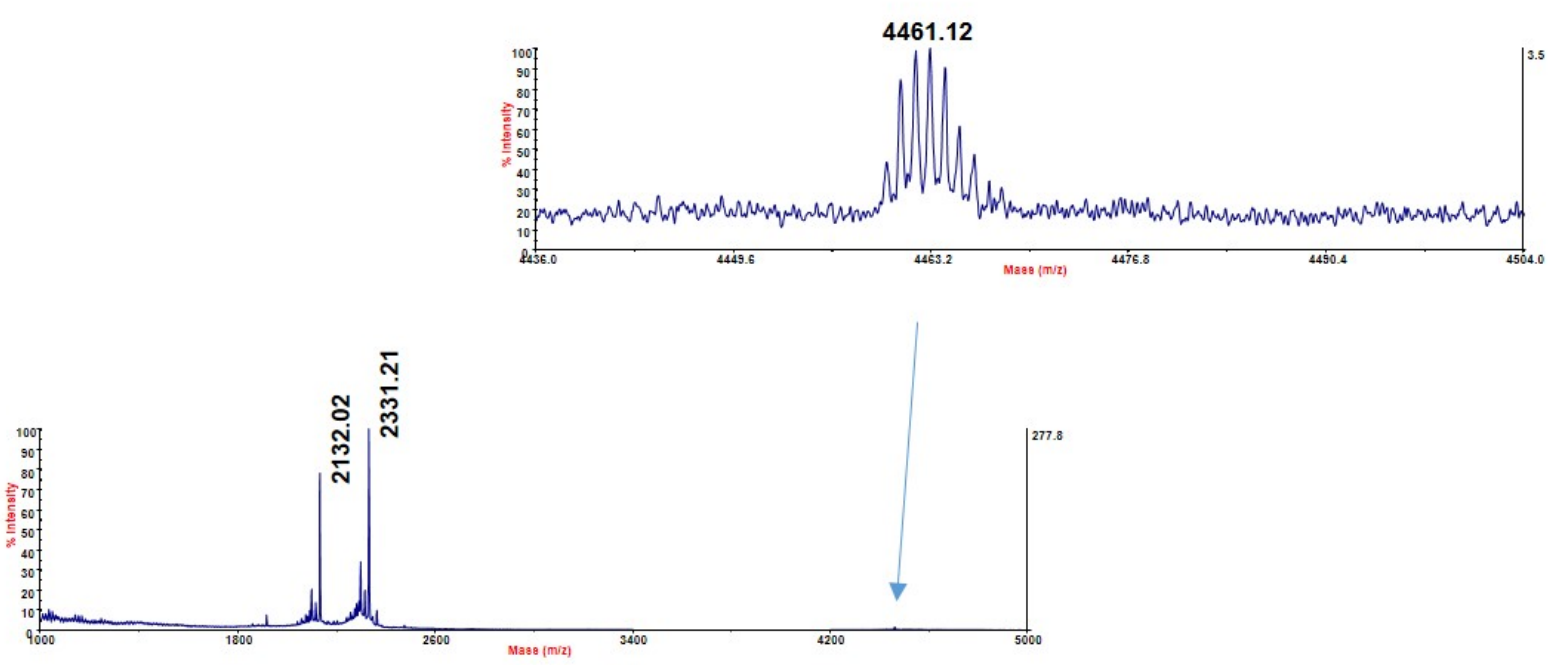

MALDI-TOF MS analysis of the [Pen]-PKCi disulfide conjugate: A) in the linear positive ions mode and $\mathbf{B}$ ) in the reflector positive ions mode (top shows a zoom on the $[\mathrm{M}+\mathrm{H}]^{+}$ peak).

Reflector mode mass spectrum:

$\mathrm{m} / \mathrm{z} 4461.1$ (monoprotonated ion of [Pen]-PKCi, calc. 4461.6).

Fragmentation of the disulfide bond gives ions at $\mathrm{m} / \mathrm{z} 2132.0(\mathrm{PKCi})$ and $\mathrm{m} / \mathrm{z} 2331.2$ [Pen]). 


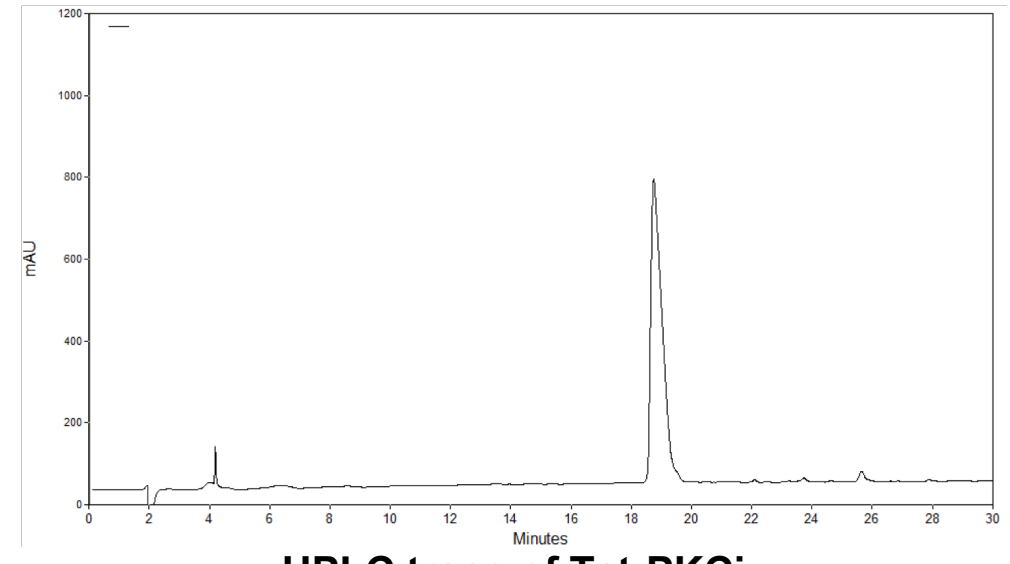

HPLC trace of Tat-PKCi

Column: Vydac C18 $5 \mu \mathrm{m}, 150 \times 4.6 \mathrm{~mm}$

Gradient: 0-30\% B in $30 \mathrm{~min}, 1 \mathrm{~mL} / \mathrm{min}$

HPLC: Agilent 1220 Infinity

A

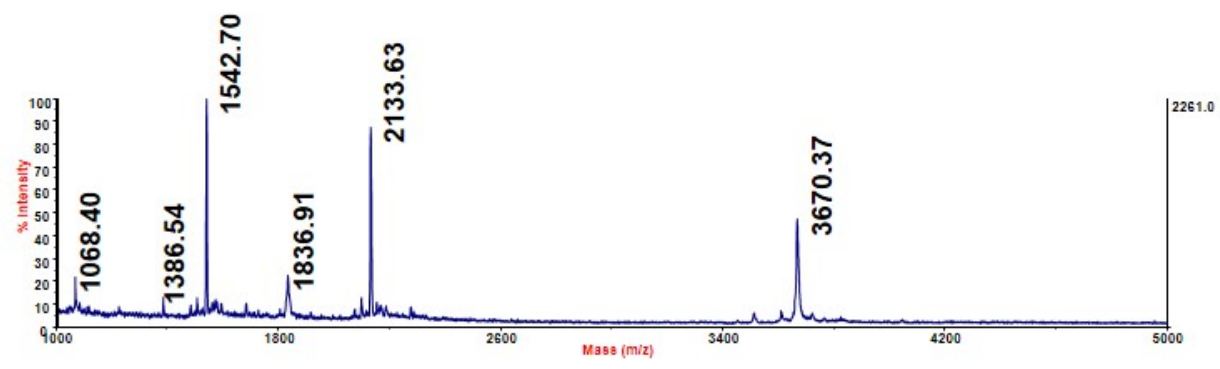

B
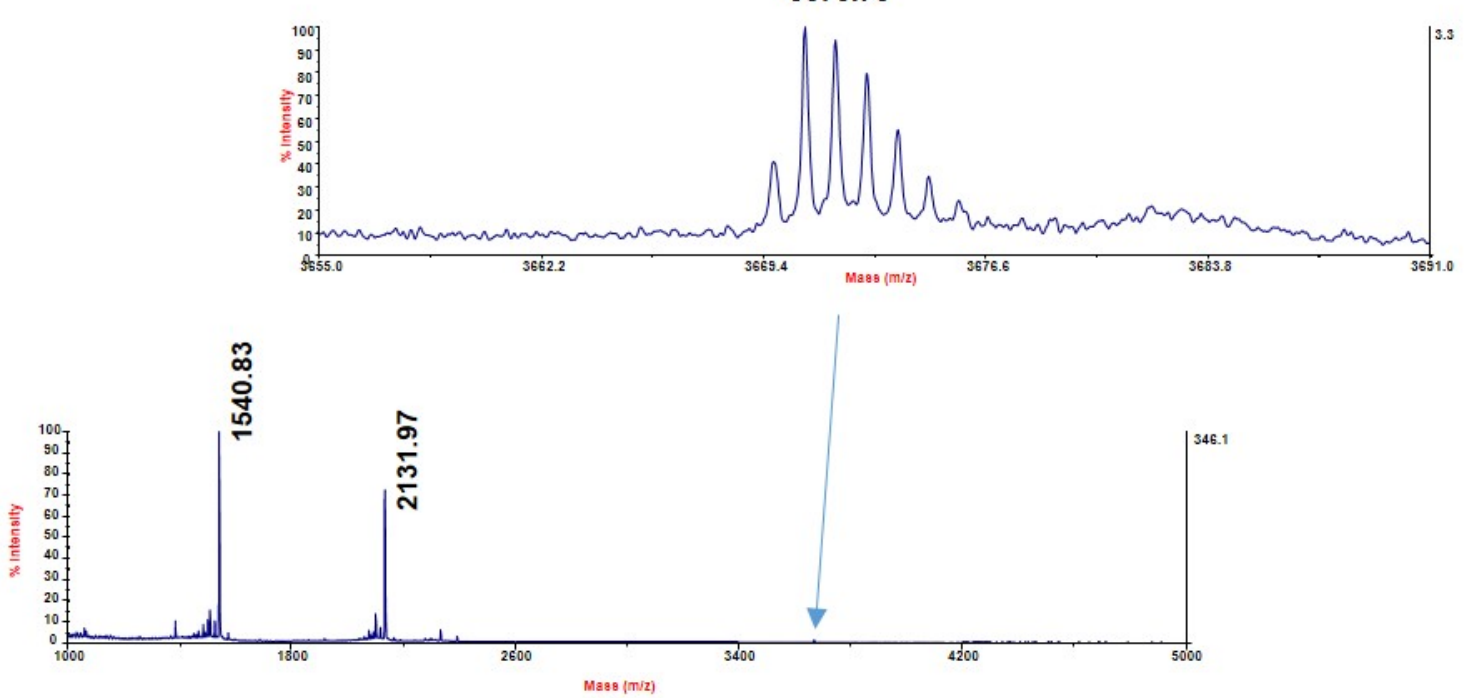

MALDI-TOF MS analysis of the Tat-PKCi disulfide conjugate: A) in the linear positive ions mode and $\mathbf{B}$ ) in the reflector positive ions mode (top shows a zoom on the $[\mathrm{M}+\mathrm{H}]^{+}$ peak).

Reflector mode mass spectrum:

$\mathrm{m} / \mathrm{z} 3670.8$ (monoprotonated ion of Tat-PKCi, calc. 3671.4).

Fragmentation of the disulfide bond gives ions at $\mathrm{m} / \mathrm{z} 2131.9$ (PKCi) and $\mathrm{m} / \mathrm{z} 1540.8$ (Tat). 
$\mathbf{R}_{6} \mathbf{W}_{3}-\mathrm{PKCi}$

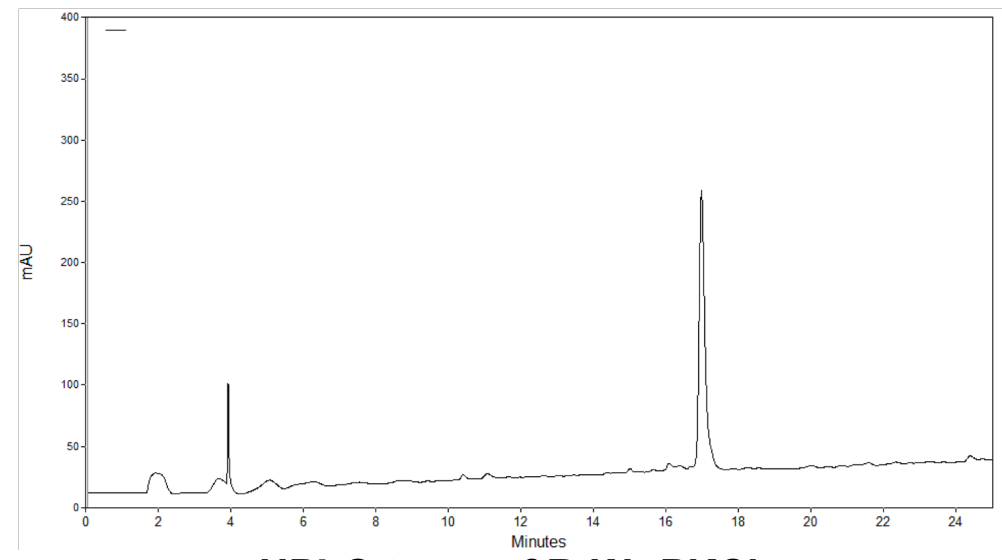

HPLC trace of $\mathbf{R}_{6} \mathbf{W}_{3}-\mathrm{PKCi}$

Column: Vydac C18 $5 \mu \mathrm{m}, 150 \times 4.6 \mathrm{~mm}$

Gradient: $0-50 \%$ B in $30 \mathrm{~min}, 1 \mathrm{~mL} / \mathrm{min}$

HPLC: Agilent 1220 Infinity

A

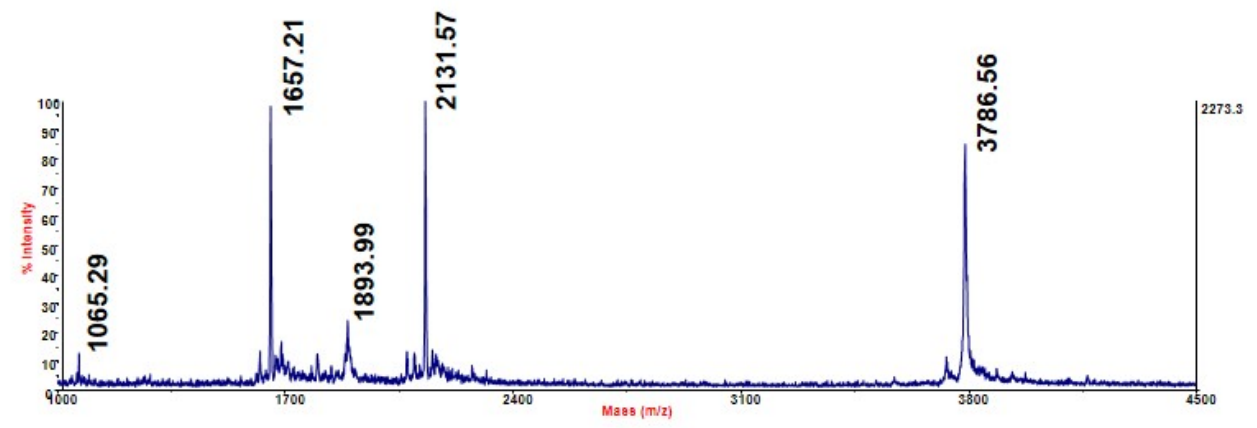

B
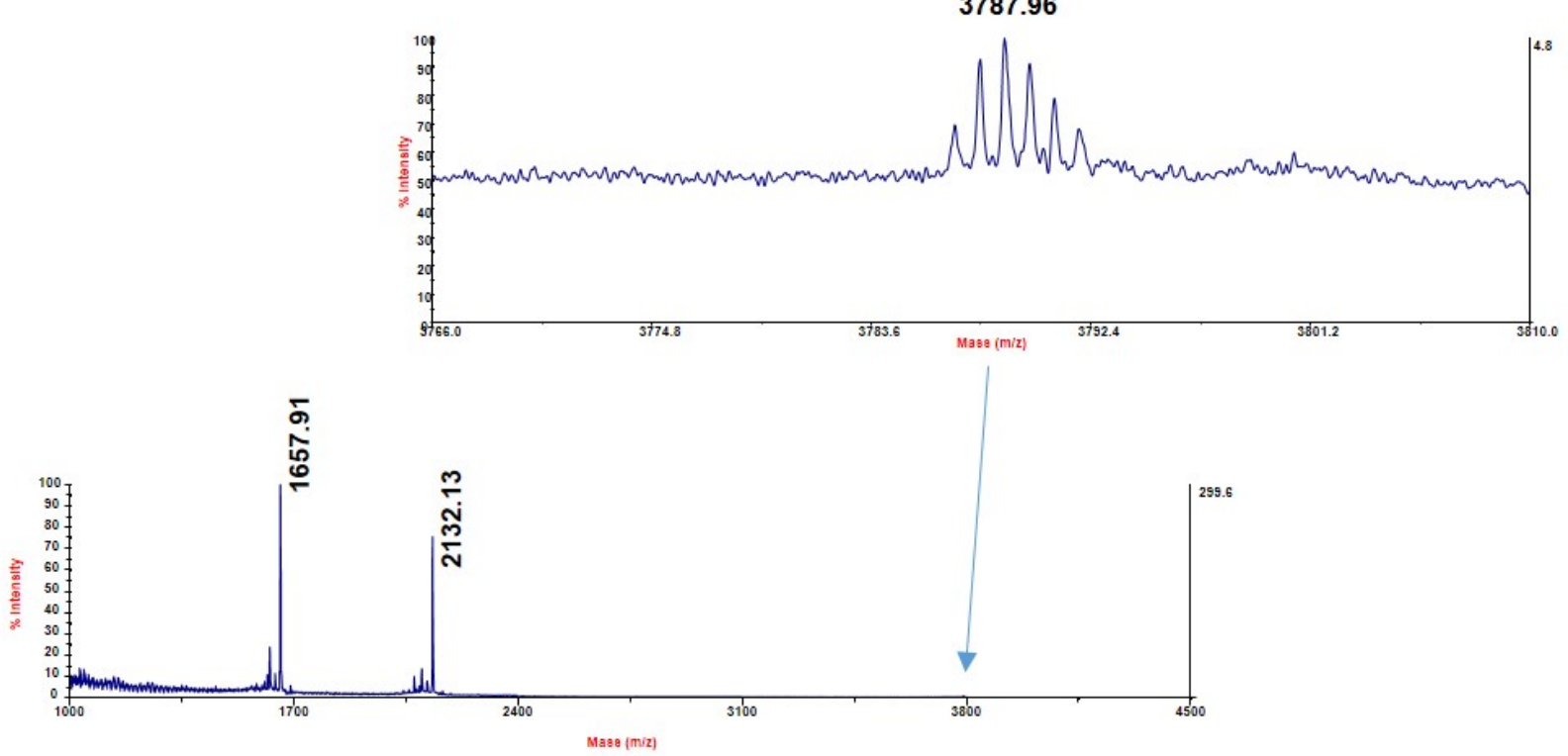

MALDI-TOF MS analysis of the $\mathbf{R}_{6} \mathbf{W}_{\mathbf{3}}-\mathrm{PKCi}$ disulfide conjugate: $\mathbf{A}$ ) in the linear positive ions mode and $\mathbf{B}$ ) in the reflector positive ions mode (top shows a zoom on the $[\mathrm{M}+\mathrm{H}]^{+}$ peak).

Reflector mode mass spectrum:

$\mathrm{m} / \mathrm{z} 3787.9$ (monoprotonated ion of $\mathrm{R}_{6} \mathrm{~W}_{3}-\mathrm{PKCi}$, calc. 3788.5).

Fragmentation of the disulfide bond gives ions at $\mathrm{m} / \mathrm{z} 2132.1$ (PKCi) and $\mathrm{m} / \mathrm{z} 1657.9\left(\mathrm{R}_{6} \mathrm{~W}_{3}\right)$. 
Pen-PKCi

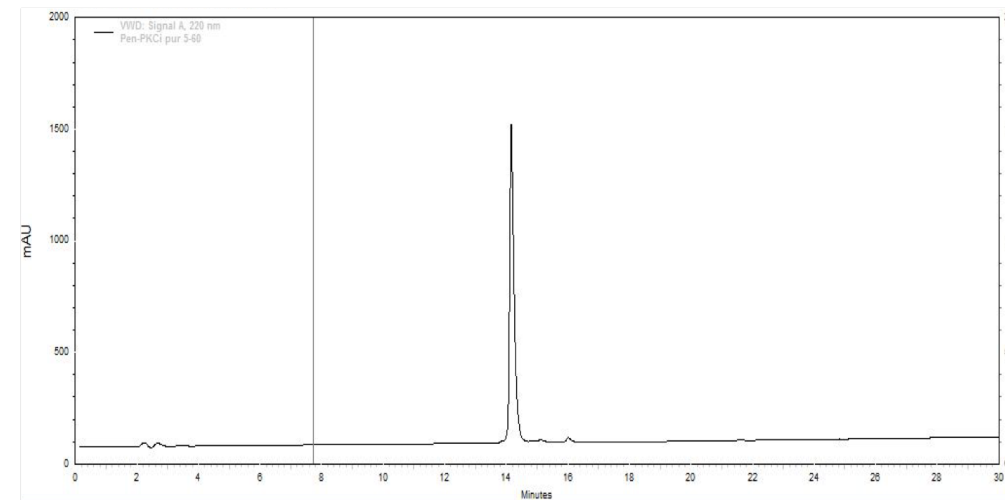

HPLC trace of Pen-PKCi

Column: Vydac C18 $5 \mu \mathrm{m}, 150 \times 4.6 \mathrm{~mm}$

Gradient: $0-60 \%$ B in $30 \mathrm{~min}, 1 \mathrm{~mL} / \mathrm{min}$

HPLC: Agilent 1220 Infinity

A

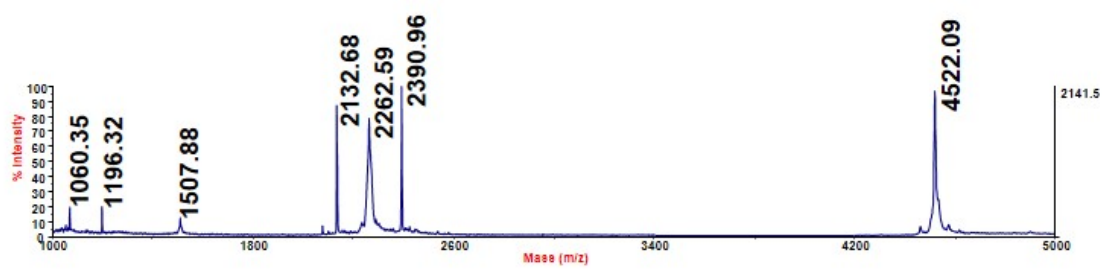

B

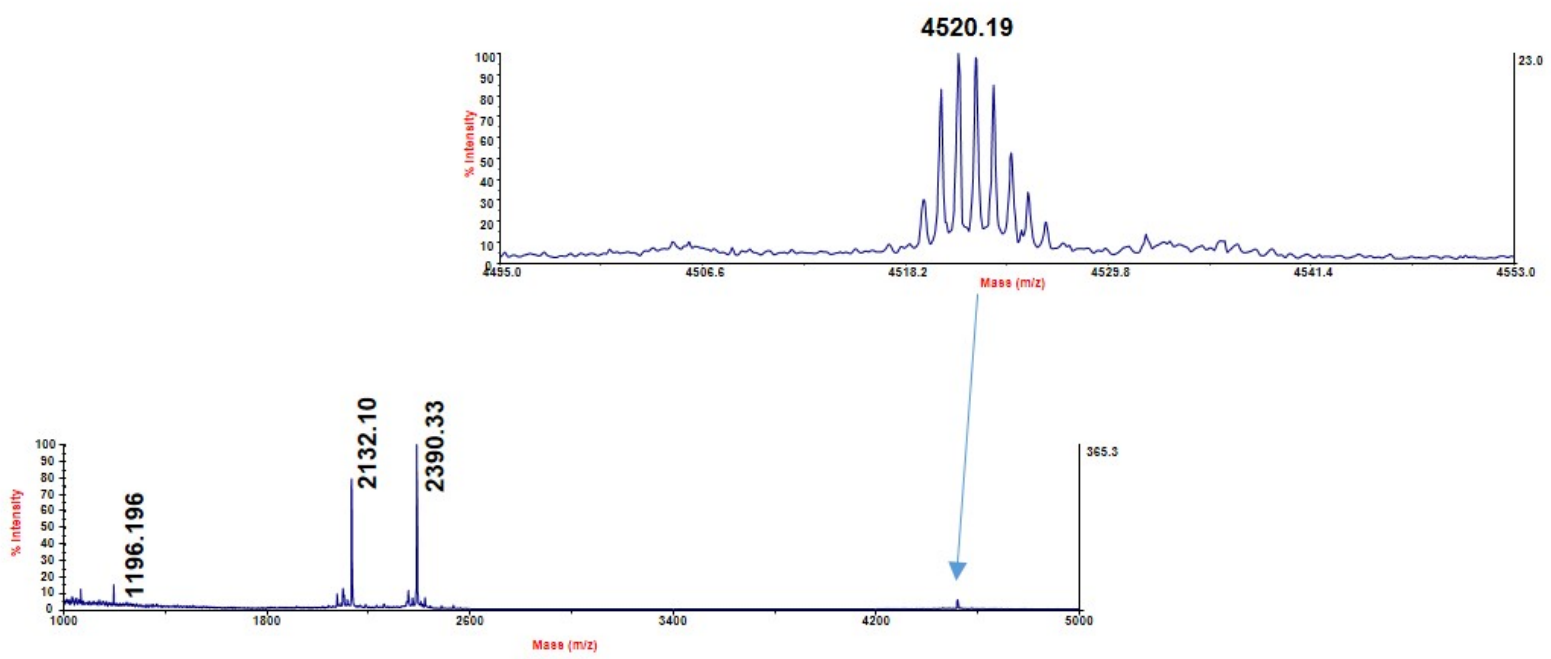

MALDI-TOF MS analysis of the Pen-PKCi disulfide conjugate: A) in the linear positive ions mode and $B$ ) in the reflector positive ions mode (top shows a zoom on the $[\mathrm{M}+\mathrm{H}]^{+}$ peak).

Reflector mode mass spectrum:

$\mathrm{m} / \mathrm{z} 4520.2$ (monoprotonated ion of Pen-PKCi, calc. 4521.4).

Fragmentation of the disulfide bond gives ions at $\mathrm{m} / \mathrm{z} 2132.1$ (PKCi) and $\mathrm{m} / \mathrm{z} 2390.3$ (Pen). 


\section{Cell culture and cell viability assays}

$\mathrm{CHO}$ cells were cultured in sterile conditions in DMEM/F-12 medium supplemented with 10 $\%$ heat-inactivated FBS in a humidified atmosphere of $5 \% \mathrm{CO}_{2}$, at $37^{\circ} \mathrm{C}$. Cell viability was evaluated using the Cell Counting Kit-8 (CCK-8). Cells were seeded in 96-well plates to obtain 5000 cells/well the day of the cell viability experiment. Cells were incubated for 75 min at $37^{\circ} \mathrm{C}$ with $100 \mu \mathrm{L}$ of the conjugate solution (7.5 $\mu \mathrm{M}$ in DMEM) and for the control experiment with $100 \mu \mathrm{L}$ of DMEM. The supernatant was removed and $100 \mu \mathrm{L}$ of CCK8 (10 $\%$ in DMEM) was added. After $2 \mathrm{~h}$ incubation at $37^{\circ} \mathrm{C}$, the absorbance was measured at $450 \mathrm{~nm}$ using a microplate reader (FLUOstar OPTIMA, BMG LABTECH) with a reference wavelength at $620 \mathrm{~nm}$. The experiments were performed in triplicates and repeated twice independently. For each conjugate, the percentage of viable cells compared to the control conditions (no conjugate) was calculated. Mean values +/- SEM are given in the histogram.

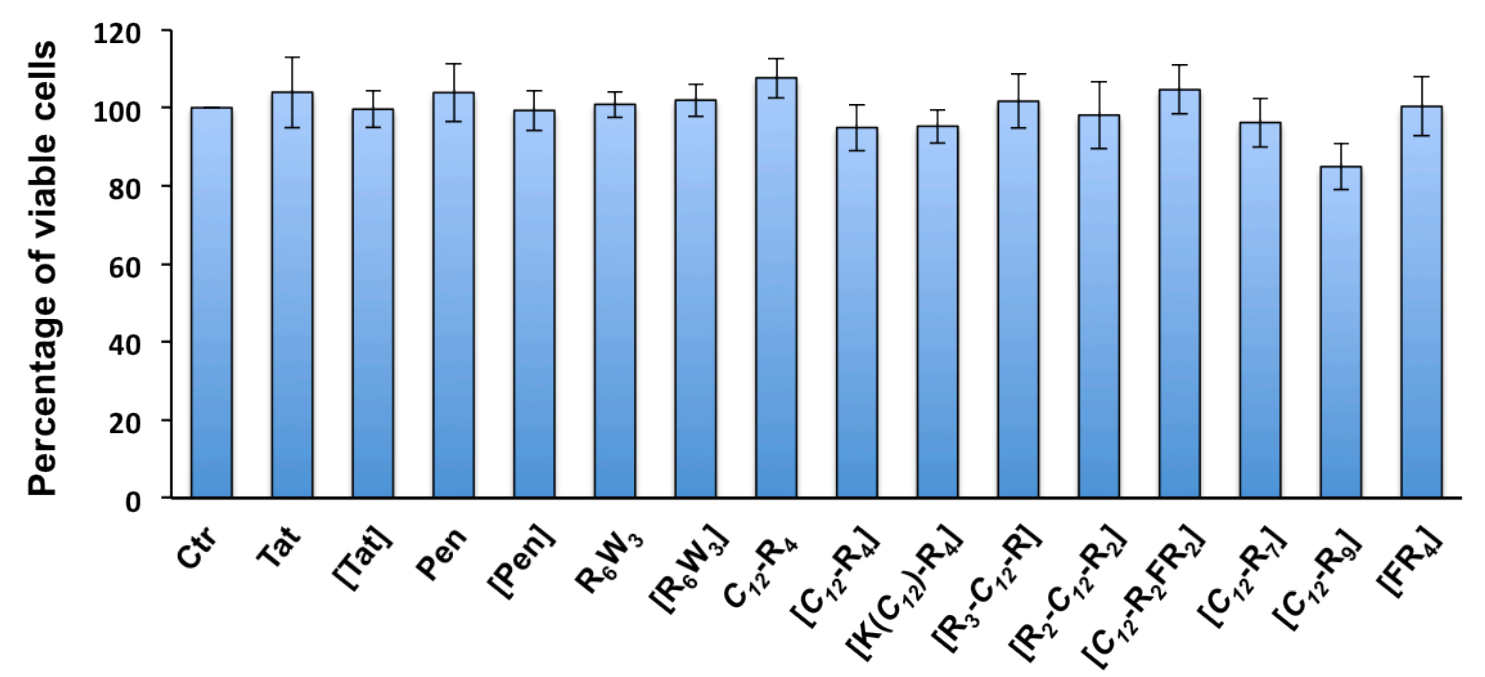

Figure S5. Viability of cells incubated with the different CPP-PKCi conjugates (Ctr $=$ control, no conjugate added to the cells)

\section{Quantification of the internalised cargo by MALDI-TOF MS}

CHO-K1 cells (named in the manuscript WT cells) or CHO-pgsA745 (GAG ${ }^{\text {neg }}$ cells) were seeded in sterile conditions in 12-well plates $24 \mathrm{~h}$ before the internalisation experiment. Internalisation experiments were performed on confluent cells $\left(10^{6} \mathrm{cells} /\right.$ well). Cells were incubated with the free ${ }^{1} \mathrm{H}-\mathrm{PKCi}$ peptide (no carrier) or with the ${ }^{1} \mathrm{H}-\mathrm{PKCi}-\mathrm{CPP}$ conjugates $\left(7.5 \mu \mathrm{M}\right.$ in DMEM, $500 \mu \mathrm{L}$ ) for $75 \mathrm{~min}$ at $37^{\circ} \mathrm{C}$ (temperature allowing conjugate entry by endocytosis and direct translocation) or at $4{ }^{\circ} \mathrm{C}$ (temperature allowing internalisation only by direct translocation).

\section{Elimination of the membrane-bound peptide:}

After incubation, cells were washed 3 times with $1 \mathrm{~mL} \mathrm{HBSS}$, treated for 3 min at rt with 200 $\mu \mathrm{L}$ TCEP $(2 \mathrm{mM}$ in $50 \mathrm{mM}$ Tris-HCl buffer $\mathrm{pH} 7.5)$ to reduce all cell-surface disulfide conjugates and washed again once with $1 \mathrm{~mL}$ HBSS.

- When internalisation experiments had been performed at $37^{\circ} \mathrm{C}$ : membrane-bound peptide was eliminated by cell treatment for $5 \mathrm{~min}$ at $37^{\circ} \mathrm{C}$ with $500 \mu \mathrm{L}$ trypsin-EDTA. Trypsin inhibitor $(100 \mu \mathrm{L}, 5 \mathrm{mg} / \mathrm{mL})$ and $\mathrm{BSA}(100 \mu \mathrm{L}, 1 \mathrm{mg} / \mathrm{mL})$ were then added and the cell suspension was transferred to a micro-tube. 
- When internalisation experiments had been performed at $4^{\circ} \mathrm{C}$ : membrane-bound peptide was eliminated by cell treatment for $10 \mathrm{~min}$ with pronase $(0.5 \mathrm{mg} / \mathrm{mL}$ in $100 \mathrm{mM}$ Tris- $\mathrm{HCl} \mathrm{pH}$ 7.5). A cocktail of protease inhibitors $(100 \mu \mathrm{L}$ of a $7 x$ solution of Complete mini, Roche) and BSA $(100 \mu \mathrm{L}, 1 \mathrm{mg} / \mathrm{mL})$ were then added and the cell suspension was transferred to a microtube.

In both cases, wells were washed with $500 \mu \mathrm{L}$ of $50 \mathrm{mM}$ Tris- $\mathrm{HCl}$ buffer $(\mathrm{pH} 7.5)$. The combined suspensions were centrifuged for 2 min at $640 \mathrm{~g}$. The pellet was washed with 1 $\mathrm{mL} 50 \mathrm{mM}$ Tris- $\mathrm{HCl} \mathrm{pH} 7.5,0.1 \% \mathrm{BSA}$ (buffer $\mathrm{A}$ ) and centrifuged again in the same conditions.

\section{Cell lysis and extraction of the biotinylated peptide:}

The cell pellet was mixed with a known amount of ${ }^{2} \mathrm{H}-\mathrm{PKCi}$ internal standard (typically between 0.1 to $10 \mathrm{pmol}$ ) and $150 \mu \mathrm{L}$ of a solution containing $0.3 \%$ Triton $\mathrm{X}-100,1 \mathrm{M} \mathrm{NaCl}$, $2 \mathrm{mM}$ DTT. The mixture was immediately heated for $15 \mathrm{~min}$ at $100{ }^{\circ} \mathrm{C}$. The lysate was centrifuged for $5 \mathrm{~min}$ at $7080 \mathrm{~g}$. The supernatant was mixed with $850 \mu \mathrm{L}$ of buffer $A$

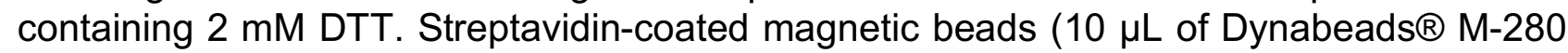
Streptavidin, Invitrogen) were added to the sample and the mixture was incubated for $1 \mathrm{~h}$ at $\mathrm{rt}$ to capture the biotinylated peptides (intact ${ }^{1} \mathrm{H}$ and ${ }^{2} \mathrm{H}-\mathrm{PKCi}$ and potential digests). After bead immobilisation with a magnet, the supernatant was removed and beads were washed twice with $200 \mu \mathrm{L}$ buffer $A$, they were incubated 10 min at $50{ }^{\circ} \mathrm{C}$ with $20 \mu \mathrm{L}$ Laemmli buffer $(\mathrm{d} 10)^{*}$, then washed twice with $200 \mu \mathrm{L}$ buffer A containing $1 \mathrm{M} \mathrm{NaCl}$, twice with $200 \mu \mathrm{L} \mathrm{H}_{2} \mathrm{O}$, incubated 2 min with $50 \mu \mathrm{L}$ biotin $\left(10 \mu \mathrm{M}\right.$ in $\left.\mathrm{H}_{2} \mathrm{O}\right)$, washed with $50 \mu \mathrm{L} \mathrm{H}_{2} \mathrm{O}$ and finally $50 \mu \mathrm{L}$ $\mathrm{CH}_{3} \mathrm{CN} / \mathrm{H}_{2} \mathrm{O}$ (1:1). The supernatant was removed and $3 \mu \mathrm{L}$ of matrix (saturated solution of $\mathrm{CHCA}$ in $\left.\mathrm{CH}_{3} \mathrm{CN} / \mathrm{H}_{2} \mathrm{O} / \mathrm{TFA}, 50: 50: 0.1\right)$ was added. The beads were incubated $10 \mathrm{~min}$ at $\mathrm{rt}$ to elute the biotinylated peptides and $1 \mu \mathrm{L}$ of the supernatant was deposited on the MALDITOF plate.

*Diluted (d10) Laemmli buffer composition: $1 \%$ SDS, 6 \% glycerol, $1 \%$ ß-mercaptoethanol, $0.025 \%$ bromophenol blue, $25 \mathrm{mM}$ Tris- $\mathrm{HCl}, \mathrm{pH} 6.8$.

\section{MALDI-TOF MS analysis:}

MALDI-TOF MS analyses were performed in the ion positive reflector mode on an $A B I$ Voyager DE-Pro MALDI-TOF mass spectrometer (Applied Biosystems). On the MALDI-TOF mass spectrum corresponding to the average of several hundreds laser shots, the area of the $[\mathrm{M}+\mathrm{H}]^{+}$signals (including all isotopes) of the ${ }^{1} \mathrm{H}-\mathrm{PKCi}$ and ${ }^{2} \mathrm{H}-\mathrm{PKCi}$ signals were measured and the amount of intact internalised cargo was calculated from the area ratio. All internalisation experiments were performed in triplicates and repeated at least twice independently.

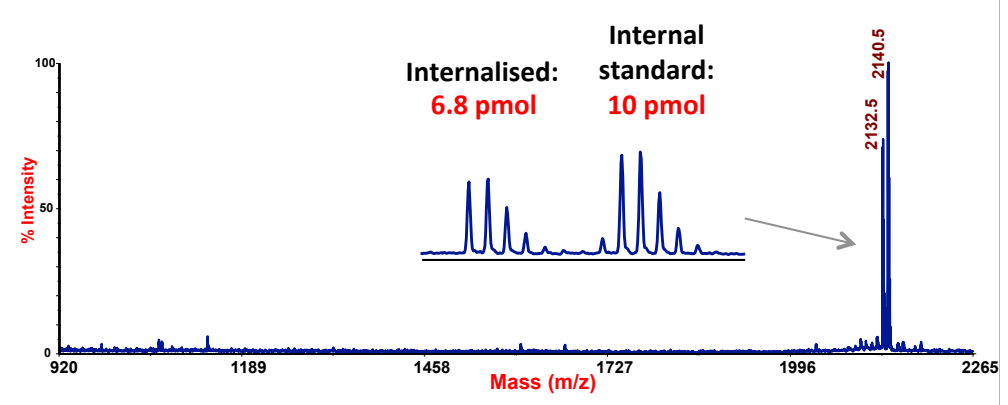

Figure S6. Mass spectrum obtained for the cellular uptake of $\left[\mathbf{R}_{6} \mathbf{W}_{3}\right]-P K C i$ conjugate at $37^{\circ} \mathrm{C}$ in $\mathrm{CHO}-\mathrm{K} 1$ cells. Insert: zoom on the intact internalised cargo $\left({ }^{1} \mathrm{H}-\mathrm{PKCi}\right)$ and the internal standard $\left({ }^{2} \mathrm{H}-\mathrm{PKCi}\right)$ peaks, which are used for quantification. 


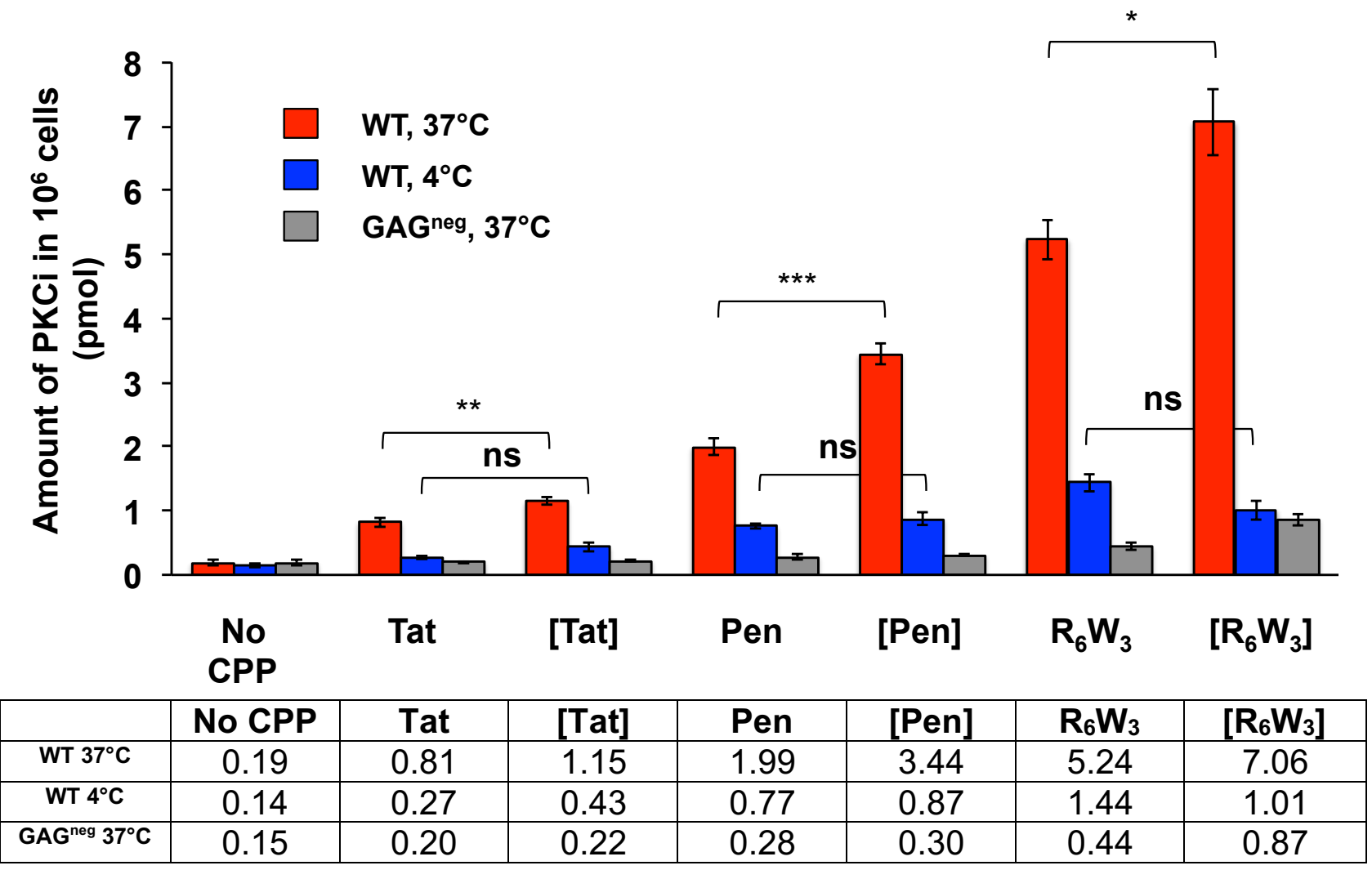

Figure S7. Amount of intact PKCi cargo delivered inside cells by the linear classical CPPs and their cyclic derivatives. The cyclic derivatives are marked under square brackets. Conjugates CPP-PKCi $(7.5 \mu \mathrm{M})$ or unconjugated PKCi (No CPP) were incubated with $10^{6}$ WT (CHO-K1) or GAG neg $(\mathrm{CHO} 745)$ cells for $75 \mathrm{~min}$ at $4^{\circ} \mathrm{C}$ or $37^{\circ} \mathrm{C}$. Mean values + - SEM are given in the histogram. Mean values are also shown in the table just below the histogram (pmol for $10^{6}$ cells).

Significance was tested using a Welch's corrected t test ( ${ }^{n s} p>0.05,{ }^{*} 0.05<p>0.01$, ${ }^{* *}$ $0.01<p>0.001,{ }^{* * *} p<0.001$ )

Table S4. Effect of cyclisation on the efficiency of endocytosis, translocation and GAGdependent entry

\begin{tabular}{|c|c|c|c|c|c|c|}
\hline $\begin{array}{c}\text { Route of } \\
\text { internalisation }\end{array}$ & Tat & [Tat] & Pen & [Pen] & $\mathbf{R}_{6} \mathbf{W}_{3}$ & {$\left[R_{6} W_{3}\right]$} \\
\hline Endocytosis $^{1}$ & 0.54 & 0.72 & 1.22 & 2.57 & 3.8 & 6.05 \\
\hline Translocation $^{2}$ & 0.27 & 0.43 & 0.77 & 0.87 & 1.44 & 1.01 \\
\hline $\begin{array}{c}\text { GAG-dependent } \\
\text { entry }^{3}\end{array}$ & 0.61 & 0.93 & 1.71 & 3.14 & 4.8 & 6.19 \\
\hline
\end{tabular}

${ }^{1}$ The efficiency of endocytosis was estimated by subtracting the amount of intact PKCi cargo (pmol) delivered in $10^{6} \mathrm{WT}$ cells at $4^{\circ} \mathrm{C}$ from the values obtained in WT cells at $37^{\circ} \mathrm{C}$.

${ }^{2}$ The efficiency of translocation is directly given by the amount of intact PKCi cargo measured in WT cells at $4^{\circ} \mathrm{C}$.

${ }^{3}$ The efficiency of GAG-dependent entry was estimated by subtracting the amount of intact PKCi cargo (pmol) delivered in $10^{6} \mathrm{GAG}^{\text {neg }}$ cells at $37^{\circ} \mathrm{C}$ from the values obtained in WT cells at $37^{\circ} \mathrm{C}$. 


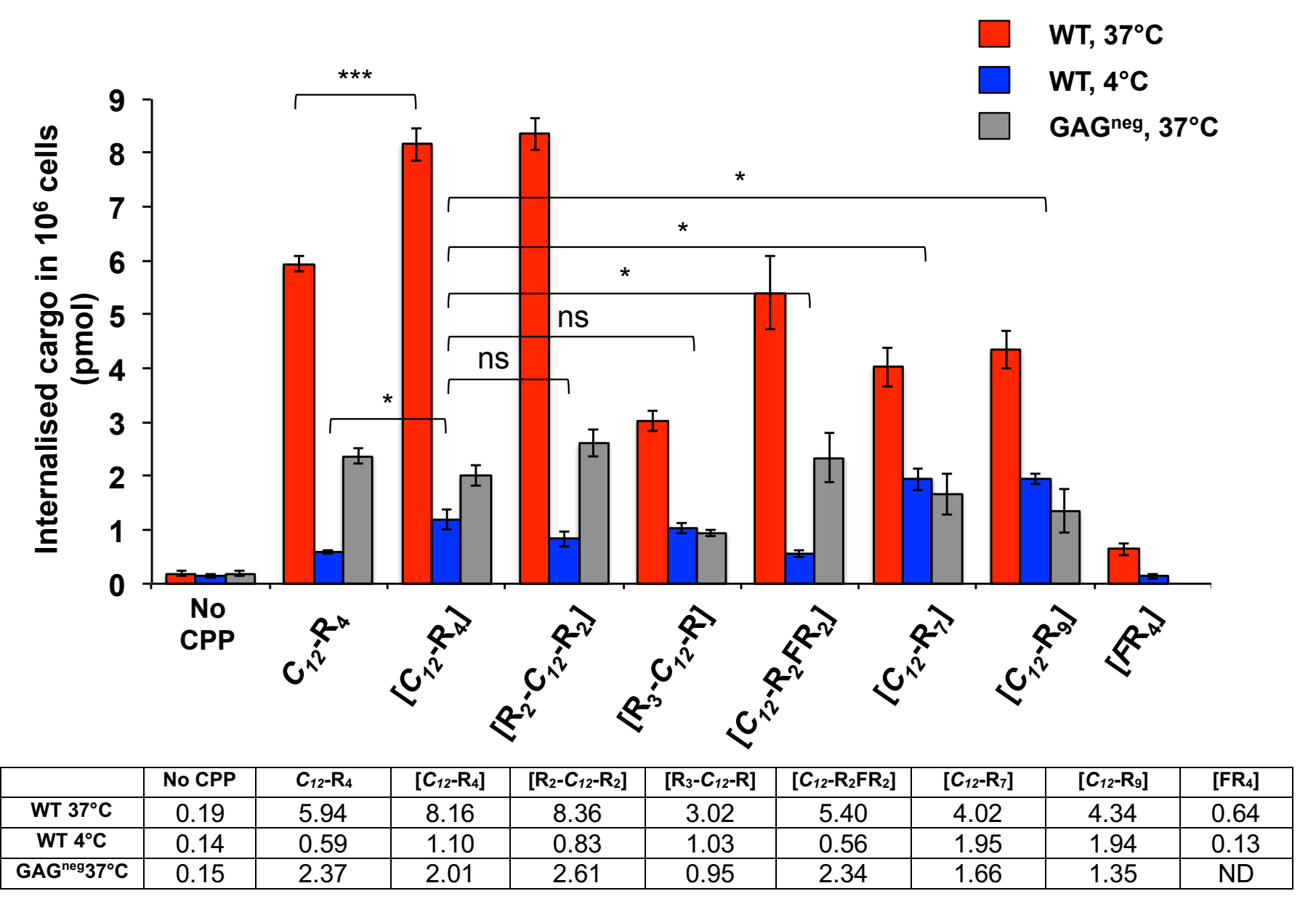

Figure S8. Amount of intact PKCi cargo delivered inside cells by the lipidated CPP and its cyclic derivatives. The cyclic derivatives are marked under square brackets. Conjugates CPP-PKCi $(7.5 \mu \mathrm{M})$ and unconjugated PKCi (No CPP) were incubated with $10^{6}$ WT (CHO-K1) or GAG ${ }^{\text {neg }}(\mathrm{CHO} 745)$ cells for $75 \mathrm{~min}$ at $4^{\circ} \mathrm{C}$ or $37^{\circ} \mathrm{C}$. Mean values $+/$ - SEM are given in the histogram. Mean values are also shown in the table below (pmol for $10^{6}$ cells). ND: not determined.

Significance was tested using a Welch's corrected t test ( ${ }^{\text {ns }} p>0.05,{ }^{*} 0.05<p>0.01$, ** $\left.0.01<p>0.001,{ }^{* * *} p<0.001\right)$.

Table S5. Effect of cyclisation on the efficiency of endocytosis, translocation and GAGdependent entry

\begin{tabular}{|c|c|c|c|c|c|c|c|}
\hline $\begin{array}{c}\text { Route of } \\
\text { internalisation }\end{array}$ & $C_{12}-R_{4}$ & {$\left[C_{12}-R_{4}\right]$} & {$\left[\mathrm{R}_{2}-\mathrm{C}_{12}-\mathrm{R}_{2}\right]$} & {$\left[\mathrm{R}_{3}-\boldsymbol{C}_{12}-\mathrm{R}\right]$} & {$\left[C_{12}-R_{2} F_{2}\right]$} & {$\left[C_{12}-R_{7}\right]$} & {$\left[C_{12}-R_{9}\right]$} \\
\hline Endocytosis $^{1}$ & 5.35 & 7.06 & 7.53 & 1.99 & 4.84 & 2.07 & 2.4 \\
\hline Translocation ${ }^{2}$ & 0.59 & 1.10 & 0.83 & 1.03 & 0.56 & 1.95 & 1.94 \\
\hline $\begin{array}{c}\text { GAG-dependent } \\
\text { entry }^{3}\end{array}$ & 3.57 & 6.15 & 5.75 & 2.07 & 3.06 & 2.36 & 2.99 \\
\hline
\end{tabular}

${ }^{1}$ The efficiency of endocytosis was estimated by subtracting the amount of intact $\mathrm{PKCi}$ cargo (pmol) delivered in $10^{6} \mathrm{WT}$ cells at $4^{\circ} \mathrm{C}$ from the values obtained in WT cells at $37^{\circ} \mathrm{C}$.

${ }^{2}$ The efficiency of translocation is directly given by the amount of intact $\mathrm{PKCi}$ cargo measured in WT cells at $4^{\circ} \mathrm{C}$.

${ }^{3}$ The efficiency of GAG-dependent entry was estimated by subtracting the amount of intact $\mathrm{PKCi}$ cargo (pmol) delivered in $10^{6} \mathrm{GAG}^{\text {neg }}$ cells at $37^{\circ} \mathrm{C}$ from the values obtained in WT cells at $37^{\circ} \mathrm{C}$. 


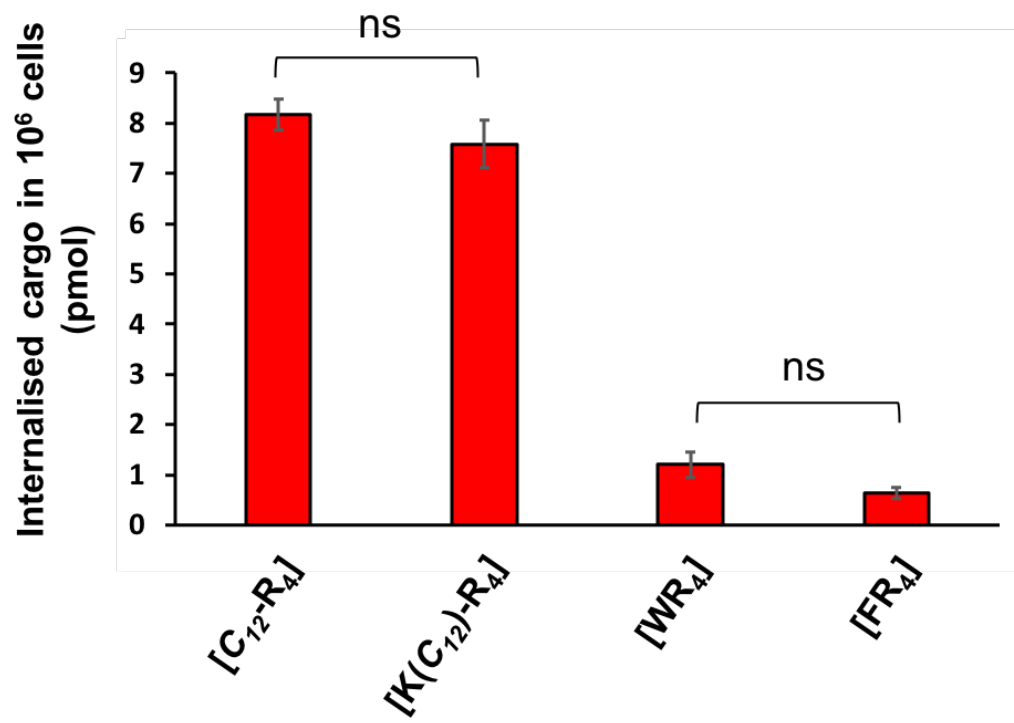

\begin{tabular}{|c|c|c|c|c|}
\hline & {$\left[\boldsymbol{C}_{12}-\mathbf{R}_{\mathbf{4}}\right]$} & {$\left[\mathbf{K}\left(\boldsymbol{C}_{12}\right)-\mathbf{R}_{4}\right]$} & {$\left[\mathbf{W R}_{4}\right]$} & {$\left[\mathbf{F R}_{\mathbf{4}}\right]$} \\
\hline $\mathbf{W T} 37^{\circ} \mathbf{C}$ & 8.16 & 7.59 & 1.2 & 0.64 \\
\hline
\end{tabular}

Figure S9: Impact of the anchoring position of the lipid chain and of its replacement by an aromatic amino-acid. Amount of intact $\mathrm{PKCi}$ cargo delivered inside cells. Conjugates CPP-PKCi $(7.5 \mu \mathrm{M})$ were incubated with $10^{6} \mathrm{WT}(\mathrm{CHO}-\mathrm{K} 1)$ at $37^{\circ} \mathrm{C}$. Mean values $+/$ - SEM are given in the histogram. Mean values are also shown in the table below (pmol for $10^{6}$ cells). Significance was tested using a Welch's corrected t test ( $\left.{ }^{n s} p>0.05\right)$.

\section{Confocal microscopy experiments}

CHO-K1 cells were seeded in sterile conditions in 12-well plates $24 \mathrm{~h}$ before the internalisation experiment. After washing with DMEM, cells were incubated with the CPPPKCi conjugates (7.5 $\mu \mathrm{M}$ in DMEM) or with the unconjugated PKCi (no CPP) for $75 \mathrm{~min}$ at $37^{\circ} \mathrm{C}$ (Fig 3) or $4{ }^{\circ} \mathrm{C}$ (Fig S10). Cells were washed 3 times with DMEM, incubated for 10 min at rt with $200 \mu \mathrm{L}$ unlabelled avidin $(10 \mu \mathrm{M})$ and washed with PBS. Cells were then incubated with $3 \%$ paraformaldehyde $\left(4{ }^{\circ} \mathrm{C}, 10 \mathrm{~min}\right)$, permeabilised with $0.1 \%$ Triton $\mathrm{X}-100$ in PBS (rt, $5 \mathrm{~min}$ ) and incubated with $10 \%$ FCS in PBS (rt, $30 \mathrm{~min}$ ). Cells were incubated with streptavidin-Alexa $488(1 \mu \mathrm{g} / \mathrm{mL})$ for $1 \mathrm{~h}$ at rt, washed again with PBS and treated with DAPI $(1.5 \mu \mathrm{g} / \mathrm{mL})$ for $10 \mathrm{~min}$ at $\mathrm{rt}$. Coverslips were mounted in Fluoromount mounting medium and imaged with a Nikon Eclipse Ti equipped with a Scan head CSUX1-A1 and Camera Evolve Metamorph $63 \mathrm{X}$. 

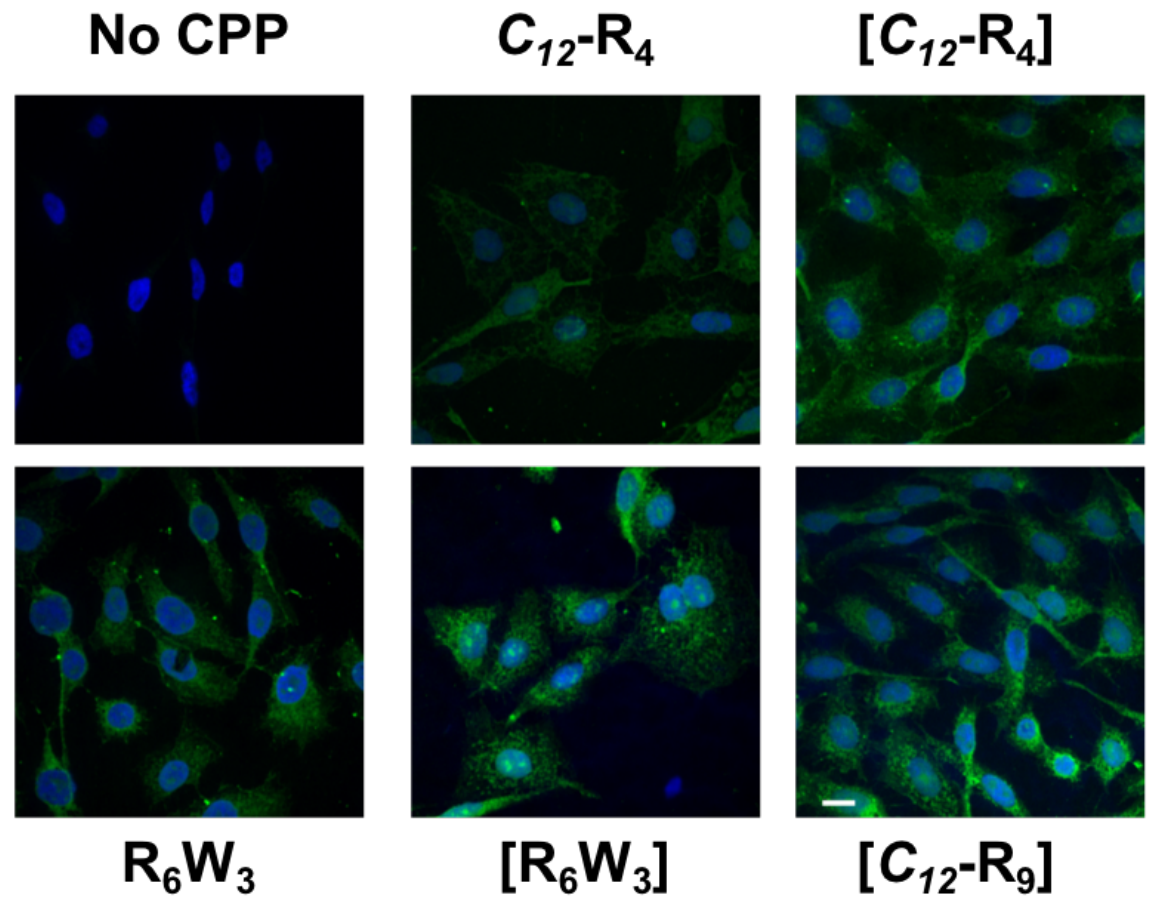

Figure S10. Intracellular distribution of the delivered $\mathrm{PKCi}$ cargo at $4^{\circ} \mathrm{C}$. CPP-PKCi conjugates or unconjugated PKCi (No CPP) $(7.5 \mu \mathrm{M})$ were incubated for 75 min with WT cells $(\mathrm{CHO}-\mathrm{K} 1)$ at $4^{\circ} \mathrm{C}$. The cargo biotin moiety was revealed with streptavidin-Alexa 488 (green). Nuclei were stained with DAPI (blue). The scale bar corresponds to $15 \mu \mathrm{m}$.

\section{1) References}

1. M. Schnölzer, P. Alewood, A. Jones, D. Alewood, S.B. Kent, Int. J. Pept. Protein Res., 1992, 40, 180.

2. B. Aussedat, E. Dupont, S. Sagan, A. Joliot, S. Lavielle, G. Chassaing, F. Burlina, Chem. Commun., 2008, 1398.

3. S. A. Bode, M. Thevenin, C. Bechara, S. Sagan, S. Bregant, S. Lavielle, G. Chassaing, F. Burlina, Chem. Commun., 2012, 48, 7179.

4. T. M. Hackeng, J. H. Griffin, P. E. Dawson, Proc. Natl. Acad. Sci. USA, 1999, 96, 10068.

5. F. Burlina, G. Papageorgiou, C. Morris, P. D. White, J. Offer, Chem. Sci., 2014, 5, 766. 